NBER WORKING PAPER SERIES

\title{
THE INCENTIVE EFFECTS OF CASH TRANSFERS TO THE POOR
}

\author{
Anna Aizer \\ Shari Eli \\ Adriana Lleras-Muney \\ Working Paper 27523 \\ http://www.nber.org/papers/w27523 \\ NATIONAL BUREAU OF ECONOMIC RESEARCH \\ 1050 Massachusetts Avenue \\ Cambridge, MA 02138 \\ July 2020
}

We are very grateful to Joe Price who directed the team of researchers at the BYU Record Linking Lab, and without whom this project would not have been feasible. We also want to thank the excellent research assistants who have worked on this project: Amanda Loyola Heufemann, Ariadna Jou, Keyoung Lee, Xuan Zhang, Tomas Guanziroli and Diego Zúñiga. We are very grateful to Nathan Hendren and Ben Sprung-Keyser who helped us with the MVFP computations in this paper. We have benefitted from conversations with Pedro Dal Bó, Bo Honoré, Caroline Hoxby, Petra Persson, Robert Pollack, Aloysius Siow and from the comments of the seminar participants at Carnegie Mellon University, the NBER Summer Institute, University of Minnesota, Princeton University, Queen's University, RAND, University of British Columbia, University of Toronto, University of Urbana-Champaign, Wharton, Washington University, UCLA, and Yale University. This project was supported by the California Center for Population Research at UCLA (CCPR), which receives core support (P2C- HD041022) from the Eunice Kennedy Shriver National Institute of Child Health and Human Development (NICHD) and from NIH grant 1 R01 HD077227-01. All errors are our own. The views expressed herein are those of the authors and do not necessarily reflect the views of the National Bureau of Economic Research.

NBER working papers are circulated for discussion and comment purposes. They have not been peer-reviewed or been subject to the review by the NBER Board of Directors that accompanies official NBER publications.

(C) 2020 by Anna Aizer, Shari Eli, and Adriana Lleras-Muney. All rights reserved. Short sections of text, not to exceed two paragraphs, may be quoted without explicit permission provided that full credit, including $($ ) notice, is given to the source. 
The Incentive Effects of Cash Transfers to the Poor

Anna Aizer, Shari Eli, and Adriana Lleras-Muney

NBER Working Paper No. 27523

July 2020

JEL No. I12,I14,I18,I32,I38,J16,N32

\section{$\underline{\text { ABSTRACT }}$}

All redistributive and social insurance programs trade off the potential benefits of transfers with the disincentives these programs generate. We investigate this trade-off using newly collected lifetime data for 16,000 women who applied to the Mothers' Pension Program, the first cash transfer program in the US. In the short-run cash transfers reduced geographic mobility and delayed marriage of recipients but did not affect who they married or where they moved to. In the long run transfers had no effect on work, marriage or fertility behaviors. They also did not improve the economic conditions of recipients or their longevity.

Anna Aizer

Brown University

Department of Economics

64 Waterman Street

Providence, RI 02912

and NBER

anna_aizer@brown.edu

Shari Eli

Department of Economics

University of Toronto

150 St. George Street

Toronto, ON M5S 3G7

CANADA

and NBER

shari.eli@utoronto.ca
Adriana Lleras-Muney

Department of Economics

9373 Bunche Hall

UCLA

Los Angeles, CA 90095

and NBER

allerasmuney@gmail.com 


\section{Introduction}

Spending on means-tested anti-poverty programs in the US accounted for $\$ 688$ billion dollars, or $16 \%$ of total federal government expenditures in 2012 , and are projected to increase to $\$ 877$ billion by $2023 .^{1}$ All large redistributive and social insurance programs trade off the potential benefits of transfers with their costs, which include the distortions they generate through eligibility rules. All social insurance programs today (the EITC, TANF, social security, food stamps) include eligibility criteria based on some combination of income, work status, and family size, creating incentives for individuals to reduce their work effort and income, remain single and increase their fertility. These distortions increase the cost of the program and might have other undesirable effects on the wellbeing of the families. ${ }^{2}$ For these reasons, incentive effects have received considerable attention in academic and policy circles (see Moffitt, 1992).

While there is a long theoretical literature exploring the negative incentive effects of meanstested anti-poverty programs, there is mixed evidence regarding the empirical importance of these incentive effects and no known estimates of long-term effects. We estimate the short- and long-run incentive effects of the first welfare program in the United States, known as the Mothers' Pension program (MPP). First implemented in 1911 in Illinois, it had been enacted in 47 states by 1930. In 1935, it was replaced by the federal Aid to Dependent Children (ADC) program, the precursor to Temporary Aid to Needy Families (TANF), today's welfare program. Like TANF, the objective of the MPP was to improve the long-term outcomes of children growing up in poverty. Before 1910, mothers who could not care for their children were forced to place their children in orphanages or training schools. But in response to evidence that children in orphanages fared very poorly, states established Mothers' Pension programs to provide cash transfers to poor mothers with dependent children to allow them to care for their children at home. Aizer et al. [2016] documents that boys of recipient mothers had higher schooling levels, lower rates of malnutrition, higher earning levels as adults and ultimately lived longer.

We now assess whether the mother's lifetime behaviors and outcomes were affected by receipt of the transfer. The Mothers' Pension program, like many transfer programs today, had built-in incentive effects related to eligibility and benefit level. Mothers who remarried would lose the transfer, encouraging women to remain unmarried. Moreover, the transfer was an increasing function of the number of children, encouraging out-of-wedlock fertility. There were also residency requirements,

\footnotetext{
${ }^{1}$ http://poverty.ucdavis.edu/sites/main/files/file-attachments/43935-means-tested-infographic.pdf

${ }^{2}$ For example, marriage and low fertility are both associated with improved outcomes among children and adults both (see Chetty et al. [2014] for family structure and Rosenzweig and Zhang [2009] for fertility) though debate remains on whether these effects are causal and universal.
} 
which affected mobility: only those who had resided for a certain amount of time in the county would be eligible, and those who left would lose benefits. Finally, most states required women to stay home and care for their children, which discouraged recipient mothers from working.

To answer the question of whether this welfare program generated negative incentive effects in the short and long run, we construct a novel dataset of about 16,000 women who applied for the program between 1911 and 1930, and follow them from the time of application until their death. We match data from the program's administrative records to family trees from FamilySearch.org, federal census records and vital statistics records. This allows us to observe how the transfers affected marriage market outcomes (remarriage, duration to remarriage and characteristics of the new husband), fertility (before and after application to the program), labor market outcomes (labor force participation, work and earnings), and geographic mobility. Many of these outcomes have not been studied before because of data limitations. These outcomes are of interest not only because they affect the cost of the program but also because they can indirectly affect the wellbeing of recipients and their children. We also directly investigate the long term effects of welfare on maternal wellbeing, measured by family income and longevity.

We make several contributions to the literature in economics investigating the incentive effects of welfare programs and other anti-poverty programs. First, our unique data allow us to improve upon previous estimates in many dimensions. We can look at lifetime behaviors, and compare shortand long-term effects of the transfers. We can do this for a large sample of women, all of whom are known to have applied for and/or received the transfers. Typical studies in the literature are limited to small samples of women whose welfare status is often unobserved or mis-measured, and who can only be tracked for a short period. Second, we employ a different identification strategy. Rather than leveraging changes in state laws or policies over time that modify benefit levels or eligibility requirements (an intensive margin), where we might expect more limited effects (Bitler et al., 2004; Blank, 2002; Blundell et al., 2016; Grogger and Karoly, 2005), we identify the effects of the program at the extensive margin. We do so by comparing the outcomes of women who applied and received cash transfers to women who applied and were deemed initially eligible but were denied upon investigation. In previous work, we documented that on average rejected women appeared slightly richer (Aizer et al., 2016). We again verify this claim using newly collected information about recipients.

We use a basic search model to make predictions about how the cash transfers affect marriage, fertility and work decisions of recipients. The model predicts that welfare receipt should increase duration to remarriage and the quality of the new match. It should also increase fertility. Similarly 
transfers will increase non-employment spells, but increase the wages of those who are employed. Finally, the model predicts that mobility will decline, but that those who move will move to better locations. Similar to the unemployment literature based on search models, our empirical findings reject many of its predictions. We find no differences in the remarriage rates of women who received transfers and those who did not - about $47 \%$ of them remarried, regardless of welfare receipt. Among those that remarried, those with transfers took an average of a year longer to find a new husband. Despite longer durations and contrary to the predictions of the theory, cash recipients did not marry higher quality partners. Cash recipients were not more likely to have children after the transfer, and they were not less likely to work. They were, however, more likely to remain in the county in which they applied for the transfer, but when they moved, they were not more likely to move to a location with better economic or marriage markets as theory would predict.

Our results suggest that that current concerns over behavioral distortions in social programs may be overstated. The average cash transfer we study amounted to about $30 \%$ of family income and was available to recipients so long as they had children under the age of 14 or 16 (depending on the state). By modern standards this program was very generous, yet we find rather modest behavioral responses. While welfare programs and welfare recipients today are very different, our results are in fact in line with research on the incentive effects of contemporary welfare with respect to fertility, marriage and work. Similar to our findings, research examining contemporary welfare reform effects in the US has found negligible effects on fertility (see for example Kearney, 2004 or Grogger and Bronars, 2001). While some research finds large effects of welfare reform in the US on marriage (Low et al., 2018a), we show these large effects on marriage are only observed in the short run and for a rather small number of recipients. In the long run, marriage rates are not different between those with and without welfare. Our findings on work disincentives mirror the findings from anti-poverty programs in developing countries today which also find modest effects of cash transfers on labor supply (Banerjee et al., 2018).

These findings raise the question of why basic economic predictions are not borne out in the data. Our results suggest that program incentives were likely small relative to other factors that determine maternal behaviors. First, while transfers were relatively large as compared to modern standards, they were insufficient for women to provide for their families, and so women still had to find alternative or additional sources of income through marriage, work or family. Second, remarriage rates fall rather dramatically with age in our data, and this cost of delaying marriage likely outweighed the benefits of receiving the transfer for longer. Economic opportunities also fell with age. ${ }^{3}$ Third, there were important norms regulating marriage and work behavior as well as

\footnotetext{
${ }^{3}$ Labor force participation rates fall among all women in the 1940 census and among MP moms after age 50. They
} 
potential stigma associated with welfare receipt that might have encouraged women to remarry or remain out of the labor force (Jayachandran [2020], Goldin [2006]) ${ }^{4}$. Indeed once stigma is added to the model, the theoretical predictions become ambiguous and can be reconciled with the empirical findings. Many of these factors are still relevant today.

Finally we find no effects on the long term economic outcomes of affected mothers and positive but small and statistically insignificant effects on their longevity. Thus in the long run, maternal outcomes were neither diminished nor improved by the program. We compute the marginal value of public funds (MVPF) using the methodology of Hendren and Sprung-Keyser [2019] for this program, and show that it is less than 1 when we only consider effects on maternal behaviors and outcomes. However if there are even modest benefits to the children in terms of longevity or income, the program pays for itself. This suggests that the overall evaluation of the program depends crucially on children's outcomes and less so on maternal incentive responses.

This paper is organized as follows. We start by providing background on the Mothers' Pension program and on the conditions of women with children before the program was implemented (Section 2). Section 3 models the marriage market and investigates the theoretical effects of welfare transfers on behaviors. Sections 4 and 5 discuss the data and empirical strategy. Section 6 presents our results with respect to welfare receipt and the remarriage decision, the duration to remarriage, and the effects on quality of the match; and also presents results for other outcomes (fertility, labor force participation and wages, mobility and welfare). Section 7 discusses the results, their applicability to modern settings and their limitations. Section 8 concludes.

\section{Background: Poor Women with Dependent Children and the Mothers' Pension Program}

\subsection{The status of poor women with children in $\mathbf{1 9 1 0}$}

At the turn of the twentieth century, before the Mothers' Pension program was introduced, women whose husbands died or abandoned them had few options to work or otherwise make a living to support their children. They could work in the formal labor market but these types of work were often poorly paid and required long hours (Goldin, 2006). Those who had farms could remain on their land if they could get additional hands to help work the land. Whether they rented or owned their home, many women supplemented their income by taking in renters. Still others supported

start falling earlier in the population compared to MP mothers. Results available upon request.

${ }^{4}$ The "substantial social stigma" associated with work prior to 1930 was due largely to the nature of the work which was often "dirty, dangerous, reptetitive and long in hours per day and days per week." Goldin [2006] 
themselves by offering laundry and cooking services. Some women chose to move in with relatives, if they had any who would receive them and their children, and others chose to remarry. However, if none of these options was feasible, women in poverty would often be forced to place their children in institutions for the poor or orphanages.

Data from the 1910 census suggests that marriage was by far the most common option (Appendix Table 1). In 1910, the vast majority of white women with children were married (92\%) and very few of them worked (4.7\%). This low labor force participation and high marriage rate among white women can be explained by both social norms and the lack of demand for female labor at the time (Goldin, 2006). However, among women who were not married, 40\% worked in the formal labor market, $20 \%$ worked on their farms, $11 \%$ lived with adult males who were not relatives (and who may be boarders) and 30\% lived with their relatives. With limited ability to provide for their children, many poor, single mothers did in fact place their children in orphanages (see Skocpol, 1995, p.425).

Early in the 20th century this system of institutionalizing poor children became less popular for several reasons. Reports appeared in the press that children in institutions fared poorly. And at the same time, there was a realization that maternal care was often superior for children's development (Aizer et al. 2016). There was also great sympathy for widows, who found themselves in poor circumstances through no fault of their own Skocpol [1995]. This resulted in a movement away from the state paying institutions to care for children, towards a system in which the state would pay mothers to stay home and look after their children. After Illinois passed the first Mother Pensions' Program in 1911, most states followed suit and passed their own welfare programs. We study 11 states with early programs for which we obtained data: Connecticut (1919), Dakota (1915), Idaho (1913), Illinois (1911), Iowa (1913), Minnesota (1913), Ohio (1913), Oklahoma (1915), Oregon (1913), Washington (1913) and Wisconsin (1913).

\subsection{Structure of the Mothers' Pension Program ${ }^{5}$}

The Mothers' Pension program was administered by individual counties, but only after each state first passed legislation allowing counties to establish a program. Not every county chose to do so. It was most often administered through the county's juvenile court or county clerks office. Women would apply to the program, pass an initial review, and then a judge (or a panel) would make a final determination regarding the application and the amount that would be granted. Some states required periodic re-application, while others granted the payment until the child turned 14 or 16

\footnotetext{
${ }^{5}$ We give only a brief description of the program here. More details are provided in Aizer et al. [2016] and on the Mothers' Pension Project website: http://individual.utoronto.ca/shari_eli/mp.html.
} 
years of age.

Eligibility criteria for aid differed slightly across states. The details for the states we study are given in Appendix Table S1 of Aizer et al. [2016]. Widows, women with husbands in jail or an asylum, and women with disabled husbands were almost always eligible. ${ }^{6}$ However, women who had been deserted or divorced were eligible in some states but not others, though over time more states made these women eligible.

The program created varying degrees of disincentives to marry, have children, work or move residence. Women who remarried were immediately ineligible and would lose the transfers. This was true in all states. Transfers increased with the number of children. State rules would specify the maximum amount per child that a woman could receive. Typically, these amounts ranged from $\$ 9$ to $\$ 15$ per month for the first child and $\$ 4$ to $\$ 10$ for each additional eligible child. With respect to work disincentives, in several states (6 out of the 11 that we study) women were required to stay home as a condition of the transfers, since the cash transfer was given in exchange for looking after the children. Other states limited the hours women could work; others levied a 100\% tax on earnings, with the transfer decreasing one-to-one for each dollar earned in the labor market. More generally, working women were by definition less likely to be deemed eligible since they had a source of income. ${ }^{7}$ Finally the program created strong disincentives to move. Typically, women had to prove they had resided in the county for 1-3 years prior to applying for the transfers, and if they moved out of the county, they would lose the transfer.

\section{A Model of Welfare Receipt and Maternal Behaviors}

We adapt the canonical model of search in the labor market with unemployment insurance, first developed by McCall [1970], to model search in the marriage market with cash transfers. We then extend the model to include decisions with respect to employment and fertility. We also discuss sources of heterogeneity and explore how relaxing some key assumptions affects the key predictions of the model.

In McCall's original model, an unemployed worker searches for an offer of employment. Offers

\footnotetext{
${ }^{6}$ In three out of the eleven states that we study, only widows were eligible.

${ }^{7}$ While the Mothers' Pension program has many similarities to modern day welfare, there are important differences. Both are means-tested programs that offer unconstrained, but limited, cash transfers. The Mothers' Pension program terminated eligibility upon remarriage (to any man), creating strong disincentives to remarry. The modern-day welfare program terminates benefits upon marriage or cohabitation with the child's father, not necessarily any man. The MP program discouraged work-several states required women to stay home as a condition for the transfer, although some regulated the amount of work or simply lowered the transfers when women brought income home. This continued to be the case in most states until the 1995 welfare reform which capped lifetime benefits and required recipients to work.
} 
of employment vary in quality, as measured by the wage, with a known distribution. Unemployed workers receive offers, which arrive at a given rate, and accept an offer if the offered wage exceeds the worker's reservation wage. If the worker rejects the offer and remains unemployed, he retains the option of waiting for another potentially better offer in the next period. In this model, unemployment insurance increases the value of remaining unemployed, thereby increasing the reservation wage. The model yields two important predictions. First, workers with unemployment insurance will remain unemployed for longer than those without. Second, when workers with unemployment insurance do accept an offer, the wage will be higher. ${ }^{8}$

We adapt this model to the marriage market where women are searching for husbands and offers of marriage arrive at an expected rate. Like offers of employment, offers of marriage also vary in quality. Cash transfers (welfare) have the same effects on the marriage market that unemployment insurance has in the labor market: it increases her outside option and therefore the "reservation quality of the match," extending her duration of search (the time to marriage), and resulting in a higher quality husband when she does remarry.

\subsection{A basic model of search in the marriage market}

A single woman must decide every period whether to marry or to stay single. If she stays single she has the option to marry the next period. If she marries, she will stay married forever. ${ }^{9}$ She has a patience level given by her discount rate $\beta$. She searches for partners, and prospects arrive at a Poisson rate $\lambda$. Each prospect has a value of $q$, which summarizes his quality as a husband. This value has an unknown distribution in the population, $q \sim F(q)$ with support $[q, \bar{q}]$ and $\bar{q}>b$. While she is single she receives a cash transfer of value $b$ every period, but this transfer is lost upon remarriage.

The value of being single is given by

$$
V_{s}=b+\beta\left(\lambda \int_{q=\underline{q}}^{\bar{q}} \max \left\{V_{m}(q), V_{s}\right\} \mathrm{d} F(q)+(1-\lambda) V_{s}\right) .
$$

and the value of being married to prospect $q$ is given by:

$$
V_{m}(q)=q+\beta V_{m}(q)=\frac{q}{1-\beta} .
$$

In this set-up, the agent accepts an offer to marry prospect $q$ if $V_{m}>V_{s}$. Since the value of

\footnotetext{
${ }^{8}$ Other features have since been added to this model, such as simultaneous offers (Burdett and Judd [1983]).

${ }^{9}$ This is a simplifying assumption, but it is well supported by the data. Most women in our sample marry only once (only $5.6 \%$ married more than once after the transfer).
} 
marriage is strictly increasing in $q$, the agent will follow a cut-off rule. There is a $q^{*}$ such that she will accept all prospects with $q>q^{*}$. The cut-off rule is implicitly defined as

$$
V_{m}\left(q^{*}\right)=V_{s}
$$

Considering that, and rearranging the definition of $V_{s}$, we can write

$$
\begin{gathered}
V_{s}=b+\beta V_{s}+\beta \lambda \int_{q=\underline{q}}^{\bar{q}}\left(\max \left\{V_{m}(q)-V_{s}, 0\right\}\right) \mathrm{d} F(q), \\
V_{s}=b+\beta V_{s}+\beta \lambda \int_{q=q^{*}}^{\bar{q}}\left(V_{m}(q)-V_{s}\right) \mathrm{d} F(q), \\
V_{s}=b+\beta V_{s}+\frac{\beta \lambda}{1-\beta} \int_{q=q^{*}}^{\bar{q}}(1-F(q)) \mathrm{d} q, \\
(1-\beta) V_{s}=b+\frac{\beta \lambda}{1-\beta} \int_{q=q^{*}}^{\bar{q}}(1-F(q)) \mathrm{d} q,
\end{gathered}
$$

This function is continuous and positive at $q^{*}=b$ and negative at $q^{*}=\bar{q}$, so there exists a solution, and because it is strictly decreasing, the solution is unique. Intuitively, this equation means that the value of the minimum acceptable marriage, $q^{*}$ should be equal to the benefit, $b$, plus the option value of holding out for a good match. Given a reservation quality, $q^{*}$, the probability of marriage is $\lambda\left(1-F\left(q^{*}\right)\right)$ and the average match quality is $\mathbb{E}\left[q \mid q>q^{*}\right]$. The duration until marriage is given by $D=1 / \lambda\left(1-F\left(q^{*}\right)\right)$. It is decreasing in the arrival rate and increasing in reservation quality.

The following propositions follow from this model and its extensions. All proofs are provided in the Appendix. We discuss each and how we test it in the data.

Proposition 1. $\partial D / \partial b>0$ and $\partial \mathbb{E}\left[q \mid q>q^{*}\right] / \partial b>0:$ An increase in benefits $b$ increases the number of periods the woman stays single and the average quality of the marriage.

We can easily test whether receiving a transfer leads to longer durations until re-marriage. Testing whether the quality of the match increases among those who marry is more difficult because there is no single indicator of the quality of a match. Suppose instead that there are many traits $X$ that matter but that prospects can be ranked using a single index function $q(X)$ as in Becker (1965). If this function is known then we can test the predictions in Proposition 1. Otherwise, we need another way to test whether the quality of the match has increased. This is given in the next proposition, under the assumption that $q$ is increasing in all its arguments $X$.

Proposition 2. Without further assumptions about the joint distribution of $X$ and the production function $q(X)$, the sign of $\partial \mathbb{E}\left[x_{i} \mid q>q^{*}\right] / \partial b$ is ambiguous for all $i$. However, the sign of $\partial \mathbb{E}\left[x_{i} \mid q>\right.$ 
$\left.q^{*}, x_{-i}\right] / \partial b>0$ for all $x_{i}$ so long as all relevant $X$ are observed.

This proposition states that the theory does not provide any guidance about the effect of transfers on any "input" into quality without knowing their joint distribution and how women trade-off these characteristics. For example, if women care about income and kindness, it is not clear that the average income (or the average kindness) among those who marry will increase by increasing the transfers. In fact, without further assumptions, both might go down, even though the average quality among those who marry is going up. ${ }^{10}$ However, the theory does predict that conditional on kindness (income), the average income (kindness) will increase when the transfer increases. If both income and kindness are observed, we can test this empirically by conditioning on one trait and estimating the impact of the transfer on another trait.

\subsection{Incorporating Age and Stigma}

This model is also stationary. It assumes that the arrival rate of offers and their distributions remains constant every period. But contemporary data shows that marriage rates fall with age (Low [2014]). A natural extension would be to let $\lambda$ vary with maternal age. While a proper treatment of this would require writing a full dynamic model, we can allow $\lambda$ to fall with age in a simple extension to derive testable implications.

Proposition 3. If the arrival rate $\lambda$ falls with age then $\partial \mathbb{E}\left[q \mid q>q^{*}\right] / \partial b>0$ and $\partial D / \partial b>0$.

This proposition states that the effects of the transfers are to delay marriage and increase the quality of marriage, and this is true even when the arrival rate falls with age. However in this case, the expected magnitude of the effects of the transfer on duration and quality declines because the cost of delay increases relative to the case where the arrival rate is constant.

Another important and natural extension is whether there is stigma associated with getting benefits. Moffitt et al. [1983] and an extensive literature in social science disciplines related to economics has documented that many individuals are reluctant to apply and collect any type of government benefit because there will be negative social judgments associated with this behavior Leff [1973] Machtinger [1999] Mink [1996] Abramovitz et al. [1996] Handler and Hollingsworth [1969] Kasman [1945]. If so, $b$ may lower the rate of arrival of prospects $\lambda$ because potential husbands might consider women on welfare less attractive.

\footnotetext{
${ }^{10}$ For example, consider a quality function $q\left(x_{1}, x_{2}\right)=x_{1} x_{2}$. The joint distribution of the traits is uniformly distributed over three mass points $(1,10) ;(10,1) ;(4,4)$. Suppose that, initially, the cutoff is $q^{*}=10$. The average of each trait conditional on a match is equal to 5 . Consider a small increase in the cutoff $\left(10<q^{*} \leq 16\right)$. The new average of each trait is 4 .
} 
Proposition 4. If $b$ lowers rate of arrival of prospects $\lambda$ (in addition to increasing the per period utility) then the sign of $\partial \mathbb{E}\left[q \mid q>q^{*}\right] / \partial b$ and $\partial D / \partial b$ becomes ambiguous.

When $\lambda$ falls and $\mathrm{b}$ is unchanged, the cutoff quality $q^{*}$ falls, and the effect of $\mathrm{b}$ on duration $D$ and is ambiguous. If lowering $\mathrm{b}$ also lowers $\lambda$, then combining the results from Proposition 1 (lowering b) with the effects of lowering $\lambda$, it becomes clear that the overall effects are ambiguous. 11

\subsection{Adding work, fertility and mobility}

So far we have considered a simple model in which marriage is the only option for a woman. We can include another option: work in the formal sector. In each period a woman might receive a job offer with an associated wage, and decides whether to accept it or wait one more period. A woman can now make two choices: whether to marry and whether to work. Assume further that married women do not work, which approximates of what we observe in 1910. In this model, single unemployed women get $b$ but they lose the transfer if they either work or marry. There are now three states: SU (single and unemployed), SE (Single and Employed) and MU (married and unemployed), where married and unemployed is the absorbing state. There are now three cutoffs to be chosen by the woman: $q_{s u}^{*}$ (the quality of husband that is acceptable for unemployed single women to marry), $q_{s e}^{*}$ (the quality of the husband that is acceptable for a single employed woman to marry) and $w_{s u}^{*}$ (the wage rate that is acceptable for a single unemployed woman to become employed). Adding this simple extension does not change the predictions for the marriage market. But we have new predictions for the labor market which match exactly those in McCall (1970).

Proposition 5. An increase in benefits b increases the number of periods the woman stays single and the average quality of the marriage. An increase in benefits $b$ also increases the number of periods the woman stays unemployed and the average wages of the women that become employed.

We consider two more extensions to the model. First we show that in this model if the transfer increases with the number of children, then women will have more children, if children are costless and do not otherwise affect marriage and labor market prospects. But if the number of kids lowers the arrival rate of marriage or jobs, then the fertility predictions become ambiguous.

Proposition 6. If $b$ is an increasing function of the number of children then fertility will increase when $b$ increases. But if having more children while single lowers the rate of arrival of prospects in

\footnotetext{
${ }^{11}$ If stigma affects the quality of offers instead of the rate of arrival, the results are the same. In particular, suppose stigma makes the distribution of offers worse in a first-order stochastic dominance sense. This effect, by itself, will lower the cutoff quality and have an ambiguous effect on duration.
} 
the labor and marriage market, then the predictions about fertility become ambiguous.

Finally, we consider the effects of the transfer on mobility. Suppose that each period the woman has the opportunity to move to a location $j$ with different labor and marriage market prospects (different $\lambda^{\prime} s$ ). But if she does move she will lose the transfer (for at least some periods). Then moving is attractive only if the alternative location has better opportunities (higher $\lambda^{\prime} s$ ).

Proposition 7. If $b$ increases, then mobility falls, and those who do migrate, move to better locations.

It is worth mentioning three important choices we made that might affect our predictions. We choose a partial equilibrium model that holds the supply of marriageable partners constant and ignores general equilibrium effects. We think this is justified because the affected population in the MP program was small relative to the population of poor women (the MP program was small). For models that do consider these issues see Chiappori and Salanié [2016]. Second, this model does not incorporate the decision of women to apply for welfare. We do not have data on women who did not apply for welfare so we cannot test predictions related to this behavior. Third, we do not consider ex-ante effects of welfare, namely how the existence of a welfare safety net affects fertility, mobility, work and marriage decisions of women who know they might eventually rely on the program but who have not yet applied or become eligible. The fact that most women gained eligibility for the program due to the accidental deaths of their husbands suggests that eligibility for most should be characterized as an unanticipated shock.

In summary, the simple model suggests that having (higher) transfers will increase the duration to remarriage and unemployment, but increase the quality of matches and increase wages among those who chose to marry or become employed. It will also increase fertility and lower geographic mobility. However, if there are strong declines in marriage or labor market prospects with age, the expected effects will be small and possibly zero. Furthermore, if transfers are associated with stigma, then the model's predictions are ambiguous.

\section{Data}

\subsection{Data collection}

Administrative data on Mothers' Pension applicants was collected directly from state and county archives in 14 states. $^{12}$ To track MP mothers and their children, we match these administrative data

\footnotetext{
${ }^{12} \mathrm{~A}$ more extensive discussion of this data collection is in Aizer et al. [2016].
} 
to family tree data available on FamilySearch.org, which includes more than 1.2 billion people. ${ }^{13}$ The mother's name combined with the names and dates of birth of her children enables us to locate the mother on a family tree. Once a mother has been found, we observe her maiden name, her date of birth and date of death, and the names, dates of birth and dates of death of all her husbands and children. If there was no existing tree, we create one. For all women in our sample, we searched for any evidence that she married after the MP program, regardless of whether there was an existing tree or not. ${ }^{14}$ We also observe marriage dates for all spouses. If this information is not already in the tree, we attempt to find it using all other records available to genealogists on Ancestry.com and FamilySearch (e.g. the Social Security Death Master File, other state death records, cemetery records, birth certificates and marriage certificates). Finally, we manually link mothers and their post-MP husbands (if they have them) to 1910, 1920, 1930 and 1940 Census Records. These data allow us to determine if women ever remarried, the duration until the marriage and the characteristics of her new husband. They also allow us to track all the children that the women ever had, before and the program. And we can observe employment and occupation in each of the census years and income in 1940 .

\subsection{Summary statistics}

We make a few sample restrictions for our analysis: we drop mothers who applied after 1930 and records of mothers who applied multiple times so that mothers only appear once in the data. ${ }^{15}$ We also drop individuals who we discovered were not in fact the mother (a handful of grandmothers, sisters and step-mothers) after searching family tree records. ${ }^{16}$ This leaves us with a total of 16,228 applicants in 130 counties across 11 states.

Table 1 shows the summary statistics for our sample. We show them for the full sample and pay particular attention to the sub-sample of unmarried women. 13,383 (82\%) of them were not married at the time of the application. The rest had husbands who were disabled or in jail, mental institutions or sanatoriums. Very few were divorced. About $10 \%$ of the applicants are rejected. The average woman in our sample was 37 years old at the time she applied and listed 2.6 children under

\footnotetext{
${ }^{13}$ While the tree database is large, it might not be representative. Recent research (Kaplanis et al 2018) suggests that although trees are posted by individuals and completed or created by volunteers, they are quite accurate when validated using genetic information. The information also appears to be representative of the population, as life expectancy and other summary measures derived from the trees reproduce the patterns that have been described elsewhere.

${ }^{14}$ Trees were updated using the information we collected.

${ }^{15}$ We only look at individuals who applied between 1911 and 1930 because the programs lost funding during the Great Depression.

${ }^{16}$ For the cases with multiple records we proceed as follows: (i) Keep only the observations of the first successful attempt. (ii) If applied successfully more than once the same year, keep the application with more children listed. (iii) Keep the smallest family id if applied successfully more than once the same year, with the same number of children.
} 
the age of 14 in the application. $98 \%$ are white, and 17\% are foreign born. As discussed in Aizer et al (2016), transfer payments comprised roughly one third of women's income and lasted three years for the median mother. ${ }^{17}$

Forty seven percent of unmarried MP mothers eventually remarried, but on average they waited 6.4 years to do so, with only $15 \%$ of all unmarried mothers married within 3 years of applying for welfare. Women married men who lived almost as long as they did (71 years for men and 74 years for women) but who were less educated than them on average (the education gap is -0.23). Post welfare receipt fertility was low with only 0.27 children born on average after applying for welfare, suggesting that any fertility effects are likely to be small.

The information on maternal work, income and location comes from decennial census data so we cannot observe the entire history of employment, income and location. Only $12 \%$ of MP moms were in the labor force in 1910-many of them were still married at this time. Women's labor force participation remained low: rising to a max of $37 \%$ in 1930 and falling to $26 \%$ by 1940 . Their wages and occupational scores were low, and so were their incomes. Appendix Figure 1 shows that the distribution of family income and wages among MP moms still alive in 1940 is low.

\subsection{Data Quality and Limitations}

The advantages of using historical administrative data for this analysis are that it allows a long follow-up period and lower attrition than modern survey data. However, there are a number of data limitations related to missing data and matching errors. For example, of the sample of 13,354 mothers who were unmarried at the time of application for welfare benefits, we found remarriage data for $80 \%$ of the sample. Among those who remarry $(5,435)$, we are missing the exact date of marriage for $30 \%$. We determined maternal longevity for $80 \%$ of mothers and found maternal education for $68 \%$ of those who were alive in 1940 .

These match rates compare very favorably with recent work using US census data from the early part of the twentieth century. ${ }^{18}$ They also compare favorably with attrition rates in survey data, which can be especially high for poor families. For example, the attrition rate in the SIPP is about 37\% over 12 waves (Zabel, 1998). In the PSID, the attrition rate over 35 years for mothers collecting welfare is $63.7 \%$. Moreover, all of the data were hand-matched across multiple sources and all data entry double checked. A validation exercise showed the accuracy of the matches to the

\footnotetext{
${ }^{17}$ We have data on the duration of the transfer or reason for termination for only a small subset of the sample. Therefore we cannot perform "common" tests in the UI literature such as testing whether people marry just before the end of the transfer.

${ }^{18}$ For example, Abramitzky et al. [2014] estimating the impact of migration on earnings trajectories achieve match rates of $16 \%$ for the native born and $12 \%$ for foreign born men.
} 
tree, the death certificates and the 1940 census to be very high (above $97 \%$ in all three cases). We discuss strategies to address missing data and data quality below. Because of the small number of women who were rejected (only 10\% of the sample), we cannot conduct heterogeneity analysis with any precision, though we do present results in an appendix. A final data limitation relates to our inability to generalize our results to African American mothers who accounted for only $1.3 \%$ of the population in the counties we study, and they account for only $2 \%$ of applicants in our data. States and counties with large black populations often did not implement the Mothers' Pension program (Eli et al., 2020), and when they did, they appear to have systematically discriminated against them as many were never deemed eligible (Eli and Salisbury, 2016, Roberts, 1993, Ward, 2009).

\section{Empirical strategy and identification}

\subsection{Empirical Strategy}

We test the model's predictions with respect to remarriage, maternal employment, fertility, location/migration and husband quality. To do so, we estimate the effects of the transfer on these outcomes using the following equation:

$$
y_{i c t}=\beta_{0}+\beta_{1} \text { Accepted }_{i}+\theta X_{i c t}+\gamma_{c}+\gamma_{t}+\varepsilon_{i c t}
$$

where $y_{i c t}$ is an outcome for woman $i$ applying to the program in county $c$ in year $t$. Accepted is a dummy equal to one if the mother was given a cash transfer and it is equal to zero if she applied for the transfer but was denied after investigation. Our main coefficient of interest is $\beta_{1}$, which represents the impact of welfare receipt on the outcome. Thus, our strategy consists in comparing the mean outcomes of accepted and rejected mothers.

If rejection was as good as random, then without any further controls $\beta_{1}$ would estimate the causal effect of transfers on outcomes. However, our work suggests that accepted and rejected women are not identical. In Aizer et al. [2016] we show that accepted mothers were slightly worse off. (We discuss differences between these groups in more detail below.) Thus, we will present estimates without any controls, and with all the predetermined controls that are available to us. These include county and year of application fixed effects $\gamma_{c}$ and $\gamma_{t}$, a vector of controls $\left(X_{i c t}\right)$ that includes the characteristics of the mother and family at the time of application: the number of children, age of the oldest and youngest, her marital status at application (widowed, divorced or missing), and maternal age at application, and county-level and state-level time varying covariates. ${ }^{19}$

\footnotetext{
${ }^{19}$ County controls include: sex ratio $(\mathrm{M} / \mathrm{F})$ aged 18-55, share females in the labor force aged 18-55, share black
} 
We report standard errors computed three ways: corrected for heteroskedasticity, clustered at the county*year, and clustered at the county level. This will allow us to assess the robustness of the results to different assumptions about the structure of the error term.

\subsection{Rejected mothers as counterfactual}

Our identification strategy relies upon using rejected mothers as the counterfactual for mothers who received welfare. For rejected mothers to be an appropriate counterfactual, it must be the case that they are not otherwise different than mothers who were accepted. Three pieces of evidence presented in our 2016 paper (Aizer et al, 2016) showed that rejected mothers were slightly better off.

First, investigating the basis for rejection in counties that recorded such, we found the most common was "other means of support" (35\%). Second, comparing accepted and rejected mothers, we found that the rejected had on average fewer children and that their children were older. We used these characteristics and marital status to predict family income using the 1915 Iowa State Census - the only income data available in the US prior to 1940. Women who were rejected from the program have higher predicted income than those who were accepted, consistent with the evidence on reasons for rejection.

A third piece of evidence comes from a comparison of the pre-application characteristics of accepted and rejected mothers whom we can find in either the Iowa State Census of 1915 (for the Iowa sample of mothers) or in the 1900-1920 US Federal Census for the Ohio sample of mothers. ${ }^{20}$ Because the census data do not include date of birth, the match rate is relatively low (10\% for Ohio and $58 \%$ for Iowa). Moreover, for the Iowa sample, we find accepted mothers at significantly lower rates (10 percentage points lower), suggesting caution when interpreting the Iowa results. For Ohio, we find that accepted mothers are less likely to be native born, less likely to be homeowners and that their first husband's income (as imputed based on occupation) is lower. In Iowa accepted mothers have lower family income, are less likely to be a homeowner, and conditional on ownership, the value of the home is lower and they have higher debt. Also, their husbands are less likely to be literate. However, in the Iowa sample the husbands do have significantly more years of schooling. (See Table 2 of Aizer et al., 2016.)

aged 18-55, share rural aged 18-55. County controls match linear interpolated information from the 1910 , 1920 and 1930 census with the year of application to the program. State-varying controls include: manufacturing wages, education/labor laws (age must enter school, age can obtain a work permit, and whether a continuation school law is in place), state expenditures in logs (education, charity, and total expenditure in social programs), state laws concerning MP transfers (work required, reapplication required, the maximum legislated amount for the first child, and the legislated amount for each additional child).

${ }^{20}$ We focused on Ohio because a large portion of our records come from Ohio. 
Therefore, we use our newly collected data to further assess the determined differences between the two groups. Specifically, we now have information on the mother's educational attainment (from 1940 census records), her date of birth, place of birth, race and ethnicity, the longevity of her first husband, and information on all her children, including those who died prior to applying for the pension, and those who were too old to be eligible (and were therefore not listed in the Mothers' Pension records) but could potentially provide income or other resources to their mothers. We also observe the number of siblings the mother had as they might represent an alternative means of support.

Appendix Table 2 shows the mean differences in predetermined characteristics for all moms and for single moms. We continue to find that rejected mothers were slightly better off compared to accepted mothers. Controlling for county and year of application fixed effects, we find that accepted mothers had more children who died before the application (which is significant for the sample of unmarried mothers) and fewer kids over the age of 14 who could help support them. They were also younger and had husbands who were younger when they died and their husbands had died more recently. All other differences (number of siblings, black, foreign born status, work and occupation in 1910 or education levels in 1940) are not statistically significant in the full sample or in the sample of unmarried mothers.

How large are these differences? To assess this we predict income again using the 1915 Iowa census with all the new data we have. Figure 1 shows the distribution of predicted income by accepted status. Accepted mothers are more likely to be at the lower end of the distribution. But these differences are modest. The predicted income of accepted mothers is about 50 dollars lower than that of rejected mothers, or about 6-7 percent lower (Appendix Table 2). Thus accepted mothers appear to be on average somewhat poorer than rejected mothers.

We conduct two exercises to assess the extent of omitted variable bias. First, we present results with and without covariates and compare estimates. We also report bounds for $\beta_{1}$ using Oster's (2017) proposed correction to assess the extent to which our assumptions about unobservables affect the coefficient estimates. ${ }^{21}$

\footnotetext{
${ }^{21}$ To compute these bounds we assume that the R-max is 1.3 times greater than the R-squared that is estimated in the regression with controls, as suggested by Oster. We assume that $\delta=(-1,1)$ for lower and upper bounds to capture that the omitted variables are positively or negatively correlated with the regressor of interest.
} 


\subsection{Assessing the potential impact of missing or low quality data on our esti- mates}

Missing data. Although we have fewer missing data compared to most long-term studies, missing data can bias our results if the data are missing differentially for accepted and rejected mothers. We investigate whether being accepted predicts missing data on outcomes. Appendix Table 3 shows that conditional on covariates, the only marriage-related outcome that is predicted by being accepted (at the $5 \%$ level) is whether the longevity of the post-MP husband is missing. For labor force outcomes the concern with missing data is larger: labor force participation, occupation scores and family income in 1940 are all less likely to be missing for accepted mothers (Appendix Table 4). Conditional on controls, the differences are about $10 \%$. The same is true for location and family income in 1940 (Appendix Table 5). Working or longevity on the other hand are not missing differentially. These results suggest missing data remains a particular concern for economic outcomes and location.

To address differential missing data, we take two approaches. First we estimate bounds based on Lee [2009]. Because these bounds cannot be computed with additional controls, we also estimate models that account for attrition using the semi-parametric approach proposed by Newey [2009]. This consists of a two-stage model, where in the first stage we predict attrition, ideally including some predictors that are not part of the main equation of interest. We use research assistant (RA) fixed effects as instruments for selection, based on the idea that RA quality affects the likelihood of finding a match. Because records are assigned to RAs arbitrarily, differences in finding rates reflect RA ability rather than underlying likelihood that the record can be matched based on observables. In the second stage, we estimate a linear regression of the outcome on controls and on a fourth degree polynomial of predicted values from the first stage, i.e. a semi-parametrical selection correction term. We report these results in all tables.

Mis-matched data. There is considerable debate in the economic history community about the quality of linked data and how it varies based on various matching methods (Bailey et al., 2017, Abramitzky et al., 2019). We test whether the quality of the match influences our results. To do this, we compute measures of the quality of matches and re-estimate results using only high quality matches. $^{22}$ We also present results using data from multiple sources-for example we can compare our marriage information from the trees to the information that is gleaned from the census. If the results are similar across different data sets, then the concern that matches to one source of

\footnotetext{
${ }^{22} \mathrm{~A}$ high quality match is a match with quality above the median. The quality measure is a weighted sum of jarowinkles assessing the similarity of the name, place of birth and age match between the different datasets. The data codebook details how we compute each quality measure.
} 
information are incorrect is reduced.

\section{The Effects of Welfare on Marriage and Fertility}

\subsection{How does welfare affect marriage decisions?}

For this analysis we use only the subsample of women who were not married at the time they applied for transfers. Mothers on welfare are not less likely to remarry over their lifetime (Table 2, Column 1). Accepted mothers are slightly (1 percentage point) less likely to remarry than rejected mothers, but the difference is not statistically significant and it is small relative to the mean for rejected mothers (47 percent). This effect remains small and statistically insignificant when we control for covariates and is not sensitive to how we estimate the standard errors. The results are similar when we estimate bounds, correct for missing data or drop the lowest quality matches. Using the largest Oster bound, being accepted lowered the probability of remarriage by 0.02 percentage points. The next three columns use observations from the census to assess effects on marital status using a different data source. Here we find that while there are no differences in marriage rates in 1930 or 1940, there is a statistically significant 25\% decrease in the likelihood of being married in 1920 (in the smaller sample of those who applied before 1920). This suggests that cash transfers increased the duration until marriage in the short run, but not the medium or long term.

We investigate this further in Figure 2. The histogram of the duration to remarriage suggests that rejected mothers were more likely to marry soon (within two years) after applying (Figure 2a). Kaplan-Meier survival estimates of the probability of remaining single, where the clock starts the day of the MP receipt and ends at death, show a similar pattern: accepted mothers remain single for longer and are more likely to remarry later (Figure $2 \mathrm{~b}$ ). While women on welfare are not less likely to ever remarry, we do find that they do wait longer to do so.

How much longer? We show results of regression of time to remarriage on accepted for the sample of women who remarried. We find that accepted moms wait 0.97-1.3 years longer to marry, depending on whether controls are included (Table 3). The coefficients are a bit larger for the largest Oster bound (1.4) but smaller (0.9) if we drop low quality matches. Relative to the duration of 5.47 years to remarriage for rejected mothers, this represents an increase of 20-24 percent relative to the mean. When we estimate an Accelerated Failure Time model (AFT), using the log of the duration as the outcome, we find similar significant increases in duration (Table 3, column 2).

Figures $2 \mathrm{a}$ and $2 \mathrm{~b}$ suggest that the main differences between accepted and rejected mothers in terms of duration to remarriage occur in the short run, with accepted mothers less likely to remarry 
immediately and more likely to remarry after 8 years. To explore this, we estimate regressions where the dependent variable is whether the mother remarries within a year, two years, five years, etc. For these regressions mothers who did not ever remarry are coded as zero. Mothers whose marital status could not be defined, or who are missing marriage dates are excluded.

We find a marginally significant effect of receiving a pension on short durations but no significant differences on longer durations, consistent with the figures (Table 3, last 5 columns). Because the baseline is low, the relative effects are relatively large: only 4 percent of mothers marry within a year so the transfer lowers the likelihood of re-marriage by $60 \%$ within a year, but falls to $15 \%$ within 5 (Figure 2c). The effect of receiving welfare on duration till marriage becomes insignificant after five years. ${ }^{23}$ These short run effects are larger if we drop low quality matches and they are still small and insignificant starting in year five.

In sum, duration to remarriage is increased by the cash transfer, but only in the short run. Duration to remarriage increased between 0.9 to 1.4 years and this increase corresponds to delaying marriages within 3-4 years of the transfer. Thus, our effects are consistent with previous findings looking at immediate effects of welfare reforms(Low et al., 2018b), but we also show that over a longer follow-up period, the difference falls to zero.

\subsection{Who do mothers on welfare remarry?}

Were these marriage delays associated with increases in the quality of the marriage match? To answer this, we investigate 5 measures of the desirability of the new match: 3 characteristics of the husband and two measures of the match. The former includes his longevity, his education and his occupation score, which serves as a measure of lifetime income. Longevity is an excellent measure of health and also an indirect measure of his lifetime resources, as it reflects the socioeconomic conditions he experienced as a child and as an adult. ${ }^{24}$ Education is a good predictor of permanent income and is also associated with marital stability Lundberg et al. [2016]. But it can only be observed in the 1940 census and $18 \%$ of remarried husbands died prior to 1940, so it is not observed for all. Finally, we predict the husband's lifetime income (in 1950 dollars) using the latest pre-marriage occupation observed in $1910,20,30$ or $40 .^{25}$

\footnotetext{
${ }^{23}$ We also estimate Logit models. The results (available upon request) are very similar to those reported here.

${ }^{24}$ Many papers document that conditions in utero affect health and longevity (for a review see Almond and Currie [2011]). Another extensive literature shows that individuals nutrition as well as their parents' income and education while growing up predict health (Case et al., 2002; MD and Gorman [2004], see Almond et al. [2017] for a review). Finally, socio-economic status (education, occupation and income) in adulthood are very large predictors of longevity (Cutler et al. [2006], Cutler et al. Chetty et al. [2016]).

${ }^{25}$ We use the IPUMS constructed "occscore." This measure assigns income to individuals based on their occupation, imputing income in that occupation in 1950. We assign each man the occupation score we observe in the latest census where he is observed before marriage under the assumption this is the most likely occupation that the MP woman
} 
We construct 2 measures of the quality of the match: the age and education gaps between spouses. Empirically, small age gaps predict greater satisfaction (Lee and McKinnish, 2018) and lower divorce rates (Lillard et al., 1995), and they are preferred in online dating (Hitsch et al., 2010). However, in most populations husbands are older than wives. Based on the work of Grow and Van Bavel [2015], we assume that the optimal gap is 2.5 years, so that gaps are considered sub-optimal if there are larger or smaller than 2.5. Equal education levels are preferred in dating markets (Hitsch et al. [2010]). Female bargaining power is also larger if she is more educated relative to her husband (Doss, 2013). We can only compute this for couples in which neither has died prior to 1940 .

We combine these measures of husband and match quality into a single index, using two methods. First, we standardize all the measures and sum them, giving each equal weight. ${ }^{26}$ Alternatively, we combine them using the model calibrated by Grow \& Van Bavel (2015) which combines age gaps, education gaps and earnings potential into a single utility based measure which is highly predictive of marriage patterns in contemporary Europe. ${ }^{27}$ Note that this is not a sorting index like those used in Becker's assortative matching models. It corresponds to the utility associated with a given match, which can be a function of both the woman's and the men's traits.

The basic model predicts that if women delay marriage they will marry more desirable husbands. Duration to remarriage is indeed positively and statistically significantly related to husbands' education, occupation, and longevity; duration is also statistically significantly associated with smaller education gaps and age gaps (Appendix Figure 2). To our knowledge this is the first paper documenting that there is a strong correlation between waiting to marry and the quality of the husband (among women with children). These patterns are consistent with the model's prediction that waiting results in a better match in the absence of stigma.

But does welfare receipt result in better husbands? Figure 3 shows the estimated densities of match quality measures for accepted and rejected mothers. The new husbands of welfare recipients appear to live longer. However, husband education and occupation-based income do not appear to differ much on average and appear lower for accepted mothers. The distribution of match quality would have observed at the time of the marriage decision.

${ }^{26}$ To do this we first normalize each measure (subtracting the mean and dividing by the standard deviation) and them sum them together as in Kling et al.. To maximize sample size we use any measure available, so the index is defined for those that have any measures.

${ }^{27}$ We use the utility function and the parameters defined and calibrated in Grow and Van Bavel (2015). The index is given by $v_{i j}=\left(\frac{S_{\max }-|s i-s j|}{S_{\max }}\right)^{w_{s}}\left(\frac{y_{i}}{Y_{\max }}\right)^{w_{y}}\left(\frac{A_{\max }-\left|\alpha_{i}-\alpha_{j}\right|}{A_{\max }}\right)^{w_{a}}$. The first term of the equation is the similarity of education, the second term is the earnings prospects and, the last term is the age gap. We follow the same categorization of variables as in the original paper, except for education, where we divide it in 4 quintile categories instead of the four categories in the paper (no schooling, primary, secondary and tertiary). The calibration parameters are given by $S_{\max }=4 ; Y \max =5 ; A_{\max }=800 ; w_{s}=0.385 ; w_{y}=1.201 ; w_{a}=10.833$. 
(age and education gaps) is very similar for both groups. In fact we cannot reject the null that the distributions of any trait are identical for accepted and rejected. (p-values are reported in the figures.)

Regression analysis yields the same findings. The results without controls (Panel A Table 4) and with controls (Panel B Table 4) suggest that mothers on welfare marry husbands who are roughly similar in terms of longevity, education, and occupation-based income: nearly all the coefficients for accepted are statistically insignificant. And while some estimated effects are positive (longevity) several are negative (occupation score and education). Estimates of the impact of welfare receipt on match quality (age and education gaps) are also insignificant and often of different signs. A joint test (column 6) shows that we cannot reject the null that all coefficients are equal to zero at the 5 percent level.

However, the theory predicts that results for individual measures of husband or match quality are not meaningful: we would want to examine the impact of welfare receipt on a single measure or index of quality. When we aggregate the multiple measures of husband quality using the utilitybased index from Grow \& Van Bavel, we find that on net, with or without controls, accepted mothers had husbands that were not different in their overall quality (column 9). If we construct an index in which we give all measures equal weights then we find a positive and significant effect on the index, but this result is mostly driven by the positive impact on longevity and it is small, on the order of 10 percent of a standard deviation in the index (columns 7 and 8). In Appendix Table 6 we show results for several other traits of the new husband (1940 income or earnings score, foreign born status, farming status and number of children). The coefficients on accepted are never statistically significant and vary in their sign.

These results, however, rely on strong assumptions about how women value different traits. If instead we conduct the conditional test for each covariate, as suggested in proposition 2, the evidence, in Panel $\mathrm{C}$ of Table 4, is again ambiguous: only longevity has a coefficient that moves in the right direction and all coefficients are statistically insignificant. These results are not affected by Oster corrections, corrections for missing data or corrections for the quality of the data (Panel E), though again the sample size is small. We further test this result by examining whether husband and wife live together in 1930 or 1940, an indicator that the marriage was long lasting and therefore a good match. We find that accepted mothers are less likely to be living with their spouses, consistent with these matches being of worse, not better quality (Appendix Table 6).

We conclude that the transfers did not meaningfully improve the quality of the matches, nor did it affect assortative mating (Appendix Figure 3). More educated women were more likely to marry 
more educated men. This is equally true among both accepted and rejected. ${ }^{28}$

Why does the theory fail? We consider three possibilities. First, waiting to marry a higher quality husband might result in a depreciation of the mother's own quality or attractiveness (her age). Appendix Figure 4 shows that, as in other settings, women are much less likely to marry as they get older. Theory (proposition 3) suggests this should not affect the predictions of the effects of the cash transfer-those who receive the transfer should still find better men, but it does suggest that the effects might be small if waiting to marry reduces her attractiveness. Panel D of Table 4 shows that if we control for the age at marriage of the mother, our conclusions are unchanged.

A second possibility is that there is selection into marriage. Perhaps women who marry late are negatively selected in some way, but there is little evidence of this. There are no predetermined characteristics that predict duration to remarriage, aside from the number of children (Appendix Table 7), suggesting that negative selection likely does not explain this.

A third possibility is that stigma associated with welfare receipt reduces the quality of the husband (proposition 4). Once stigma is included in the model, the predictions with respect to partner quality can reverse, even if duration is increasing. ${ }^{29}$ We try to assess this empirically by stratifying the sample by whether we think there is more or less stigma associated with welfare receipt in the state. We assume that in states that accepted only widows, MP recipients would be less stigmatized. We also assume that in states that required women to stay home and encouraged them not to work, stigma would be lower.

When we stratify the sample based on this characterization, we find some weak support for stigma (Appendix Table 8A). In states that only accepted widows, duration to remarriage is longer and the quality of the match appears to increase more for longevity but the age gap increases. But these differences are not statistically significant across the two groups of states. When we split by work requirements we find no differences at all. While crude, these tests provide at best weak evidence for stigma.

The bulk of the evidence presented here suggest that the transfers did initially delay marriage, but that in the long run, women who received welfare married similar men, at similar rates relative to women who did not receive welfare. Overall the negative effects of age and the effects of stigma appear to be the best explanations for the findings but our evidence does not conclusive prove these are the causes.

\footnotetext{
${ }^{28}$ There is a small decrease in the degree of assortativeness based on education among accepted mothers, but no change based on longevity or age.

${ }^{29}$ The predictions of the model with respect to quality are still ambiguous even though duration increases. This is because a duration increase is to be expected even if quality didn't change. The only way duration could decrease is if the quality cutoff was substantially lower with the transfer. In other words, both an increase and a small decrease in quality are consistent with duration increasing.
} 


\subsection{Effects on Fertility}

Though the program included incentives to increase fertility, there is little empirical evidence to support an increase in child bearing as a result of the transfer. Fertility post application to the Mothers' Pension program was relatively modest: $86 \%$ of mothers did not have any children and the differences across the two groups are very small (Figure 4). Though women on welfare did have 0.414 more children on average, this difference pre-existed welfare receipt (Table 5 Panel A column $1 \& 2$ ). Moreover, once we control for the younger maternal age of welfare recipients and greater number of children at application in Panel B, welfare recipients appear to have fewer children though this is statistically insignificant (Table 5 Panel B column $1 \& 2$ ). To rule out that this is due to the relatively old age of mothers in our sample (age 37), we show that the results are identical if look at only the youngest mothers in the sample (Appendix Table 8B).

These results are based on the data from the family trees. A second measure of fertility is derived from the number of children in her household as measured in the 1930 and 1940 census (Table 5, columns 3, 4, 7 and 8). This conditions on the mother surviving to 1930 and 1940. We see the same pattern: more children to mothers on welfare when we do not control for maternal characteristics at application (Panel A), but little difference once we do (Panel B). Again these conclusions are not changed when we look at Oster bounds, correct for missing data or drop observations with low quality. The largest effects we find (Oster bound) are increases in the number of children: 0.14 in the full sample, and 0.17 for unmarried mothers, still very small numbers of additional children.

In sum, we find no significant effects on fertility. Perhaps this is due to the fact that the average age of mothers in our sample is 37. But Appendix Table 8b shows our results are identical if we split the sample based on the median age of the mother at the time of the application.

\section{Work, mobility and lifetime maternal welfare}

\subsection{Transfers, labor force participation and earned income}

We estimate the impact of welfare receipt on mothers' labor force participation, occupation and mobility, using data from the 1930 and 1940 censuses. $^{30}$ Theory predicts that the transfer would increase the quality of the employment match just as UI would. Among women who were rejected by the Mothers' Pension program, 33 percent were part of the labor force and 29 percent were working in 1930 (Table 6, top row). By 1940, those numbers had fallen to 21 and 19 percent, respectively,

\footnotetext{
${ }^{30}$ We can include results for 1920 but there are several issues with the 1920 data. First a large number of mother have not yet applied to the program, so the sample for whom 1920 is a post-period is smaller. Second our match rate for 1920 is lower than for other censuses. Last, 1920 does not include labor force participation and work separately.
} 
which is consistent with women remarrying over time leading to lower labor force participation.

Without controls (Table 6 Panel A), mothers receiving welfare are roughly five percentage points more likely to be in the labor force or work in both 1930 and 1940. However, once we control for their greater underlying disadvantage, the point estimates fall by roughly half their size and are no longer significantly different from zero in most of the specifications (Table 6, Panel B).

For women who participated in the labor force, we can examine their occupational scores in 1930 and 1940 and their earned incomes in 1940. The density of these outcomes is shown in Figure 4: they are similar for accepted and rejected, and a formal test cannot reject that they are the same. Regression estimates that include controls (Table 6) confirm that there are no large or significant effects of welfare receipt on short or long term labor market outcomes. When we consider bounds for omitted variable bias as in Oster (2017) or the Newey 95\% CI, we can still rule out any meaningful differences in employment, occupation or income between those who received welfare and those who did not. ${ }^{31}$

\subsection{Transfers and geographic mobility}

Welfare receipt created a disincentive for geographic mobility since the transfer was lost once women left the county of application. To examine whether welfare receipt reduced mobility empirically, we examine whether women remained in the same county in which they applied for welfare in 1930 and 1940 and if they moved, what the characteristics were of the county to which they moved.

As of 1930, 65 percent of rejected women who applied for mothers pension but were rejected still lived in the same county and 85 percent still lived in the state. By 1940, that number had fallen slightly to 59 percent and 83 percent, respectively. In contrast to labor market outcomes, geographic mobility does appear to be affected by the receipt of cash transfers. Women who receive welfare are about eight percent more likely to live in the same county as they did when they applied for welfare than mothers who applied and were rejected (Table 7 Columns 1 and 3). The Oster bounds are tight for these outcomes (Table 7 Panel C). The largest upper bound we estimate for the effect is 0.10 (from the CI of the Newey estimates), which is a 15 percent increase in the likelihood of remaining in the same county.

Theory predicts that not only would women on welfare be less likely to move, but that when they do, they should move to "better" neighborhoods. We test this by proxying for the quality of the neighborhood with the average level of education in the county, the sex ratio in the county (more

\footnotetext{
${ }^{31}$ For example the upper bound for 1940 income is 16 dollars relative to a mean of 479 , so a 3.5 percent increase at most. For work, the Oster bounds do not include negative values, though the Newey $95 \%$ CI includes 10 percent decreases. Newey results available upon request.
} 
males, better), and average female labor force participation rates in the county (higher rates better for single mothers) calculated from the 1930 and 1940 censuses. We find no effect of the transfer on these measures regardless of the controls or the other estimation corrections we apply.

\subsection{Overall maternal welfare}

Did the program benefit mothers? To answer this, we collected two measures of her long run well-being: longevity of the mother and her household income in 1940. In Figure 5 we compare the distributions of longevity (5a) and 1940 household income (5b) of the mother by acceptance status. In both cases, we cannot reject that the distributions are identical (p-values reported in the figure). We follow this with regression analysis (Table 8). There do not appear to be any large or significant effects of welfare receipt on long run maternal well-being. Once full controls are included, there appears to be a small positive but insignificant effect of welfare receipt on maternal longevity (column 1), and a small negative but insignificant effect on income (column 2). Again these conclusions are not affected by our various corrections. For longevity, we cannot rule out relatively large positive increases of about half a year (Oster) or more (Newey CI) in life expectancy. While maternal physical well-being was perhaps improved by the transfers, the transfer did not improve economic well-being. Our estimates suggest that in 1940 accepted mothers were poorer than rejected mothers, and this difference is similar to what it was at the time of application (see last column of Appendix Table 2). All mothers who applied for welfare were poor and remained so by 1940, regardless of welfare receipt, earning roughly half of a typical household's income.

\subsection{Was the program worth it? Marginal value of public funds computations.}

We find that cash transfers resulted in marriage delays of about a year and decreases in geographic mobility. But they otherwise had no statistically significant negative impacts on behavior and no positive effects on outcomes. We compute the marginal value of public funds (MVPF) using the methodology of Hendren and Sprung-Keyser [2019]. The computations are in Table 9. Considering only the benefits to mothers, the MVPF of the program once we include the dollar value of behavioral responses is 0.84 , below one.

However, a more realistic and comprehensive calculation would also consider whether the transfers benefitted children. Using Aizer et al.'s (2016) findings for children's longevity and income, we find that the MVPF of the program is greater than 5 even with maternal behavioral responses. We also compute the smallest increases in income or longevity of the children that would be needed for the MVPF to be larger than one. If the children's income over the lifetime increases by only 
$0.75 \%$ then the MVPF exceeds one. Alternatively if their longevity increases by 0.3 years of life the MVPF would also exceed one. Thus relatively small benefits for children allows the program to pay for itself, in part because behavioral responses from the mother are relatively minor. ${ }^{32}$

\subsection{Limitations.}

While the data are unique in that they allow us to follow the short and long run trajectories for the mothers, they are limited as we are missing outcomes data for a non-trivial number of the mothers. We address this by calculating bounds of the effects which address both missing outcomes data and potential omitted variable bias. While these approaches have limitations, we note that missing data is an equally important issue for contemporary studies of welfare receipt, given the documented high rates of attrition of this population in survey data and high rates of non-formal employment among adult recipients.

The Mothers' Pension program was in practice a small program that served fewer than $1 / 3$ of the eligible families in the places where it existed (Eli et al., 2020) which is similar to the rate of participation in the modern welfare program. Thus while the effects we estimate are likely to reflect "partial equilibrium" effects and cannot speak to a situation where a much larger share of the population has access to the program, this analysis is useful for understanding effects in the current US welfare program.

Finally, we did not investigate whether the existence of the program affected behaviors ex-ante. For example, it is possible that fertility increased among women who were not in the program because the MPP provided a form of insurance. Similarly it is possible that individuals moved to certain locations to insure access to the program over the long run. Future work should consider these effects as well. We note here that these effects seem unlikely to occur given that the direct effects we estimate are modest or non-existent.

\section{Conclusion}

We study the short and long run incentive effects of the first welfare program in the US. Tracking 16,000 women over their lifetime, we establish that the behavioral responses to the incentives were small. Women tended to remarry at high rates. Those with transfers were not less likely to marry over their lifetime and they delayed marriage only in the short term by about a year. Ultimately,

\footnotetext{
${ }^{32}$ The table also shows alternative computations. For example in the benefits of the program we count the transfer as a benefit. If we do not count it, and instead only count the benefits for the children, then we require a $6 \%$ increase in child income or a 1.5 increase in longevity for the MVPF to be greater than one.
} 
they did not have more children, nor were they less likely to work. The only dimension in which we find a meaningful effect is migration: women were more likely to stay in the county in which they applied. Thus our findings reject many predictions of a simple search model of welfare and the marriage and labor markets.

Our findings suggest that current concerns over the incentive effects of social insurance programs are overstated - individuals are less responsive to economic incentives than one might anticipate. Our results suggest that on average, other forces such as age, norms and stigma may be more important determinants of marriage and labor force behaviors than the monetary incentives embedded in these government programs. Incorporating these forces into standard models of behavior and further assessing their empirical importance is an important area for future research.

The program did not generate large negative incentive effects as predicted by economic models, but it did not help mothers escape poverty either. It did help alleviate short term cash needs and may have improved the longevity of the mothers a bit, though these effects are small and statistically insignificant. Thus, ultimately the program should be judged mostly by the impact it had on its intended beneficiaries - the children. We compute that the program would pay for itself if it generates relatively small benefits in terms of increased health or income of the children.

These results are relevant for developing countries today where economic conditions are similar to those that were experienced by the women in our sample. Developing countries face similar issues of income/poverty measurement, large fertility rates and low levels of female participation in formal labor markets. Short term evaluations of contemporary conditional and unconditional cash transfers in developing countries have found limited behavioral responses among adults and improvements in outcomes among adults and children. Our work can help shed light on what the expected long term effects of these programs might be, though future work should attempt to confirm our long term effects in these settings.

\section{References}

Ran Abramitzky, Leah Platt Boustan, and Katherine Eriksson. A nation of immigrants: Assimilation and economic outcomes in the age of mass migration. Journal of Political Economy, 122(3):467-506, 2014. doi: 10.1086/675805. URL https://doi.org/10.1086/675805.

Ran Abramitzky, Leah Platt Boustan, Katherine Eriksson, James J Feigenbaum, and Santiago Pérez. Automated linking of historical data. Technical report, National Bureau of Economic Research, 2019.

Mimi Abramovitz et al. Regulating the lives of women: Social welfare policy from colonial times to the present. South End Press, 1996. 
Anna Aizer, Shari Eli, Joseph Ferrie, and Adriana Lleras-Muney. The long-run impact of cash transfers to poor families. American Economic Review, 106(4):935-71, April 2016. doi: 10.1257/aer.20140529. URL http://www. aeaweb.org/articles?id=10.1257/aer. 20140529.

Douglas Almond and Janet Currie. Killing me softly: The fetal origins hypothesis. Journal of economic perspectives, 25(3):153-72, 2011.

Douglas Almond, Janet Currie, and Valentina Duque. Childhood circumstances and adult outcomes: Act ii. Working Paper 23017, National Bureau of Economic Research, January 2017. URL http://www.nber . org/papers/w23017.

Martha Bailey, Connor Cole, Morgan Henderson, and Catherine Massey. How well do automated linking methods perform? lessons from us historical data. Technical report, National Bureau of Economic Research, 2017.

Abhijit Banerjee, Rema Hanna, Jordan Kyle, Benjamin A Olken, and Sudarno Sumarto. Tangible information and citizen empowerment: Identification cards and food subsidy programs in indonesia. Journal of Political Economy, 126(2):451-491, 2018.

Marianne Bitler, Jonah Geobach, Hilary Hoynes, and Madeline Zavodny. The impact of welfare reform on marriage and divorce. Demography, 41(2):213-36, 2004.

Rebecca Blank. Evaluating welfare reform in the united states. Journal of Economic Literature, 40(4): 1105-1166, 2002.

Richard Blundell, Luigi Pistaferri, and Itay Saporta-Eksten. Consumption inequality and family labor supply. American Economic Review, 106(2):387-435, 2016.

Kenneth Burdett and Kenneth L Judd. Equilibrium price dispersion. Econometrica: Journal of the Econometric Society, pages 955-969, 1983.

Anne Case, Darren Lubotsky, and Christina Paxson. Economic status and health in childhood: The origins of the gradient. American Economic Review, 92(5):1308-1334, December 2002. doi: 10.1257/ 000282802762024520. URL http://www. aeaweb.org/articles?id=10.1257/000282802762024520.

Raj Chetty, Nathaniel Hendren, Patrick Kline, and Emmanuel Saez. Where is the land of opportunity? the geography of intergenerational mobility in the united states. The Quarterly Journal of Economics, 129 (4):1553-1623, 2014.

Raj Chetty, Michael Stepner, Sarah Abraham, Shelby Lin, Benjamin Scuderi, Nicholas Turner, Augustin Bergeron, and David Cutler. The association between income and life expectancy in the united states, 2001-2014. Jama, 315(16):1750-1766, 2016.

Pierre-André Chiappori and Bernard Salanié. The econometrics of matching models. Journal of Economic Literature, 54(3):832-61, 2016. 
David Cutler, Angus Deaton, and Adriana Lleras-Muney. The determinants of mortality. Journal of economic perspectives, 20(3):97-120, 2006.

David M Cutler, Adriana Lleras-Muney, and Tom Vogl. Socioeconomic status and health: Dimensions and mechanisms. In The Oxford Handbook of Health Economics.

Cheryl Doss. Intrahousehold bargaining and resource allocation in developing countries. The World Bank Research Observer, 28(1):52-78, 2013.

Shari Eli and Laura Salisbury. Patronage politics and the development of the welfare state: Confederate pensions in the american south. The Journal of Economic History, 76(4):1078-1112, 2016.

Shari Eli, Adriana Lleras-Muney, and James Uguccioni. The emergence of the modern welfare system: Evidence from the mothers? pension program. Technical report, Working Paper, 2020.

Claudia Goldin. The quiet revolution that transformed women's employment, education, and family. American economic review, 96(2):1-21, 2006.

J Grogger and LA Karoly. Employment, labor supply, and earnings. Welfare reform: Effects of a decade of change, pages 134-154, 2005.

Jeff Grogger and Stephen G Bronars. The effect of welfare payments on the marriage and fertility behavior of unwed mothers: Results from a twins experiment. Journal of Political Economy, 109(3):529-545, 2001.

André Grow and Jan Van Bavel. Assortative mating and the reversal of gender inequality in education in europe: An agent-based model. PloS one, 10(6), 2015.

Joel F Handler and Ellen Jane Hollingsworth. Stigma, privacy, and other attitudes of welfare recipients. Stan. L. Rev., 22:1, 1969.

Nathaniel Hendren and Benjamin D Sprung-Keyser. A unified welfare analysis of government policies. Technical report, National Bureau of Economic Research, 2019.

Günter J Hitsch, Ali Hortaçsu, and Dan Ariely. What makes you click??mate preferences in online dating. Quantitative marketing and Economics, 8(4):393-427, 2010.

Seema Jayachandran. Social norms as a barrier to women's employment in developing countries. Working Paper 27449, National Bureau of Economic Research, June 2020. URL http://www.nber.org/papers/ w27449.

Ruth A Kasman. Employed mothers of children in the adc program cook county bureau of public welfare. Social Service Review, 19(1):96-110, 1945.

Melissa Schettini Kearney. Is there an effect of incremental welfare benefits on fertility behavior? a look at the family cap. Journal of Human Resources, 39(2):295-325, 2004. 
Jeffrey R Kling, Jeffrey B Liebman, and Lawrence F Katz. Experimental analysis of neighborhood effects. Econometrica, 75(1):83-119. doi: 10.1111/j.1468-0262.2007.00733.x. URL https://onlinelibrary . wiley.com/doi/abs/10.1111/j.1468-0262.2007.00733.x.

David S Lee. Training, wages, and sample selection: Estimating sharp bounds on treatment effects. The Review of Economic Studies, 76(3):1071-1102, 2009.

Wang-Sheng Lee and Terra McKinnish. The marital satisfaction of differently aged couples. Journal of population economics, 31(2):337-362, 2018.

Mark H Leff. Consensus for reform: The mothers'-pension movement in the progressive era. Social Service Review, 47(3):397-417, 1973.

Lee A Lillard, Michael J Brien, and Linda J Waite. Premarital cohabitation and subsequent marital. Demography, 32(3):437-457, 1995.

Corinne Low. Pricing the biological clock: Reproductive capital on the us marriage market. Manuscript, Wharton School of Business, 2014.

Hamish Low, Costas Meghir, Luigi Pistaferri, and Alessandra Voena. Marriage, labor supply and the dynamics of the social safety net. Working Paper 24356, National Bureau of Economic Research, February 2018a. URL http://www.nber.org/papers/w24356.

Hamish Low, Costas Meghir, Luigi Pistaferri, and Alessandra Voena. Marriage, labor supply and the dynamics of the social safety net. Technical report, National Bureau of Economic Research, 2018b.

Shelly Lundberg, Robert A Pollak, and Jenna Stearns. Family inequality: Diverging patterns in marriage, cohabitation, and childbearing. Journal of Economic Perspectives, 30(2):79-102, 2016.

Barbara Machtinger. The us children's bureau and mothers' pensions administration, 1912-1930. Social Service Review, 73(1):105-118, 1999.

J. J. McCall. Economics of information and job search. The Quarterly Journal of Economics, 84(1):113-126, 1970. ISSN 00335533, 15314650. URL http://www.jstor.org/stable/1879403.

Hayward MD and BK Gorman. The long arm of childhood: the influence of early life social conditions on men's mortality. Demography, 41(1):87-107, 2004.

Gwendolyn Mink. The wages of motherhood: Inequality in the welfare state, 1917-1942. Cornell University Press, 1996.

Robert Moffitt. Incentive effects of the u.s. welfare system: A review. Journal of Economic Literature, 30 (1):1-61, 1992. ISSN 00220515. URL http://www.jstor.org/stable/2727878.

Robert Moffitt et al. An economic model of welfare stigma. American economic review, 73(5):1023-1035, 1983. 
Whitney K Newey. Two-step series estimation of sample selection models. The Econometrics Journal, 12: S217-S229, 2009.

Dorothy E Roberts. The value of black mothers' work. Conn. L. Rev., 26:871, 1993.

Mark R Rosenzweig and Junsen Zhang. Do population control policies induce more human capital investment? twins, birth weight and china's ?one-child? policy. The Review of Economic Studies, 76(3): $1149-1174,2009$.

Theda Skocpol. Protecting soldiers and mothers. Harvard University Press, 1995.

Deborah E Ward. The white welfare state: The racialization of US welfare policy. University of Michigan Press, 2009.

Jeffrey E Zabel. An analysis of attrition in the panel study of income dynamics and the survey of income and program participation with an application to a model of labor market behavior. Journal of Human Resources, pages 479-506, 1998.

\section{Appendix}

\section{Basic Model}

In order to make the appendix self-contained, we set up the model as we did in the main text.

A woman is either single or married. While single, she receives a flow benefit of $b$ and, with probability $\lambda$, she finds a potential partner with quality $q$ (the flow utility she would get from marriage) and decides whether to marry him or stay single. For simplicity, we say that marriage lasts forever. The quality of a partner $q$ is distributed $F(q)$ with support $[\underline{q}, \bar{q}]$ and $\bar{q}>b$. She discounts the future at rate $\beta$.

The value of being single is

$$
V_{s}=b+\beta\left(\lambda \int_{q=\underline{q}}^{\bar{q}} \max \left\{V_{m}(q), V_{s}\right\} \mathrm{d} F(q)+(1-\lambda) V_{s}\right) .
$$

The value of being married to a partner with quality $q$ is

$$
V_{m}(q)=q+\beta V_{m}(q)=\frac{q}{1-\beta} .
$$

Since the value of marriage is strictly increasing in $q$, the agent will follow a cut-off rule. There is a cutoff quality, $q^{*}$, such that she will accept all prospects with $q>q^{*}$. The cutoff rule is implicitly defined as

$$
V_{m}\left(q^{*}\right)=V_{s}
$$


Considering that, and rearranging the definition of $V_{s}$, we can write

$$
\begin{gathered}
V_{s}=b+\beta V_{s}+\beta \lambda \int_{q=q}^{\bar{q}}\left(\max \left\{V_{m}(q)-V_{s}, 0\right\}\right) \mathrm{d} F(q), \\
V_{s}=b+\beta V_{s}+\beta \lambda \int_{q=q^{*}}^{\bar{q}}\left(V_{m}(q)-V_{s}\right) \mathrm{d} F(q), \\
V_{s}=b+\beta V_{s}+\frac{\beta \lambda}{1-\beta} \int_{q=q^{*}}^{\bar{q}}(1-F(q)) \mathrm{d} q, \\
(1-\beta) V_{s}=b+\frac{\beta \lambda}{1-\beta} \int_{q=q^{*}}^{\bar{q}}(1-F(q)) \mathrm{d} q,
\end{gathered}
$$

where the third line followed from integration by parts. From the definition of $q^{*}$, we have obtained an implicit equation for $q^{*}$ (which contains no other endogenous variables)

$$
\begin{gathered}
q^{*}=b+\frac{\beta \lambda}{1-\beta} \int_{q=q^{*}}^{\bar{q}}(1-F(q)) \mathrm{d} q . \\
0=-q^{*}+b+\frac{\beta \lambda}{1-\beta} \int_{q=q^{*}}^{\bar{q}}(1-F(q)) \mathrm{d} q .
\end{gathered}
$$

We can see that this function is continuous and positive at $q^{*}=b$ and negative at $q^{*}=\bar{q}$, so there exists a solution. Also, the function is strictly decreasing so its solution is unique.

Intuitively, this equation says that the value of the minimum acceptable marriage, $q^{*}$ should be equal to the benefit, $b$, plus the option value of holding out for a good match. Given a reservation quality, $q^{*}$, the probability of marriage is $\lambda\left(1-F\left(q^{*}\right)\right)$ and the average match quality is $\mathbb{E}\left[q \mid q>q^{*}\right]$. The duration until remarriage is given by $D=1 / \lambda\left(1-F\left(q^{*}\right)\right)$.

Before proving Proposition 1, we establish the following useful result.

Lemma. The reservation quality, $q^{*}$, is increasing in benefits, $b$. Moreover, the reservation quality is also increasing in the probability of finding prospects, $\lambda$, and the distribution of quality $F(q)$ (in the senses of first-order stochastic dominance).

Proof. This result can be seen on equation 1. An increase in $b, \lambda$, or the distribution $F$ increases the right-hand side of the equation which corresponds to the value of waiting. In order to preserve the equality, the cutoff must be higher. Waiting is more attractive when the benefits are higher, the offers appear more often, or the offers are stochastically better. Then, the woman will only find it worthwhile to settle for a higher cutoff quality.

Now, we are ready to prove Proposition 1.

Proposition 8. $\partial D / \partial b>0$ and $\partial \mathbb{E}\left[q \mid q>q^{*}\right] / \partial b>0$ : An increase in benefits, $b$, increases the number of periods the woman stays single and the average quality of the marriage. 
Proof. From our previous lemma, an increase in benefits will increase the cutoff quality. Since the probability of marriage is decreasing in the cutoff quality, the increase in benefits decreases the probability of marriage and increases the expected number of periods the woman stays single. The average quality of the marriage increases because the woman now rejects relatively lower quality proposals.

In order to test the second prediction of Proposition 1, we would need to observe the quality of the marriage. what we observe are several traits that matter for the quality. We assume that there exists a quality function, $q: \mathcal{X} \rightarrow[q, \bar{q}]$, that maps a vector of characteristics into a single quality index. For exposition, and without loss of generality, we assume that the function $q$ is increasing in each trait.

Proposition 9. Without further assumptions about the joint distribution of $X$ and the production function $q(X)$, the sign of $\partial \mathbb{E}\left[x_{i} \mid q>q^{*}\right] / \partial b$ is ambiguous for all $i$. However the sign of $\partial \mathbb{E}\left[x_{i} \mid q>\right.$ $\left.q^{*}, x_{-i}\right] / \partial b$ is positive for all $x_{i}$ so long as all relevant $X$ are observed.

It might seem natural to expect that higher benefits would result in higher (better) traits in the accepted marriages. This is not necessarily true and it could be that every trait becomes worse.

Example 1. Consider a quality function $q\left(x_{1}, x_{2}\right)=x_{1} x_{2}$. The joint distribution of the traits is uniformly distributed over three mass points $(1,10) ;(10,1) ;(4,4)$. Suppose that, initially, the cutoff is $q^{*}=10$. The average of each trait conditional on a match is equal to 5 . Consider a small increase in the cutoff $\left(10<q^{*} \leq 16\right)$. The new average of each trait is 4 .

As the example shows, each trait could be, on average, lower with a higher cutoff quality. Still, we can predict an increase in a particular trait when conditioning for all the other relevant traits. In order to see this, notice that for a given value of the other traits, a higher cutoff will only eliminate matches where the trait we are interested in was low.

\section{Extensions}

\section{Age}

We show that the predictions of the model still hold when we incorporate aging considerations. In order to maintain the simple recursive structure of the model, we model aging as a random independent process that moves the agent from a young state to an old state. In the young state, a woman receives a proposal with probability $\lambda_{Y}$. In the old state, she receives a proposal with probability $\lambda_{O}<\lambda_{Y}$. There is a probability $\pi$ of transitioning from young to old and, naturally, no 
probability of the reverse transition. The transition, or lack of, is realized at the end of each period after the offer has been accepted or rejected.

The old single woman's problem is the same as the original problem. Let us define $V_{s, O}$ and $q_{O}^{*}$ as the value of being single and the cutoff quality when old.

The young woman's problem is slightly different. The opportunity cost of accepting a proposal is given by $V:=(1-\pi) V_{s, Y}+\pi V_{s, O}$, where $V_{s, Y}$ is the value of being single when young.

$$
V_{s, Y}=b+\beta\left(\lambda_{Y} \int_{q=\underline{q}}^{\bar{q}} \max \left\{V_{m}(q), V\right\} \mathrm{d} F(q)+\left(1-\lambda_{Y}\right) V\right) .
$$

The cutoff rule is defined by $V_{m}\left(q_{Y}^{*}\right)=q_{Y}^{*} /(1-\beta)=V$. Then, $\pi\left(V_{s, Y}-V_{s, O}\right)=\frac{\pi}{1-\pi}\left(V-V_{s, O}\right)=$ $\frac{\pi}{1-\pi} \frac{q_{Y}^{*}-q_{O}^{*}}{1-\beta}$.

$$
\begin{aligned}
V_{s, Y} & =b+\beta V+\beta \lambda_{Y} \int_{q=\underline{q}}^{\bar{q}}\left(\max \left\{V_{m}(q)-V, 0\right\}\right) \mathrm{d} F(q), \\
V_{s, Y} & =b+\beta V+\beta \lambda_{Y} \int_{q=q_{Y}^{*}}^{\bar{q}}\left(V_{m}(q)-V\right) \mathrm{d} F(q), \\
V_{s, Y} & =b+\beta V+\frac{\beta \lambda_{Y}}{1-\beta} \int_{q=q_{Y}^{*}}^{\bar{q}}(1-F(q)) \mathrm{d} q \\
(1-\beta) V & =b+\pi\left(V_{s, O}-V_{s, Y}\right)+\frac{\beta \lambda_{Y}}{1-\beta} \int_{q=q_{Y}^{*}}^{\bar{q}}(1-F(q)) \mathrm{d} q, \\
q_{Y}^{*} & =b-\frac{\pi}{1-\pi} \frac{q_{Y}^{*}-q_{O}^{*}}{1-\beta}+\frac{\beta \lambda_{Y}}{1-\beta} \int_{q=q_{Y}^{*}}^{\bar{q}}(1-F(q)) \mathrm{d} q,
\end{aligned}
$$

This equation takes into account the probability of transitioning into old age. It is easy to see that the cutoff quality will not be the same if $\lambda_{Y}>\lambda_{O}$.

Proposition 10. If the arrival rate $\lambda$ falls with age then $\partial \mathbb{E}\left[q \mid q>q^{*}\right] / \partial b>0$ and $\partial D / \partial b>0$.

Proof. First, for the old woman, the analysis of the basic model applies and the result follows immediately. Second, for the young woman, we can apply the same kind of analysis. Higher benefits increase the value of waiting both directly and indirectly. The direct effect comes from enjoying the benefits while single and young and the indirect effect comes from the benefits while old (which shows up through the cutoff quality of old). Thus, all cutoff qualities increase which implies higher expected qualities conditional on a match and a higher duration of single-hood.

\section{Stigma}

Getting the benefits could also bring about negative effects if there is stigma associated with participating in the program. In the model, we can think of this issue in two ways. First, being in the 
program lowers the probability of receiving an offer. Second, the distribution of offers gets worse.

In either case, the presence of the stigma makes the predictions of the model ambiguous.

Proposition 11. If $b$ lowers the rate of arrival of prospects $\lambda$ or worsens the distribution $F(q)$ in the sense of first-order stochastic dominance (in addition to increasing the per period utility) then the sign of $\mathbb{E}\left[q \mid q>q^{*}\right] / \partial b$ and $\partial D / \partial b$ becomes ambiguous.

Proof. Lemma 1 established that the cutoff quality moved in the same direction as the benefits, the change in the probability of proposals, $\lambda$, and the distribution, $F(q)$. With a stigma effect, the program increases $b$ but lowers $\lambda$ or $F$. The original effect increases the cutoff but the stigma effect lowers it. It is unclear which one we should expect to dominate.

\section{Work}

The initial predictions are maintained when we introduce a labor decision in the model. In this extension, a woman has a probability $\lambda_{E}$ of receiving an employment opportunity. A job offer is characterized by its wage $w$ which is distributed $G(w)$ with support $[\underline{w} \cdot \bar{w}]$ and $\bar{w}>b$. We assume that marriage lasts forever and that an employed woman loses her job with probability $\delta$ each period. We also assume that an employed woman can receive marriage offers at rate $\lambda_{m, e}$ and with quality distributed $\hat{F}(q)$.

In this extension, there exist three possible states: single and unemployed, single and employed, and married. The value of being single and unemployed is

$V_{s, u}=b+\beta \lambda_{m} \int_{q} \max \left\{V_{m, u}(q), V_{s, u}\right\} d F(q)+\beta \lambda_{e} \int_{w} \max \left\{V_{s, e}(w), V_{s, u}\right\} d G(w)+\beta\left(1-\lambda_{m}-\lambda_{e}\right) V_{s, u}$

The value of being married to a partner with quality $q$ is

$$
V_{m, u}(q)=q+\beta V_{m, u}(q)=q /(1-\beta) .
$$

The value of being employed at wage $w$ is

$$
V_{s, e}(w)=w+\beta \lambda_{m, e} \int_{q=\underline{q}}^{\bar{q}} \max \left\{V_{s, e}(w), V_{m, u}(q)\right\} \mathrm{d} \hat{F}(q)+\beta \delta V_{s, u}+\beta\left(1-\lambda_{m, e}-\delta\right) V_{s, e}(w) .
$$

Let $w^{*}$ be the cutoff wage and $q^{*}$ be the cutoff quality for the single, unemployed woman. Then, by definition of cutoff wage and quality

$$
(1-\beta) V_{s, u}=(1-\beta) V_{s, e}\left(w^{*}\right)=(1-\beta) V_{m, u}\left(q^{*}\right)=q^{*}
$$


Evaluating the expression above at $w^{*}$, we get

$$
q^{*}=w^{*}+\frac{\beta \lambda_{m, e}}{1-\beta} \int_{q=q^{*}}^{\bar{q}}\left[q-q^{*}\right] \mathrm{d} \hat{F}(q)=w^{*}+\frac{\beta \lambda_{m, e}}{1-\beta} \int_{q=q^{*}}^{\bar{q}}[1-\hat{F}(q)] \mathrm{d} q .
$$

For each wage $w$, there will be a cutoff marriage quality, $q(w)$, such that all proposals with quality $q>q(w)$ will be taken. The cutoff marriage quality is implicitly defined by

$$
V_{s, e}(w)=V_{m, u}(q(w))=\frac{q(w)}{1-\beta} .
$$

Then, we can write,

$$
\begin{gathered}
{[1-\beta(1-\delta)] V_{s, e}(w)=w+\beta \lambda_{m, e} \int_{q=q}^{\bar{q}} \max \left\{0, V_{m, u}(q)-V_{s, e}(w)\right\} \mathrm{d} \hat{F}(q)+\beta \delta V_{s, u} .} \\
{[1-\beta(1-\delta)] V_{s, e}(w)=w+\frac{\beta \lambda_{m, e}}{1-\beta} \int_{q=q(w)}^{\bar{q}}[1-\hat{F}(q)] \mathrm{d} q+\beta \delta V_{s, u} .} \\
{[1-\beta(1-\delta)]\left[V_{s, e}(w)-V_{s, u}\right]=w+\frac{\beta \lambda_{m, e}}{1-\beta} \int_{q=q(w)}^{\bar{q}}[1-\hat{F}(q)] \mathrm{d} q-(1-\beta) V_{s, u} .} \\
{[1-\beta(1-\delta)]\left[V_{s, e}(w)-V_{s, u}\right]=w+\frac{\beta \lambda_{m, e}}{1-\beta} \int_{q=q(w)}^{\bar{q}}[1-\hat{F}(q)] \mathrm{d} q-q^{*} .} \\
{[1-\beta(1-\delta)]\left[V_{s, e}(w)-V_{s, u}\right]=w-q^{*}+\frac{\beta \lambda_{m, e}}{1-\beta} \int_{q=q(w)}^{\bar{q}}[1-\hat{F}(q)] \mathrm{d} q .} \\
q(w)=q^{*}+\frac{1-\beta}{1-\beta(1-\delta)}\left(w-q \tilde{n}^{*}\right)+\frac{\beta \lambda_{m, e}}{1-\beta(1-\delta)} \int_{q=q(w)}^{\bar{q}}[1-\hat{F}(q)] \mathrm{d} q .
\end{gathered}
$$

We can directly establish the existence and uniqueness of the solution of $q\left(w^{*}\right)$ (the cutoff marriage quality at the reservation wage) by evaluating this expression at $w=w^{*}$. The cutoff marriage quality accounts for the current wage, the search value, and the possibility of the job being lost.

Now, the value of being single and unemployed is given as before.

$$
\begin{aligned}
& (1-\beta) V_{s, u}=b+\beta \lambda_{M} \int_{q=q}^{\bar{q}}\left(\max \left\{V_{m}(q)-V_{s, u}, 0\right\}\right) \mathrm{d} F(q)+\beta \lambda_{E} \int_{w=\underline{w}}^{\bar{w}}\left(\max \left\{V_{s, e}(w)-V_{s, u}, 0\right\}\right) \mathrm{d} G(w), \\
& (1-\beta) V_{s, u}=b+\beta \lambda_{M} \int_{q=q^{*}}^{\bar{q}}\left(V_{m}(q)-V_{s, u}\right) \mathrm{d} F(q)+\beta \lambda_{E} \int_{w=w^{*}}^{\bar{w}}\left(V_{s, e}(w)-V_{s, u}\right) \mathrm{d} G(w), \\
& (1-\beta) V_{s, u}=b+\frac{\beta \lambda_{M}}{1-\beta} \int_{q=q^{*}}^{\bar{q}}(1-F(q)) \mathrm{d} q+\frac{\beta \lambda_{E}}{1-\beta(1-\delta)} \int_{w=w^{*}}^{\bar{w}}(1-G(w)) \mathrm{d} q(w), \\
& (1-\beta) V_{s, u}=b+\frac{\beta \lambda_{M}}{1-\beta} \int_{q=q^{*}}^{\bar{q}}(1-F(q)) \mathrm{d} q+\frac{\beta \lambda_{E}}{1-\beta(1-\delta)} \int_{w=w^{*}}^{\bar{w}}(1-G(w)) \mathrm{d} q(w),
\end{aligned}
$$




$$
q^{*}=b+\frac{\beta \lambda_{M}}{1-\beta} \int_{q=q^{*}}^{\bar{q}}(1-F(q)) \mathrm{d} q+\frac{\beta \lambda_{E}}{1-\beta(1-\delta)} \int_{w=w^{*}}^{\bar{w}}(1-G(w)) \mathrm{d} q(w) .
$$

Then, we can solve for all cutoffs in the following way. We first solve for the cutoffs at the single, unemployed state. Those cutoffs are $w^{*}$ and $q^{*}$. Equation (2) is increasing in $w^{*}$ while equation (4) is decreasing in $w^{*}$. This means that if a solution exists, it is unique. We can also solve for the cutoff marriage quality at a job with wage $w$ using equation (3). Clearly, $q\left(w^{*}\right)=q^{*}$ and $q(w)$ is a strictly increasing function.

We can now establish the comparative statics with respect to the benefits.

Proposition 12. An increase in benefits b increases the number of periods the woman stays single and the average quality of the marriage. An increase in benefits $b$ also increases the number of periods the woman stays unemployed and the average wages of the women that become employed.

Proof. As before, all we need to do is establish that the increase in benefits increases the cutoff qualities and wages. For the single and unemployed cutoffs, notice that equation (4) is the only one affected by the change in benefits and that this equation is decreasing in $w^{*}$. Therefore, $q^{*}$ and $w^{*}$ must increase.

For the single and employed cutoffs, the higher benefits have an indirect effect through the single and unemployed cutoff which we already established was increasing. Intuitively, higher benefits make it better to wait before marrying even when employed because if the woman were to lose the job, she would enjoy those benefits.

\section{Fertility}

An extra dimension that we can consider is fertility. A woman's incentives to have more children are affected by the program. We model this dimension as a binary decision that a woman makes in each period. If a woman decides to have children, she gets one next period with probability $\pi_{c}$. In the model, we limit the number of extra children a woman can have to one. We do this by considering a small state space. That is, a woman can be single with $\mathrm{n}$ children, single with $\mathrm{n}+1$ children, or married with $n$ and $n+1$ children. A decision to have children while married does not affect the analysis and is thus omitted.

Let us compare the decision of having children when enrolled in the program and when not. The value of being single with $\mathrm{n}$ children is

$$
V_{s, n}^{i}=b_{n}^{i}+a_{n}+\beta\left(\lambda_{n}^{i} \int_{q=\underline{q}}^{\bar{q}} \max \left\{V_{m}(q), \hat{V}_{s, n}^{i}\right\} \mathrm{d} \tilde{F}_{n}(q)+\left(1-\lambda_{n}^{i}\right) \hat{V}_{s, n}^{i}\right),
$$


where the $i$ superscript is either 0 or 1 , indicating if the woman is participating in the program. $\hat{V}_{s, n}^{i}$ is the optimal continuation (next period) value of a single woman who has $n$ children in this period. $\hat{V}_{s, n}^{i}=\max \left\{V_{s, n}^{i}, \pi_{c} V_{s, n+1}^{i}+\left(1-\pi_{c}\right) V_{s, n}^{i}\right\}$.

Also, $a_{n}$ is the utility flow of having $n$ children. Finally, $b_{n}^{i}$ is the transfers that a woman who has $n$ children receives. Some conditions change when a woman enrolls in the program. For instance, if a woman is enrolled in the program, she will receive a transfer $b_{n}^{1}>b_{n}^{0}=0$. If $b_{n+1}^{1}>b_{n}^{1}$, the program provides extra incentives to have children (because $b_{n+1}^{0}=b_{n}^{0}$ ). At the same time, if $\lambda_{n+1}^{i}<\lambda_{n}^{i}$

and $\lambda_{n+1}^{1}-\lambda_{n}^{1}<\lambda_{n+1}^{0}-\lambda_{n}^{0}$ (the effect of an extra child on the arrival of prospects is more negative when participating in the program), there are fewer incentives to have children. When combined with the effect of the higher transfers, the overall effect of the program on fertility is ambiguous.

Proposition 13. If $b$ is an increasing function of the number of children then fertility will increase when $b$ increases. But if more children while single lower the rate of arrival of prospects in the labor and marriage market, then the predictions about fertility become ambiguous.

\section{Mobility}

Now, we introduce the possibility of moving to a new location. Locations are indexed by $j$ and have different characteristics $\left(\lambda_{j}\right)$. We consider the case where the transfer is lost upon moving to a new location. Opportunities to move to a new location arrive randomly with probability $\mu$. We assume that a married woman does not receive moving opportunities.

$$
V_{s}=b+\beta\left(\lambda \int_{q=\underline{q}}^{\bar{q}} \max \left\{V_{m}(q), V_{s}\right\} \mathrm{d} F(q)+\mu \int_{j} \max \left\{V_{s, j}, V_{s}\right\} \mathrm{d} H(j)+(1-\lambda-\mu) V_{s}\right) .
$$

The value of being married to a partner with quality $q$ is

$$
V_{m}(q)=q+\beta V_{m}(q)=\frac{q}{1-\beta} .
$$

We take the value of being single in the new location, $V_{s, j}$, as exogenous. While we could make it endogenous, the only relevant assumption is that for each specific new location, the value of being single there is not affected by $b$.

The decision to migrate is governed by $\max \left\{V_{s, j}, V_{s}\right\}$. Define the set of locations the agent would move to as $J^{*}:=\left\{j \mid V_{s, j} \geq V_{s}\right\}$. The probability of moving to a new location is given by $\mu H\left(J^{*}\right)$. The expected quality of new locations a woman moves to is given by $\mathbb{E}\left[V_{s, j} \mid j \in J^{*}\right]$.

Proposition 14. If $b$ increases, then mobility falls, and those who do migrate, move to better locations. 
Proof. By applying standard dynamic programming arguments, we can show that $V_{s}$ is a strictly increasing function of \$b\$. [First, the Bellman operator satisfies Blackwell's sufficient conditions for a contraction so there is a fixed point and it is unique. Second, the operator preserves the property of being an increasing function of $b$, and the operator maps weakly increasing functions of $b$ to strictly increasing functions of $b$.] Since $V_{s}$ is a strictly increasing function of $b$ and each $V_{s, j}$ is constant on $b$, the set $J^{*}$ is decreasing in $b$ (i.e., when $b$ increases, the set gets smaller as some locations are now excluded). Thus, the probability of moving is lower. Finally, the expected quality of a new location a woman moves to is higher when $b$ is higher. That is because the expected quality when $b$ is lower is a weighted average of the locations that remain when $b$ is higher and the locations that were excluded. By construction, the latter has a lower value than any of the former which proves the result. 
Figure 1: Distribution of predicted income by accepted, predicted Income using IOWA census Sample: women with non missing predicted income. Income $<1$ set to $=1$.

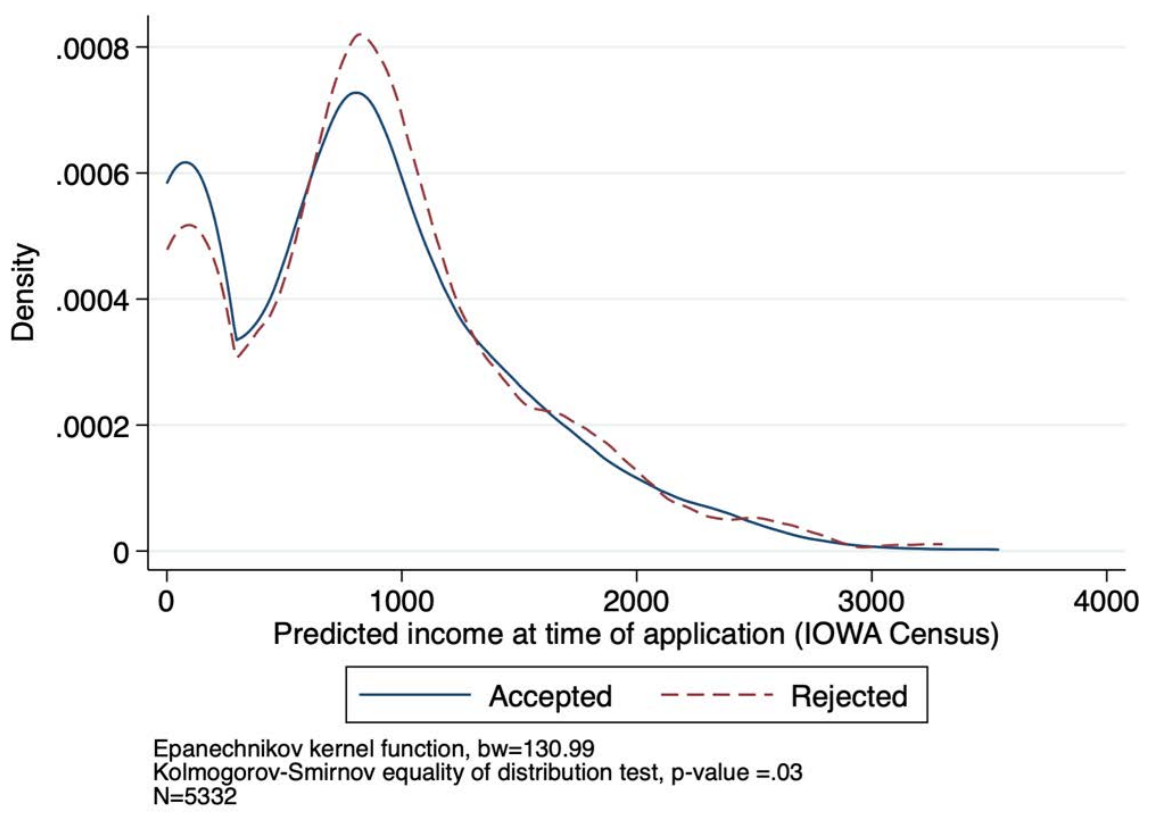

Note: Data comes from administrative data collected by the authors. See text for details. Sample includes 5332 individuals for whom we could compute predicted income using the lowa census. The predicted income was computed by running a regression of family income on covariates (widow, mother age at application, number of kids at each age (0-18), age of the youngest and oldest kid, number of kids over 14 , mother is foreign, black, education and occupation score. We include interactions of the covariates with the variable widow, and some of the covariates are included in a dummy format.) in the lowa Census and then using the estimated betas to predict income for all mothers in the MP sample. In the MP sample we use the 1910 census occupation scores and 1040 census education. 
Figure 2: Welfare Receipt and Duration until Remarriage (among women who were not married at the time of application)

2a. Histograms of duration until the first remarriage (in years) by welfare receipt

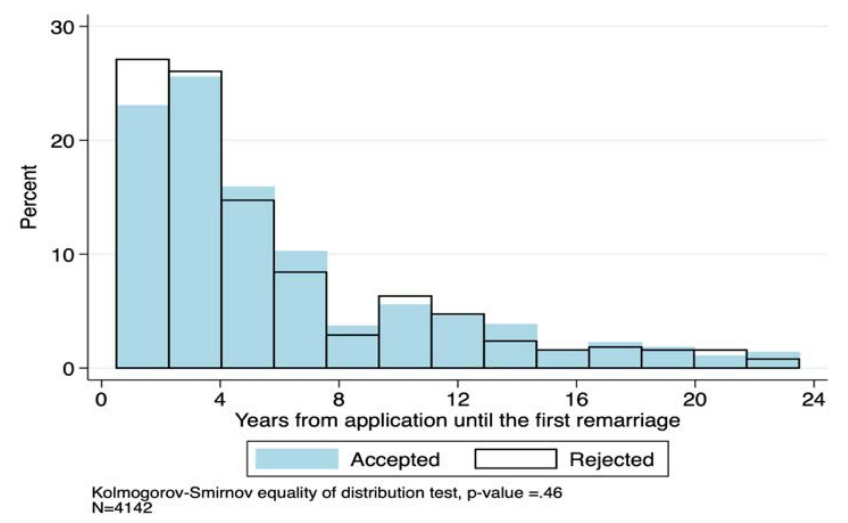

2b. survival curves over 40 years: probability of remaining single by welfare receipt

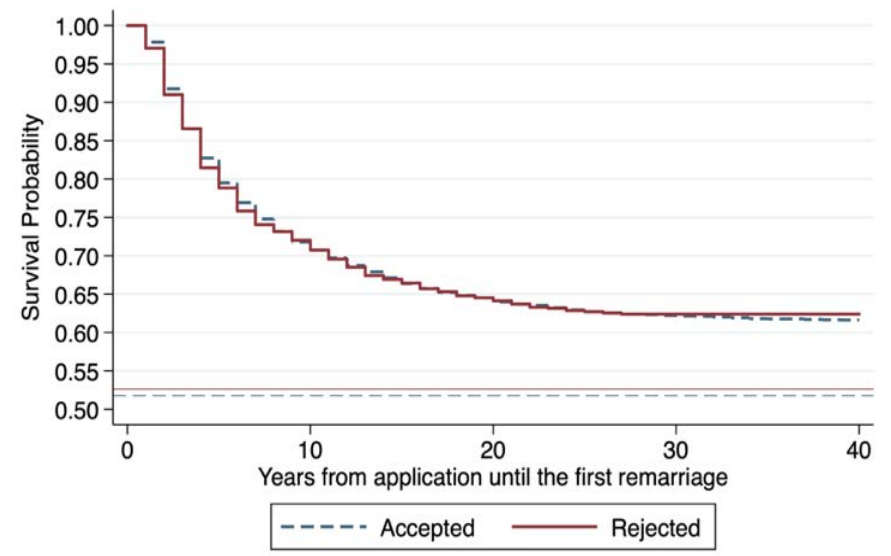

Horizontal lines show the fraction of accepted/rejected mothers that never remarried Gap is due to women with missing dates of remarriage Figure does not include mothers with missing dates of death and remarriage
$\mathrm{N}=10976$

2c. Effect of obtaining cash transfer on probability of remarriage by year, as a function of baseline probability of remarriage

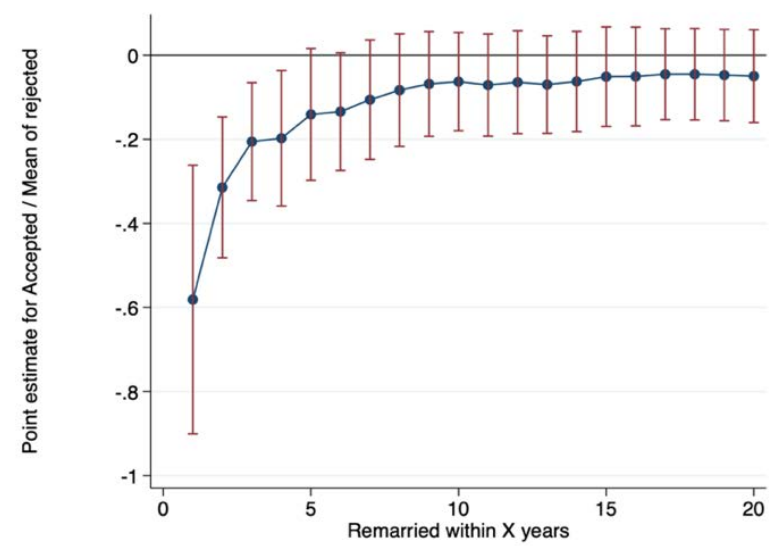

Notes: Panel a. The figure plots the duration until the first remarriage by accepted. We cannot reject that the distributions are equal. Sample includes only women that remarried. Panel b: The figure plots the survival curves by accepted for the duration until the first remarriage. Panel c: The figure plots the estimated coefficients of "accepted" divided by the baseline probability of remarriage among rejected applications. And 95\% confident intervals. Coefficients come from regressions where we regress a dummy indicating that the mother remarried within $x$ years on accepted status and all predetermined characteristics. Standard Errors are clustered at the county level. See information in Table 3. 


\section{Figure 3: Women with transfers did not marry better man in all dimensions}
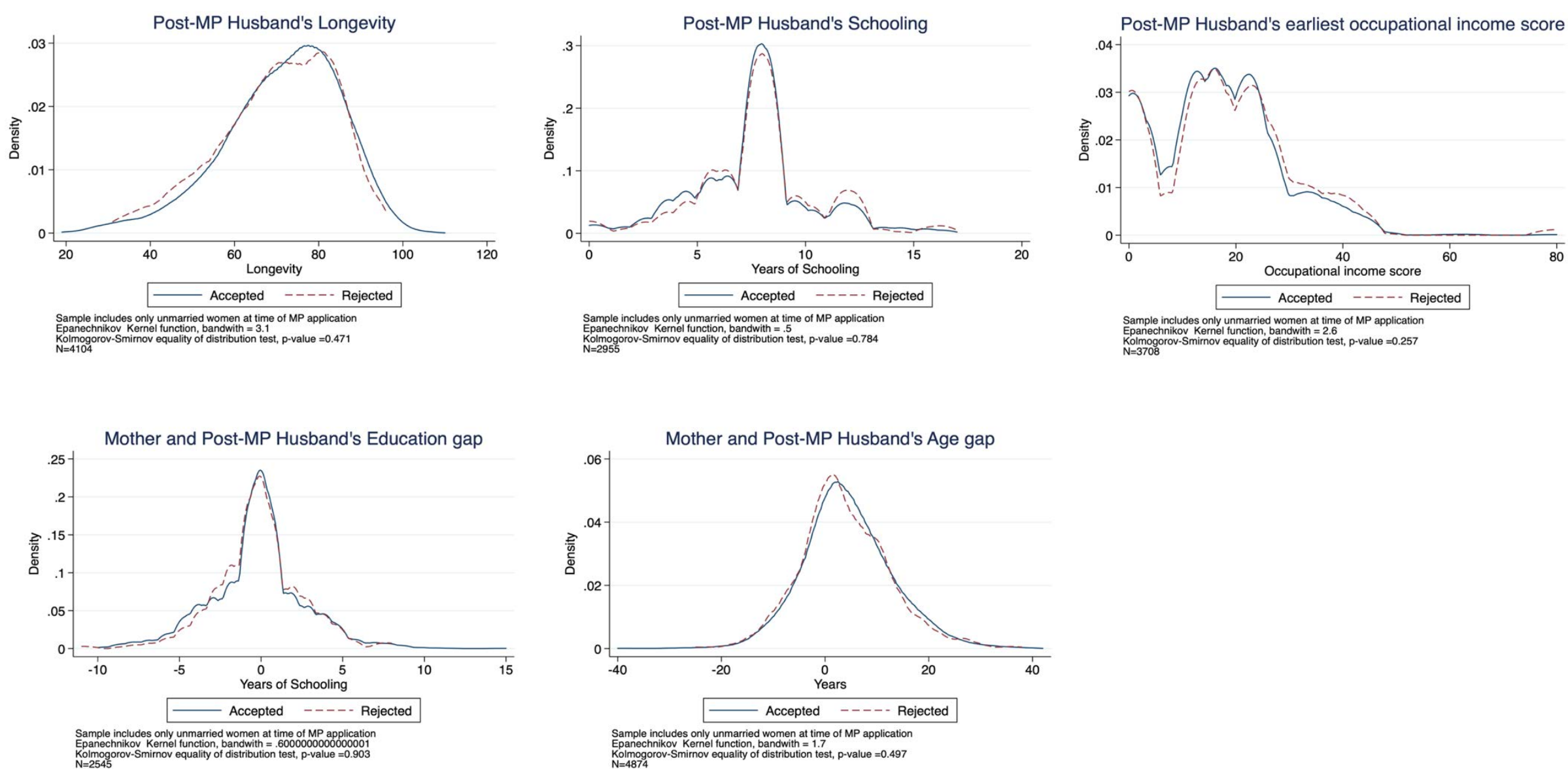

Notes: All figures are estimated densities. The number of observations varies because we do not always observe a given outcome. We use the maximum number of observations available for each figure. 
Figure 4: Fertility, work and income of MP mothers

a. Distribution of number of children born after the MP application by accepted

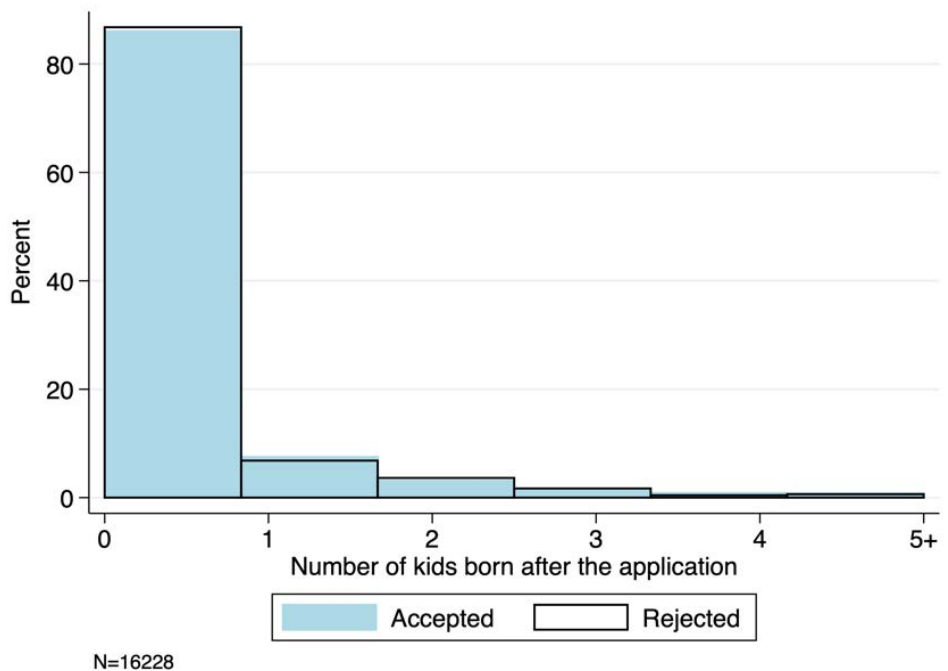

b. Distribution of 1930 occupation-based income of the mother by accepted

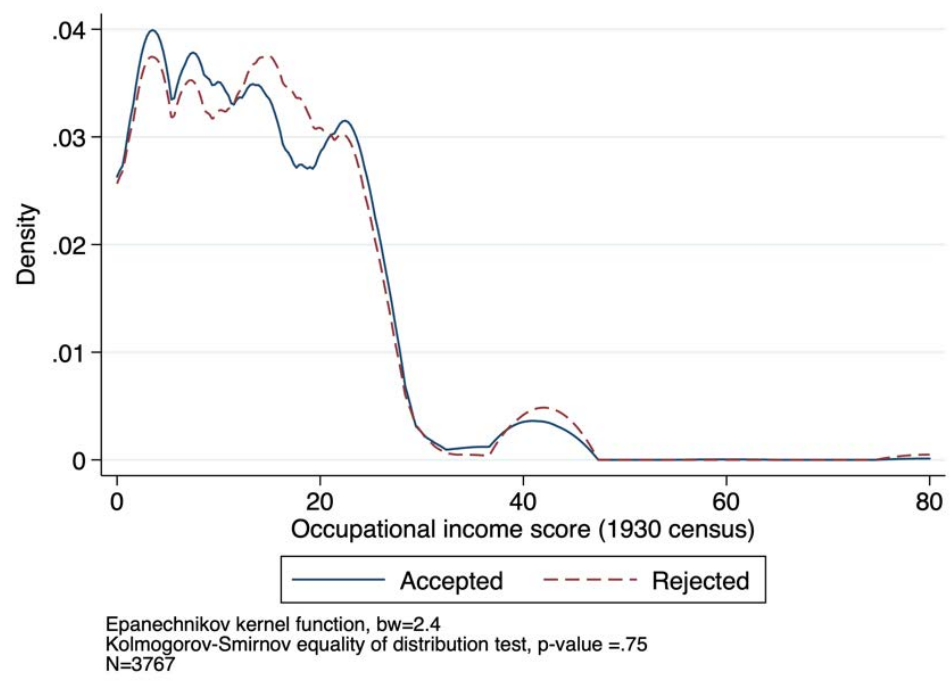

Note: Panel a plots the distribution of kids born after application by accepted. The sample includes all women. Panel b plots the distribution of 1930 occupation-based income by accepted. We cannot reject that both distributions are equal. The sample includes all women with non-missing occupation score. 
c. Distribution of the 1940 occupation-based income of the mother by accepted

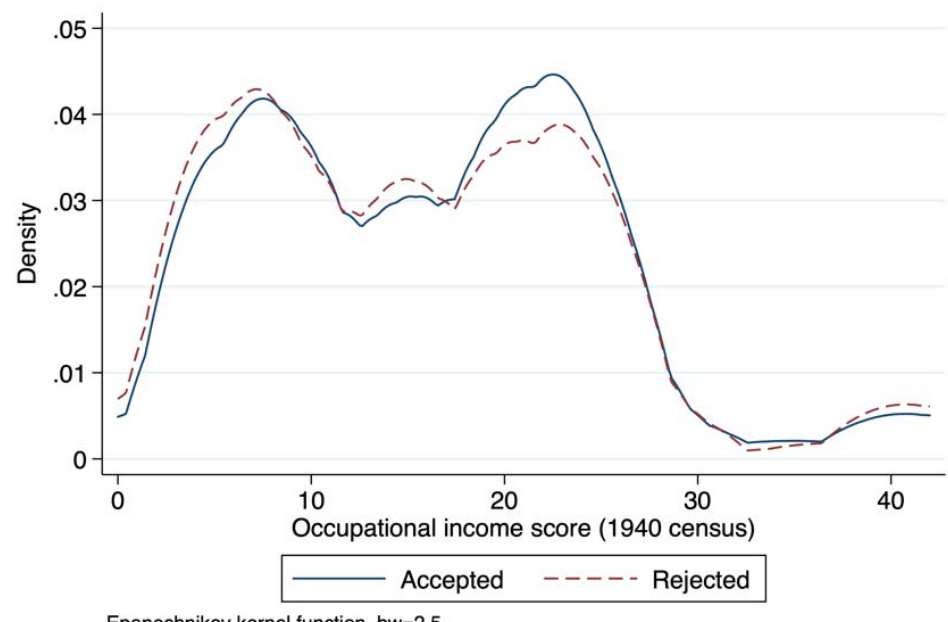

Epanechnikov kernel function, $\mathrm{bw}=2.5$

Kolmogorov-Smirnov equality of distribution test, $\mathrm{p}$-value $=.9500000000000001$ $\mathrm{N}=2201$

d. Distribution of 1940 mother income by accepted

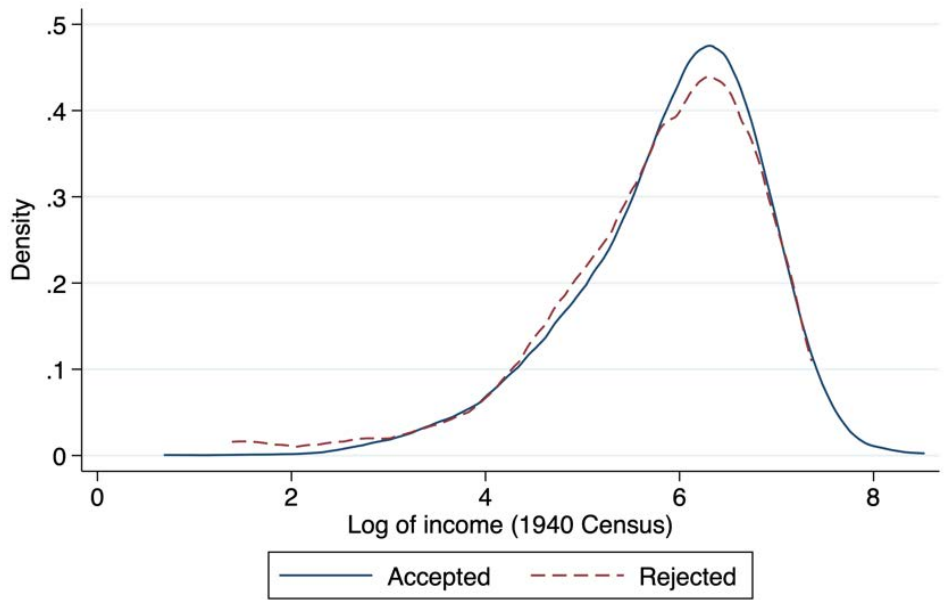

Epanechnikov kernel function, $\mathrm{bw}=.3$

Kolmogorov-Smirnov equality of distribution test, $\mathrm{p}$-value $=.5$ $\mathrm{N}=2083$

Note: Panel c figure plots the distribution of 1940 occupation based income by accepted. We cannot reject that both distributions are equal. The sample includes all women with non-missing occupation score. Panel $\mathbf{d}$ figure plots the

distribution of 1940 mother income by accepted. We cannot reject that both distributions are equal. The sample includes all women with non-missing and nonzero income. 
Figure 5: Effect of cash transfer on maternal long term well being

a. Distribution of longevity of the mother by accepted

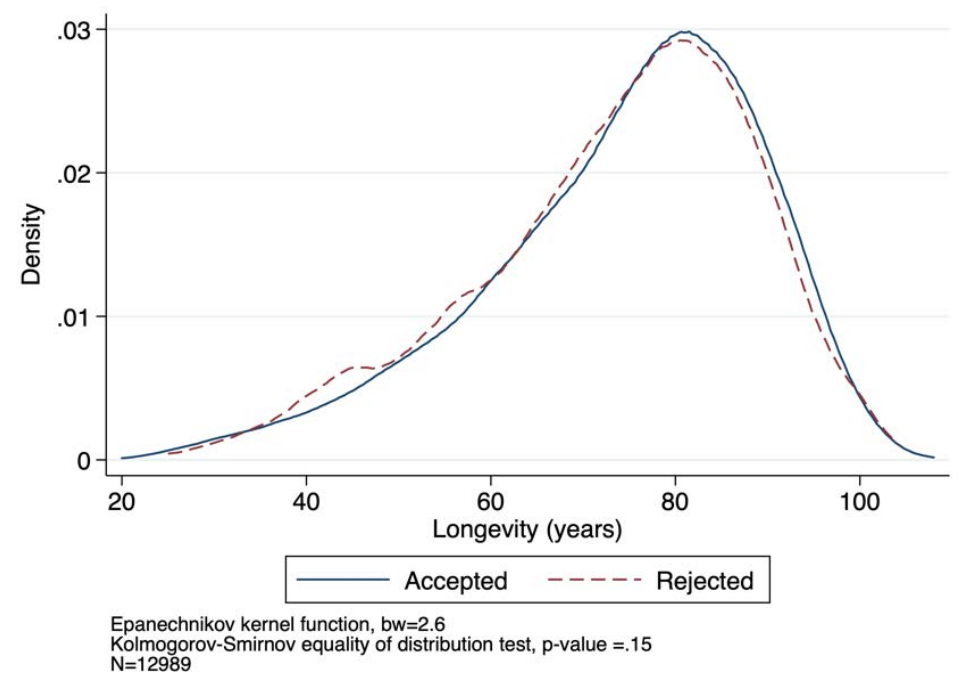

b. Distribution of $\mathbf{1 9 4 0}$ household income of the mother by accepted Sample: Women with non-missing and non-zero household income

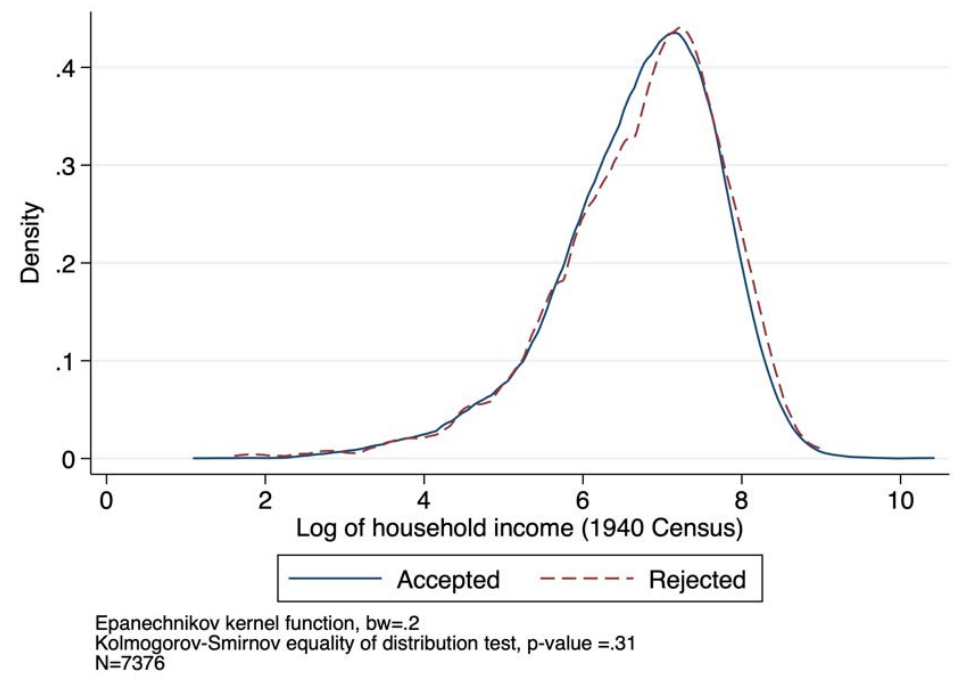

Note: Panel a The figure plots the distribution of the longevity of the mother by accepted. We cannot reject that both distributions are equal. The sample includes all women with non-missing longevity. Panel $\mathbf{b}$ figure plots the distribution of 1940 household income by accepted. We cannot reject that both distributions are equal. The sample includes all women with non-missing and non-zero household income. 


\begin{tabular}{|c|c|c|c|c|c|c|}
\hline \multirow[b]{2}{*}{ Variable } & \multicolumn{3}{|c|}{ All MP applicants } & \multicolumn{3}{|c|}{$\begin{array}{c}\text { Unmarried MP } \\
\text { applicants at time of } \\
\text { application }^{1}\end{array}$} \\
\hline & Obs & Mean & Std. Dev. & Obs & Mean & Std. Dev. \\
\hline Found remarriage information & 16228 & 0.84 & 0.37 & 13383 & 0.84 & 0.36 \\
\hline Share accepted & 16228 & 0.90 & 0.30 & 13383 & 0.90 & 0.30 \\
\hline \multicolumn{7}{|l|}{ Dependent variables } \\
\hline \multicolumn{7}{|l|}{ Remarrriage rates } \\
\hline Mom ever remarried & 13638 & 0.47 & 0.50 & 11286 & 0.48 & 0.50 \\
\hline$\%$ remarried within 1 years ${ }^{2}$ & 11509 & 0.02 & 0.15 & 9423 & 0.03 & 0.16 \\
\hline$\%$ remarried within 2 years & 11509 & 0.08 & 0.28 & 9423 & 0.09 & 0.29 \\
\hline$\%$ remarried within 3 years & 11509 & 0.14 & 0.34 & 9423 & 0.15 & 0.35 \\
\hline$\%$ remarried within 5 years & 11509 & 0.21 & 0.41 & 9423 & 0.22 & 0.41 \\
\hline \multicolumn{7}{|l|}{ Among moms that remarried } \\
\hline Duration to remarriage in years & 4255 & 6.71 & 7.73 & 3572 & 6.36 & 7.55 \\
\hline Year of first remarriage & 4255 & 1927.1 & 9.60 & 3572 & 1926.7 & 9.37 \\
\hline Mom age at remarriage & 4240 & 38.89 & 9.98 & 3558 & 38.77 & 9.80 \\
\hline \multicolumn{7}{|l|}{ Post-MP husband } \\
\hline age at remarriage - FS & 4179 & 43.31 & 12.63 & 3507 & 43.27 & 12.53 \\
\hline longevity - FS & 6384 & 71.30 & 12.02 & 5435 & 71.28 & 12.04 \\
\hline died before 1940 - FS & 4850 & 0.18 & 0.38 & 4123 & 0.19 & 0.39 \\
\hline died before 1930 - FS & 4850 & 0.07 & 0.25 & 4123 & 0.07 & 0.26 \\
\hline died before 1920 - FS & 4850 & 0.02 & 0.14 & 4123 & 0.02 & 0.14 \\
\hline wage income - 1940 & 3301 & 693.60 & 770.05 & 2815 & 674.77 & 759.27 \\
\hline highest schooling grade - 1940 & 3460 & 7.59 & 2.75 & 2955 & 7.56 & 2.72 \\
\hline occupational earnings score - latest census ${ }^{3}$ & 3932 & 40.49 & 29.56 & 3328 & 39.68 & 29.62 \\
\hline occupation income score - latest census ${ }^{3}$ & 4206 & 20.24 & 10.79 & 3556 & 20.09 & 10.83 \\
\hline was a farmer - latest census ${ }^{3}$ & 5264 & 0.11 & 0.31 & 4457 & 0.12 & 0.32 \\
\hline lives in owned housing unit - 1920 & 2843 & 0.56 & 0.50 & 2418 & 0.57 & 0.49 \\
\hline foreign born - FS & 5522 & 0.16 & 0.37 & 4673 & 0.16 & 0.36 \\
\hline foreign status is missing in FS & 6384 & 0.14 & 0.34 & 5435 & 0.14 & 0.35 \\
\hline number of children at time of marriage - FS & 4255 & 0.56 & 1.11 & 3572 & 0.57 & 1.10 \\
\hline \multicolumn{7}{|l|}{ Quality of match } \\
\hline Age gap - FS & 5771 & 4.22 & 8.68 & 4874 & 4.32 & 8.71 \\
\hline Education gap - 1940 & 2978 & -0.23 & 2.88 & 2545 & -0.23 & 2.83 \\
\hline \multicolumn{7}{|l|}{ Other Maternal outcomes } \\
\hline Mom's longevity & 12989 & 74.29 & 15.04 & 10749 & 74.32 & 14.84 \\
\hline Mom died before 1940 & 13064 & 0.17 & 0.38 & 10810 & 0.18 & 0.38 \\
\hline Mom's income in 1940 & 8226 & 130.3 & 306.9 & 6697 & 125.40 & 305.68 \\
\hline Mom's occupation score 1930 & 11178 & 4.73 & 8.60 & 9174 & 4.72 & 8.65 \\
\hline Mom's occupation score 1940 & 9358 & 4.66 & 8.81 & 7635 & 4.48 & 8.67 \\
\hline Mom in the labor force in 1930 & 11170 & 0.37 & 0.48 & 9166 & 0.37 & 0.48 \\
\hline Mom in the labor force in 1940 & 9351 & 0.26 & 0.44 & 7630 & 0.25 & 0.43 \\
\hline Mom worked in 1930 & 11178 & 0.34 & 0.47 & 9174 & 0.33 & 0.47 \\
\hline Mom worked in 1940 & 9358 & 0.24 & 0.42 & 7635 & 0.23 & 0.42 \\
\hline Mom was married in 1940 & 9330 & 0.45 & 0.50 & 7615 & 0.42 & 0.49 \\
\hline Mom's household income in 1940 & 9070 & 956.0 & 1050.3 & 7398 & 955.59 & 1053.2 \\
\hline Mom's number of own kids living together in 1940 & 9358 & 1.74 & 1.59 & 7635 & 1.71 & 1.57 \\
\hline Number of kids born after MP application & 16228 & 0.27 & 0.83 & 13383 & 0.26 & 0.82 \\
\hline
\end{tabular}


Table 1 continued: Summary statistics for MP applicants

\begin{tabular}{|c|c|c|c|c|c|c|}
\hline \multirow[b]{2}{*}{ Variable } & \multicolumn{3}{|c|}{ All MP applicants } & \multicolumn{3}{|c|}{$\begin{array}{l}\text { Unmarried MP applicants } \\
\text { at the time of application }\end{array}$} \\
\hline & Obs & Mean & Std. Dev. & Obs & Mean & Std. Dev. \\
\hline \multicolumn{7}{|c|}{ Characteristics at time of application observed in the application } \\
\hline Year of application & 16228 & 1921.6 & 5.31 & 13383 & 1921.45 & 5.27 \\
\hline Number of children & 16228 & 2.61 & 1.52 & 13383 & 2.61 & 1.53 \\
\hline Age of the youngest & 16228 & 6.09 & 3.99 & 13383 & 6.20 & 4.04 \\
\hline Age of the oldest & 16228 & 10.38 & 4.00 & 13383 & 10.51 & 3.97 \\
\hline Share widowed (in MP application) & 16228 & 0.53 & 0.50 & 13383 & 0.64 & 0.48 \\
\hline $\begin{array}{l}\text { Share married (present or absent husband), } \\
\text { divorced and single in MP application }\end{array}$ & 16228 & 0.21 & 0.40 & 13383 & 0.04 & 0.19 \\
\hline Share missing marital status in MP application & 16228 & 0.26 & 0.44 & 13383 & 0.32 & 0.46 \\
\hline Time to MP application since husband death & 7244 & 1.67 & 2.80 & 7067 & 1.66 & 2.74 \\
\hline \multicolumn{7}{|c|}{ Characteristics at time of application observed with family tree data and census data } \\
\hline Number of kids died pre-MP application & 16228 & 0.23 & 0.62 & 13383 & 0.23 & 0.63 \\
\hline Number of live kids $14+$ at MP application & 16228 & 1.51 & 2.27 & 13383 & 1.59 & 2.33 \\
\hline Mom's year of birth (all) & 15351 & 1884.4 & 10.0 & 12656 & 1883.80 & 9.97 \\
\hline Mom's schooling & 9222 & 7.75 & 2.68 & 7521 & 7.74 & 2.67 \\
\hline Mother age at application & 15313 & 37.21 & 8.67 & 12629 & 37.64 & 8.71 \\
\hline Mother is foreign born & 14968 & 0.17 & 0.37 & 12337 & 0.17 & 0.37 \\
\hline Mother foreign status is missing & 16228 & 0.08 & 0.27 & 13383 & 0.08 & 0.27 \\
\hline Mother is black (all census) & 14824 & 0.02 & 0.13 & 12205 & 0.02 & 0.14 \\
\hline Mother number of siblings & 16228 & 4.37 & 4.23 & 13383 & 4.45 & 4.27 \\
\hline Age at death of pre-husband - FS & 9938 & 49.70 & 16.33 & 8463 & 47.42 & 15.17 \\
\hline Age at death of pre husband missing - FS & 16228 & 0.39 & 0.49 & 13383 & 0.37 & 0.48 \\
\hline Pre-MP husband is foreign - FS & 12766 & 0.18 & 0.38 & 10550 & 0.18 & 0.39 \\
\hline Pre-MP husband foreign status is missing - FS & 16228 & 0.21 & 0.41 & 13383 & 0.21 & 0.41 \\
\hline Mom in the labor force in 1910 & 7648 & 0.12 & 0.33 & 6507 & 0.12 & 0.33 \\
\hline Mom's total number of children - FS & 16228 & 4.50 & 2.81 & 13383 & 4.56 & 2.82 \\
\hline Predicted Income & 5225 & 808.60 & 633.62 & 4360 & 757.84 & 649.84 \\
\hline \multicolumn{7}{|l|}{ County of application characteristics ${ }^{4}$} \\
\hline Sex ratio (Male/Female) & 16228 & 1.15 & 0.18 & 13383 & 1.15 & 0.17 \\
\hline Share of females who are in the labor force & 16228 & 0.20 & 0.06 & 13383 & 0.20 & 0.05 \\
\hline Share of white married mothers in labor force & 16228 & 0.05 & 0.02 & 13383 & 0.05 & 0.02 \\
\hline Share black & 16228 & 0.01 & 0.02 & 13383 & 0.01 & 0.02 \\
\hline Share rural & 16228 & 0.54 & 0.26 & 13383 & 0.56 & 0.25 \\
\hline
\end{tabular}

Notes: ${ }^{1}$ Unmarried MP applicants include widowed, divirced and never married women. ${ }^{2}$ People who remarried and have missing dates are dropped. The duration measure starts at 0.5 (the variable is duration +0.5 , so we assume that marriages occur uniformly within a year). We also assume that if women married the same year they applied for the pension (and the exact data of marriage is missing) that the marriage took place after the MP application. ${ }^{3}$ Defined from pre marriage data: uses 1940 if available, then 1930, then 1920, then 1910. Never uses a measure that is observed post-MP marriage. ${ }^{4}$ measured in year of application. Yearly measures are constructed through linear interpolation using census data from 1910, 1920 and 1930. All measures use the universe of people who are between 18 and 55 years old. Sample restriction: we drop mothers that applied after 1930 or records for mothers that applied multiple times so mothers only appear once in the data and individuals who we discovered in the family tree were not the mother (a handfull of grandmothers, sisters and stepmothers). 
Table 2: Welfare mothers are not less likely to remarry

Sample: mothers that were not married at MP application ${ }^{1}$

\begin{tabular}{|c|c|c|c|c|}
\hline \multirow{2}{*}{$\begin{array}{l}\text { Data source: } \\
\text { Dependent variable }\end{array}$} & \multirow{2}{*}{$\begin{array}{c}\text { FamilySearch } \\
\text { Ever } \\
\text { remarried }=1\end{array}$} & \multicolumn{3}{|c|}{ Census } \\
\hline & & Married in $1920^{2}$ & $\begin{array}{r}\text { Married in } \\
1930 \text {, all }\end{array}$ & $\begin{array}{c}\text { Married in } \\
1940 \text {, all }\end{array}$ \\
\hline Mean of Y for rejected & 0.47 & 0.39 & 0.41 & 0.43 \\
\hline \multicolumn{5}{|l|}{ Panel A: No controls } \\
\hline Accepted & 0.009 & -0.069 & -0.022 & -0.009 \\
\hline Robust standard errors & $(0.016)$ & $(0.025)^{* * *}$ & $(0.018)$ & $(0.021)$ \\
\hline Clustered at county & {$[0.026]$} & {$[0.021]^{* * *}$} & {$[0.021]$} & {$[0.026]$} \\
\hline Clustered at county*year & $\{0.019\}$ & $\{0.026\} * * *$ & $\{0.021\}$ & $\{0.022\}$ \\
\hline Bounds for missing data (Lee 2009) & {$[-0.02 ; 0.04]$} & {$[-0.16 ; 0.08]$} & {$[-0.12 ; 0.04]$} & {$[-0.15 ; 0.09]$} \\
\hline R-squared & 0.000 & 0.002 & 0.000 & 0.000 \\
\hline \multicolumn{5}{|l|}{ Panel B: Full controls } \\
\hline Accepted & -0.014 & -0.099 & -0.012 & -0.006 \\
\hline Robust standard errors & $(0.016)$ & $(0.026)^{* * *}$ & $(0.018)$ & $(0.020)$ \\
\hline Clustered at county & [0.020] & {$[0.022]^{* * *}$} & [0.019] & [0.020] \\
\hline Clustered at county*year & $\{0.016\}$ & $\{0.027\} * * *$ & $\{0.018\}$ & $\{0.020\}$ \\
\hline R-squared & 0.228 & 0.189 & 0.199 & 0.219 \\
\hline Observations & 11286 & 3522 & 9155 & 7615 \\
\hline \multicolumn{5}{|l|}{ Panel C: Checks } \\
\hline 1- Correction for OVB (Oster 2017) & {$[-0.02 ;-0.01]$} & {$[-0.11 ;-0.09]$} & {$[-0.02 ;-0.01]$} & {$[-0.01 ;-0.01]$} \\
\hline \multicolumn{5}{|c|}{ 2- Semi-parametric sample selection correction (Newey, 2009) } \\
\hline Accepted & -0.014 & -0.100 & -0.013 & -0.005 \\
\hline $95 \%$ Confidence interval & {$[-0.05 ; 0.02]$} & {$[-0.14 ;-0.06]$} & {$[-0.05 ; 0.03]$} & {$[-0.05 ; 0.03]$} \\
\hline F-Stat & 72.37 & 13.05 & 24.20 & 62.77 \\
\hline P-Value & 0.000 & 0.000 & 0.000 & 0.000 \\
\hline \multicolumn{5}{|l|}{ 3- Drop if quality of match low } \\
\hline Accepted & -0.027 & $-0.097 * * *$ & -0.021 & 0.000 \\
\hline Clustered at county & $(0.028)$ & $(0.025)$ & $(0.022)$ & $(0.025)$ \\
\hline Observations & 5463 & 1538 & 4495 & 3752 \\
\hline
\end{tabular}

Notes: Panel B controls for county and year-of-application fixed effects and individual, county and state controls. Individual controls: Kids: MP age of the youngest and oldest, MP dummies for number, FS number older than 14, FS number that died before MP, FS number with dates missing. Mother: last name lenght, dummies for divorced, widowed and missing marital status, age at application, missing age, number of siblings, foreign, missing nativity, first husband's longevity, first husband's longevity is missing. County controls: for ages 18-55: sex ratio $(\mathrm{M} / \mathrm{F})$, shares of white married mothers in the labor force, black and rural. County controls match linear interpolated information from the 1910, 1920 and 1930 census with the year of MP application. State controls: manufacturing wages, education/labor laws (age must enter school, work permit age, and continuation school law in place), state expenditures in logs (education, charity, and social programs), state laws concerning MP transfers (work required, reapplication required, maximum amount for the first child and for each additional child). Bounds: All bounds report coefficients (not standard deviations). We follow Lee (2009) to construct bounds for missing data. We use Oster (2017) to construct ommited variable bias (OVB) bounds. We assume that the R-max is 1.3 times greater than the R-squared from panel $\mathrm{B}$. We assume delta $=(-1$, 1) for lower and upper bounds. Sample Selection Correction: We follow the two-step estimation suggested by Newey (2009) to correct for sample selection. First, we regress the dummy indicating whether the outcome is mising on RA fixed effects (73 dummies) and all other controls. We report the F-statistic and P-value of the test of relevance of these dummies. Second, we estimate a linear regression of the outcome on controls and on a fourth degree polynomial of predicted values from the first stage. We jointly bootstrap the two stages and report the $95 \%$ bias corrected confidence interval clustered at the county level, from 200 repetitions. Quality of match: Regressions that drop low quality matches (quality measure below its median) include all controls and cluster the standard errors at the county level. The quality of match between census, family search and administrative data is constructed as the weighted sum of variables that access the similarity between first name, last name, full name, age and place of birth in each dataset. ${ }^{1}$ Sample includes mothers whose marital status at the time of application is missing. ${ }^{2} \mathrm{Post}$ MP application sample. See Table 1 for sample restrictions. 
Table 3: Women with cash transfers wait a little bit longer to marry

Sample: Women who were not married at time of application.

\begin{tabular}{|c|c|c|c|c|c|c|c|}
\hline Dependent variable Y: & Duration $^{1}$ & Log duration $^{1}$ & $\begin{array}{c}\text { Remarried } \\
\text { within } 1 \\
\text { year } \\
\end{array}$ & $\begin{array}{c}\text { Remarried } \\
\text { within } 2 \\
\text { years } \\
\end{array}$ & $\begin{array}{c}\text { Remarried } \\
\text { within } 3 \\
\text { years } \\
\end{array}$ & $\begin{array}{c}\text { Remarried } \\
\text { within } 5 \\
\text { years } \\
\end{array}$ & $\begin{array}{c}\text { Remarried } \\
\text { within } 10 \\
\text { years } \\
\end{array}$ \\
\hline Notes: & OLS & OLS & \multicolumn{5}{|c|}{$\begin{array}{l}\text { OLS specification. Women that never married are coded as zero, women who } \\
\text { married but have missing remarriage dates are dropped from sample }\end{array}$} \\
\hline Mean of Y for rejected & 5.47 & 1.23 & 0.04 & 0.11 & 0.16 & 0.22 & 0.30 \\
\hline \multicolumn{8}{|l|}{ Panel A: No controls } \\
\hline Accepted & 0.971 & 0.174 & -0.017 & -0.021 & -0.013 & -0.004 & 0.011 \\
\hline Robust standard errors & $(0.327) * * *$ & $(0.061)^{* * *}$ & $(0.007) * *$ & $(0.011)^{*}$ & $(0.013)$ & $(0.015)$ & $(0.016)$ \\
\hline Clustered at county & {$[0.389]^{* *}$} & {$[0.055]^{* * *}$} & {$[0.006]^{* * *}$} & {$[0.012]^{*}$} & {$[0.016]$} & {$[0.026]$} & {$[0.029]$} \\
\hline Clustered at county*year & $\{0.356\}^{* * *}$ & $\{0.064\} * * *$ & $\{0.006\} * * *$ & $\{0.011\}^{*}$ & $\{0.013\}$ & $\{0.016\}$ & $\{0.018\}$ \\
\hline Bounds for missing data (Lee 2009) & {$[-0.17 ; 1.26]$} & {$[0.08 ; 0.27]$} & {$[-0.03 ;-0.02]$} & {$[-0.03 ;-0.02]$} & {$[-0.02 ;-0.01]$} & {$[-0.01 ;-0.00]$} & {$[0.00 ; 0.02]$} \\
\hline R-squared & 0.001 & 0.003 & 0.001 & 0.000 & 0.000 & 0.000 & 0.000 \\
\hline \multicolumn{8}{|l|}{ Panel B: Full controls } \\
\hline Accepted & 1.275 & 0.238 & -0.024 & -0.035 & -0.033 & -0.032 & -0.019 \\
\hline Robust standard errors & $(0.412)^{* * *}$ & $(0.065)^{* * *}$ & $(0.007)^{* * *}$ & $(0.012)^{* * *}$ & $(0.014)^{* *}$ & $(0.015)^{* *}$ & $(0.016)$ \\
\hline Clustered at county & {$[0.444]^{* * *}$} & {$[0.061]^{* * *}$} & {$[0.007]^{* * *}$} & {$[0.009]^{* * *}$} & {$[0.011]^{* * *}$} & {$[0.018]^{*}$} & {$[0.017]$} \\
\hline Clustered at county*year & $\{0.372\}^{* * *}$ & $\{0.068\} * * *$ & $\{0.007\} * * *$ & $\{0.012\} * * *$ & $\{0.013\}^{* *}$ & $\{0.015\}^{* *}$ & $\{0.015\}$ \\
\hline R-squared & 0.338 & 0.115 & 0.039 & 0.091 & 0.121 & 0.170 & 0.228 \\
\hline Observations & 3572 & 3572 & 9423 & 9423 & 9423 & 9423 & 9423 \\
\hline \multicolumn{8}{|l|}{ Panel C: Checks } \\
\hline 1- Correction for OVB (Oster 2017) & {$[1.17 ; 1.39]$} & {$[0.22 ; 0.26]$} & {$[-0.03 ;-0.02]$} & {$[-0.04 ;-0.03]$} & {$[-0.04 ;-0.03]$} & {$[-0.04 ;-0.02]$} & {$[-0.03 ;-0.01]$} \\
\hline \multicolumn{8}{|c|}{ 2- Semi-parametric sample selection correction (Newey, 2009) } \\
\hline Accepted & 1.305 & 0.243 & -0.024 & -0.035 & -0.033 & -0.032 & -0.019 \\
\hline $95 \%$ Confidence interval & {$[0.42 ; 2.19]$} & {$[0.12 ; 0.36]$} & {$[-0.04 ;-0.01]$} & {$[-0.05 ;-0.02]$} & {$[-0.05 ;-0.01]$} & {$[-0.07 ; 0.00]$} & {$[-0.05 ; 0.02]$} \\
\hline F-Stat & 32.81 & 32.81 & 28.01 & 28.01 & 28.01 & 28.01 & 28.01 \\
\hline P-Value & 0.000 & 0.000 & 0.000 & 0.000 & 0.000 & 0.000 & 0.000 \\
\hline \multicolumn{8}{|l|}{ 3- Drop if quality of match low } \\
\hline Accepted & $0.979 * *$ & $0.213 * * *$ & $-0.045 * * *$ & $-0.061 * * *$ & $-0.045 *$ & -0.029 & -0.005 \\
\hline Clustered at county & $(0.424)$ & $(0.067)$ & $(0.013)$ & $(0.021)$ & $(0.023)$ & $(0.030)$ & $(0.025)$ \\
\hline Observations & 3334 & 3334 & 4495 & 4495 & 4495 & 4495 & 4495 \\
\hline
\end{tabular}

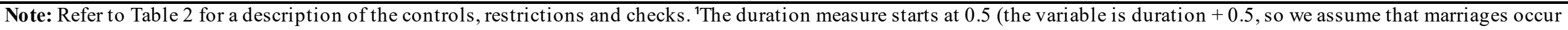

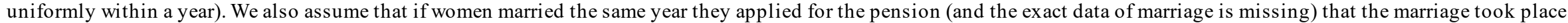
after the MP application. ${ }^{2}$ Low quality of match is defined as observations with remarriage dates that do not include day, month and year of marriage. 
Table 4: Does welfare increase quality of Post-MP husband?

Sample women who were unmarried at the time of application

\begin{tabular}{|c|c|c|c|c|c|c|c|c|c|}
\hline \multirow{2}{*}{$\begin{array}{l}\text { Data source: } \\
\text { Outcome: }\end{array}$} & \multicolumn{2}{|c|}{ Family Search } & \multicolumn{3}{|c|}{ Censuses } & \multirow[b]{2}{*}{$\begin{array}{c}\mathrm{P}- \\
\text { value } \\
(\mathrm{H} 0: \\
\text { all }=0) \\
(6)\end{array}$} & \multicolumn{3}{|c|}{ Summary index using... } \\
\hline & $\begin{array}{c}\text { Post-MP } \\
\text { Husband } \\
\text { Longevity } \\
(1)\end{array}$ & $\begin{array}{c}\text { Age gap } \\
\text { (shifted by } \\
2.5 \text { years) }{ }^{1} \\
(2)\end{array}$ & Occ Score ${ }^{2}$ & $\begin{array}{c}\text { Post-MP } \\
\text { Husband } \\
\text { Education } \\
\text { (4) }\end{array}$ & $\begin{array}{c}\text { Education } \\
\text { gap }^{3} \\
(5)\end{array}$ & & $\begin{array}{c}\text { Equal } \\
\text { weights }{ }^{4} \\
(7) \\
\end{array}$ & $\begin{array}{l}\text { Equal weights } \\
\text { (no age, } \\
\text { education } \\
\text { gap) } \\
(8)\end{array}$ & $\begin{array}{c}\text { Satisfaction } \\
\text { weights }{ }^{5} \\
(9)\end{array}$ \\
\hline $\begin{array}{l}\text { Panel A: No Controls } \\
\text { Mean of outcome for rejected }\end{array}$ & 70.130 & 6.661 & 21.220 & 7.798 & 1.821 & & -0.0470 & -0.0465 & 0.361 \\
\hline Accepted & $\begin{array}{c}1.313 \\
(0.845)\end{array}$ & $\begin{array}{c}0.091 \\
(0.248)\end{array}$ & $\begin{array}{l}-1.245^{*} \\
(0.642)\end{array}$ & $\begin{array}{l}-0.254 \\
(0.202)\end{array}$ & $\begin{array}{c}0.122 \\
(0.151)\end{array}$ & 0.146 & $\begin{array}{c}0.050 \\
(0.043)\end{array}$ & $\begin{array}{c}0.045 \\
(0.050)\end{array}$ & $\begin{array}{l}-0.001 \\
(0.018)\end{array}$ \\
\hline $\begin{array}{l}\text { Observations } \\
\text { Panel B: control for predeter }\end{array}$ & $\begin{array}{c}4,104 \\
\text { variables }\end{array}$ & 4,874 & 3,556 & 2,955 & 2,545 & & 4,894 & 4,606 & 2,540 \\
\hline Accepted & $\begin{array}{l}1.821 * * \\
(0.903)\end{array}$ & $\begin{array}{c}0.275 \\
(0.289)\end{array}$ & $\begin{array}{l}-0.828 \\
(0.574)\end{array}$ & $\begin{array}{l}-0.226 \\
(0.228)\end{array}$ & $\begin{array}{l}-0.064 \\
(0.185)\end{array}$ & 0.095 & $\begin{array}{c}0.095 * * \\
(0.046)\end{array}$ & $\begin{array}{l}0.087 * \\
(0.044)\end{array}$ & $\begin{array}{l}-0.006 \\
(0.021)\end{array}$ \\
\hline Observations & 4,104 & 4,874 & 3,556 & 2,955 & 2,545 & & 4,894 & 4,606 & 2,540 \\
\hline $\begin{array}{l}\text { Panel C: control for pre-dete } \\
\text { Mean of outcome for rejected }\end{array}$ & $\begin{array}{l}\text { d variables } \\
73.99\end{array}$ & $\begin{array}{c}\text { and other in } \\
6.345\end{array}$ & 20.18 & 7.946 & 1.818 & & & & \\
\hline $\begin{array}{l}\text { Accepted } \\
\text { Observations }\end{array}$ & $\begin{array}{c}1.368 \\
(1.309) \\
1,887\end{array}$ & $\begin{array}{c}0.247 \\
(0.599) \\
1,887\end{array}$ & $\begin{array}{c}-0.425 \\
(0.749) \\
1,887\end{array}$ & $\begin{array}{c}-0.334 \\
(0.279) \\
1,887\end{array}$ & $\begin{array}{c}0.031 \\
(0.239) \\
1,887\end{array}$ & 0.719 & & & \\
\hline $\begin{array}{l}\text { Panel D: control for pre-dete } \\
\text { Mean of outcome for rejected }\end{array}$ & $\begin{array}{l}\text { variables } \\
71.08\end{array}$ & $\begin{array}{l}\text { d mom's a } \\
6.826\end{array}$ & $\begin{array}{l}\text { t marriage } \\
20.28\end{array}$ & 7.905 & 1.924 & & 0.0214 & 0.0184 & 0.360 \\
\hline $\begin{array}{l}\text { Accepted } \\
\text { Observations }\end{array}$ & $\begin{array}{c}0.906 \\
(0.960) \\
3,116\end{array}$ & $\begin{array}{c}0.133 \\
(0.346) \\
3,499\end{array}$ & $\begin{array}{c}-1.293 * * \\
(0.624) \\
2,424\end{array}$ & $\begin{array}{c}-0.362 \\
(0.221) \\
2,218\end{array}$ & $\begin{array}{c}-0.044 \\
(0.198) \\
1,893\end{array}$ & 0.115 & $\begin{array}{c}0.103 * \\
(0.058) \\
3,505\end{array}$ & $\begin{array}{c}0.103 * \\
(0.056) \\
3,333\end{array}$ & $\begin{array}{c}-0.013 \\
(0.022) \\
1,889\end{array}$ \\
\hline
\end{tabular}


Table 4 continued: Does welfare increase quality of Post-MP husband?

Sample women who were unmarried at the time of application

Data source: Family Search

\begin{tabular}{lll} 
& \multicolumn{2}{c}{ Censuses } \\
\hline Occ Score $^{2}$ & $\begin{array}{l}\text { Post-MP } \\
\text { Husband } \\
\text { Education }\end{array}$ &
\end{tabular}

Outcome:

\begin{tabular}{cc}
\hline & Age gap \\
Post-MP & (shifted \\
Husband & by 2.5 \\
Longevity & years) \\
& $(1)$
\end{tabular}

\section{Panel E: Checks (for panel C)}

1- Correction for OVB (Oster 2017)

[ $1.32 ; 1.43[0.15 ; 0.36] \quad[-0.45 ;-0.39]$

(4)

2- Semi-parametric sample selection correction (Newey, 2009)

Accepted

$\begin{array}{ll}1.368 & 0.247\end{array}$

95\% Confidence interval

[-1.22;3.96] [-0.94;1.43]

$-0.425$

$-0.34 ;-0.33]$

$[-0.00 ; 0.06]$

\section{F-Stat}

P-Value

Observations

$$
1,887
$$

$$
1,887
$$

$[-1.91 ; 1.06][-0.89 ; 0.22]$

0.031

3- Drop if quality of match low

Accepted

$\begin{array}{ccccc}1.397 & 0.433 & 0.099 & -0.364 & -0.010 \\ (1.464) & (0.713) & (0.973) & (0.308) & (0.239) \\ 1305 & 1305 & 1305 & 1305 & 1305\end{array}$

Clustered at county

Observations

Note: Standard errors are clustered at the county level. Please refer to Table 2 for a full description of the controls, restrictions and checks. Panel C includes the other inputs (Post-MP Husband longevity, age gap, Post-MP Husband latest occupational score, Post-MP Husband 1940 education and education gap) as controls (except if the input is the regression dependent variable). In column 6, we present the P-value of the test with null hypothesis that the estimates from columns 1 to 5 are jointly equal to zero. ${ }^{1}$ Age gap is defined as the absolute value of the husband's age minus the mother's age minus $2.5 .{ }^{2}$ Defined from pre marriage data: uses 1940 if available, then 1930, then 1920, then 1910. Never uses a measure that is observed post-MP marriage. ${ }^{3}$ Education gap is defined as the absolute value of the difference in highest grade between the mother and the husband. ${ }^{4}$ Equal Weights regressions give the same weight to each of the quality measures. Values are standardized to zero mean and variance equals one. ${ }^{5}$ Satisfaction weights include husband's occupational score, education and longevity. We use the utility function and the parameters defined and calibrated in Grow and Van Bavel (2015) to construct the dependent variable. The equation below presents the utility function. The first term of the equation is the similarity of education, the second term is the earnings prospect and, the last term is the age gap. We follow the same categorization of variables as in the original paper, except for education, where we divide it in 4 quintile categories instead of the four categories in the paper (no schooling, primary, secundary and terciary). $\alpha_{\mathrm{i}}=\mathrm{a}_{\mathrm{i}}+25$ To take into accoun that female agents prefer partners who are about 2.5 years older. The parameters are: $S \max =4 ; \mathrm{Ymax}=5 ; \mathrm{Amax}=800 ; \mathrm{ws}=0.385 ; \mathrm{wy}=1.201 ; \mathrm{wa}=10.833$

$$
v_{i j}=\left(\frac{S_{\max }-\left|s_{i}-s_{j}\right|}{S_{\max }}\right)^{w_{s}}\left(\frac{y_{j}}{Y_{\max }}\right)^{w_{y}}\left(\frac{A_{\max }-\left|\alpha_{i}-a_{j}\right|}{A_{\max }}\right)^{w_{a}}
$$


Table 5: Do the cash transfers affect Fertility?

Results for all mothers and mothers that were unmarried at the time of application

\begin{tabular}{|c|c|c|c|c|c|c|c|c|}
\hline \multirow{4}{*}{$\begin{array}{l}\text { Sample: } \\
\text { Data source } \\
\text { Outcome }\end{array}$} & \multicolumn{4}{|c|}{ All mothers } & \multicolumn{4}{|c|}{ Mothers that were not married at time of } \\
\hline & \multicolumn{2}{|c|}{ Family Search } & \multicolumn{2}{|c|}{ Census } & \multicolumn{2}{|c|}{ Family Search } & \multicolumn{2}{|c|}{ Census } \\
\hline & \multirow[t]{2}{*}{$\begin{array}{l}\text { Post MP } \\
\text { kids born }\end{array}$} & \multirow[t]{2}{*}{$\begin{array}{l}\text { Children } \\
\text { ever born }\end{array}$} & \multicolumn{2}{|c|}{$\begin{array}{c}\text { Number of own } \\
\text { children in household }\end{array}$} & \multirow[t]{2}{*}{$\begin{array}{l}\text { Post MP } \\
\text { kids born }\end{array}$} & \multirow[t]{2}{*}{$\begin{array}{l}\text { Children } \\
\text { ever born }\end{array}$} & \multicolumn{2}{|c|}{$\begin{array}{l}\text { Number of own } \\
\text { children in household }\end{array}$} \\
\hline & & & 1930 & 1940 & & & 1930 & 1940 \\
\hline Mean of $Y$ for rejected & 0.25 & 4.13 & 2.38 & 1.54 & 0.22 & 4.16 & 2.39 & 1.57 \\
\hline \multicolumn{9}{|l|}{ Panel A: No controls } \\
\hline Accepted & 0.022 & 0.414 & 0.417 & 0.212 & 0.038 & 0.446 & 0.382 & 0.151 \\
\hline Robust standard errors & $(0.021)$ & $(0.074)^{* * *}$ & $(0.061) * * *$ & $(0.059) * * *$ & $(0.022)^{*}$ & $(0.081)^{* * *}$ & $(0.067) * * *$ & $(0.065)^{* *}$ \\
\hline Clustered at county & {$[0.025]$} & {$[0.086] * * *$} & {$[0.131]^{* * *}$} & {$[0.103]^{* *}$} & {$[0.025]$} & {$[0.093]^{* * *}$} & {$[0.123]^{* * *}$} & {$[0.103]$} \\
\hline Clustered at county*year & $\{0.022\}$ & $\{0.079\} * * *$ & $\{0.078\} * * *$ & $\{0.075\} * * *$ & $\{0.024\}$ & $\{0.082\} * * *$ & $\{0.082\} * * *$ & $\{0.080\}^{*}$ \\
\hline Bounds for missing data (Lee 2009) & {$[0.02 ; 0.25]$} & {$[0.41 ; 4.13]$} & {$[-0.12 ; 0.79]$} & {$[-0.37 ; 0.61]$} & {$[0.04 ; 0.22]$} & {$[0.45 ; 4.16]$} & {$[-0.16 ; 0.76]$} & {$[-0.44 ; 0.55]$} \\
\hline R-squared & 0.000 & 0.002 & 0.004 & 0.001 & 0.000 & 0.002 & 0.003 & 0.001 \\
\hline \multicolumn{9}{|l|}{ Panel B: Full controls } \\
\hline Accepted & -0.023 & 0.037 & -0.069 & -0.036 & -0.009 & 0.061 & -0.067 & -0.056 \\
\hline Robust standard errors & $(0.021)$ & $(0.035)$ & $(0.051)$ & $(0.055)$ & $(0.022)$ & $(0.037)^{*}$ & $(0.056)$ & $(0.060)$ \\
\hline Clustered at county & {$[0.018]$} & {$[0.032]$} & {$[0.051]$} & {$[0.049]$} & {$[0.021]$} & {$[0.034]^{*}$} & {$[0.059]$} & {$[0.051]$} \\
\hline Clustered at county*year & $\{0.020\}$ & $\{0.033\}$ & $\{0.052\}$ & $\{0.060\}$ & $\{0.021\}$ & $\{0.036\} *$ & $\{0.056\}$ & $\{0.067\}$ \\
\hline R-squared & 0.160 & 0.799 & 0.412 & 0.279 & 0.162 & 0.805 & 0.407 & 0.274 \\
\hline Observations & 16228 & 16228 & 11178 & 9358 & 13383 & 13383 & 9174 & 7635 \\
\hline \multicolumn{9}{|l|}{ Panel C: Checks } \\
\hline 1- Correction for OVB (Oster 2017) & {$[-0.04 ;-0.01]$} & $-0.08 ; 0.14]$ & {$[-0.25 ; 0.10]$} & {$[-0.13 ; 0.05]$} & {$[-0.03 ; 0.01]$} & $-0.05 ; 0.17]$ & {$[-0.24 ; 0.09]$} & {$[-0.13 ; 0.01]$} \\
\hline \multicolumn{9}{|l|}{ 2- Semi-parametric sample } \\
\hline Accepted & -0.023 & 0.037 & -0.063 & -0.012 & -0.009 & 0.061 & -0.063 & -0.037 \\
\hline $95 \%$ Confidence interval & {$[-0.06 ; 0.01]$} & {$[-0.03 ; 0.10]$} & {$[-0.16 ; 0.04]$} & {$[-0.11 ; 0.08]$} & {$[-0.05 ; 0.03]$} & {$[-0.01 ; 0.13]$} & {$[-0.18 ; 0.05]$} & {$[-0.14 ; 0.07]$} \\
\hline F-Stat & . & . & 25.57 & 116.82 & 75.57 & 75.57 & 26.33 & 80.59 \\
\hline P-Value & . & . & 0.000 & 0.000 & 0.000 & 0.000 & 0.000 & 0.000 \\
\hline \multicolumn{9}{|l|}{ 3- Drop if quality of match low } \\
\hline Accepted & -0.014 & 0.004 & -0.049 & -0.061 & 0.008 & 0.015 & -0.043 & -0.053 \\
\hline Clustered at county & $(0.028)$ & $(0.040)$ & $(0.071)$ & $(0.066)$ & $(0.031)$ & $(0.044)$ & $(0.077)$ & $(0.076)$ \\
\hline Observations & 7577 & 7577 & 5589 & 4679 & 6266 & 6266 & 4501 & 3759 \\
\hline
\end{tabular}

Note: please refer to Table 2 for a full description of the controls, restrictions and checks. 
Table 6: Do the cash transfers affect Labor supply and wages?

Sample includes all women in application

\begin{tabular}{|c|c|c|c|c|c|c|c|}
\hline \multirow{2}{*}{$\begin{array}{l}\text { Outcome: } \\
\text { Census year }\end{array}$} & \multicolumn{2}{|c|}{ Labor force participation } & \multicolumn{2}{|c|}{ Work } & \multicolumn{2}{|c|}{$\begin{array}{c}\text { Occupation Score } \\
\text { occupation not missing }\end{array}$} & \multirow{2}{*}{$\begin{array}{c}\text { Earned Income } \\
\text { income }>0\end{array}$} \\
\hline & 1930 & 1940 & 1930 & 1940 & 1930 & 1940 & \\
\hline Mean of Y for rejected & 0.33 & 0.21 & 0.29 & 0.19 & 15.85 & 15.79 & 479.08 \\
\hline \multicolumn{8}{|l|}{ Panel A: No controls } \\
\hline Accepted & 0.046 & 0.050 & 0.045 & 0.054 & -0.677 & 0.154 & 38.030 \\
\hline Robust standard errors & $(0.016) * * *$ & $(0.015) * * *$ & $(0.015) * * *$ & $(0.015) * * *$ & $(0.610)$ & $(0.729)$ & $(32.968)$ \\
\hline Clustered at county & {$[0.013] * * *$} & {$[0.020] * *$} & {$[0.012] * * *$} & {$[0.018]^{* * *}$} & {$[0.578]$} & {$[0.597]$} & {$[37.463]$} \\
\hline Clustered at county*year & $\{0.016\} * * *$ & $\{0.016\} * * *$ & $\{0.015\} * * *$ & $\{0.016\} * * *$ & $\{0.666\}$ & $\{0.745\}$ & $\{30.602\}$ \\
\hline Bounds for missing data (Lee 2009) & {$[-0.05 ; 0.10]$} & {$[-0.12 ; 0.11]$} & {$[-0.06 ; 0.10]$} & {$[-0.12 ; 0.11]$} & {$[-4.17 ; 2.20]$} & {$[-5.27 ; 5.26]$} & {$[-203.18 ; 247.58]$} \\
\hline R-squared & 0.001 & 0.001 & 0.001 & 0.001 & 0.000 & 0.000 & 0.000 \\
\hline \multicolumn{8}{|l|}{ Panel B: Full controls } \\
\hline Accepted & 0.012 & 0.027 & 0.014 & 0.032 & -0.487 & -0.349 & 5.434 \\
\hline Robust standard errors & $(0.017)$ & $(0.017)$ & $(0.016)$ & $(0.016)^{* *}$ & $(0.642)$ & $(0.795)$ & $(37.659)$ \\
\hline Clustered at county & {$[0.016]$} & {$[0.017]$} & {$[0.014]$} & {$[0.016] * *$} & {$[0.522]$} & {$[0.614]$} & {$[28.688]$} \\
\hline Clustered at county*year & $\{0.016\}$ & $\{0.017\}$ & $\{0.016\}$ & $\{0.016\}^{*}$ & $\{0.679\}$ & $\{0.822\}$ & $\{35.857\}$ \\
\hline R-squared & 0.072 & 0.067 & 0.059 & 0.061 & 0.097 & 0.108 & 0.160 \\
\hline Observations & 11170 & 9351 & 11178 & 9358 & 3472 & 2737 & 2083 \\
\hline \multicolumn{8}{|l|}{ Panel C: Checks } \\
\hline 1 - Correction for OVB (Oster 2017) & {$[-0.00 ; 0.02]$} & {$[0.02 ; 0.04]$} & {$[0.00 ; 0.02]$} & {$[0.02 ; 0.04]$} & {$[-0.55 ;-0.41]$} & {$[-0.55 ;-0.18]$} & {$[-8.04 ; 16.94]$} \\
\hline \multicolumn{8}{|c|}{ 2- Semi-parametric sample selection correction (Newey, 2009) } \\
\hline Accepted & 0.011 & 0.025 & 0.013 & 0.030 & -0.457 & -0.358 & 7.543 \\
\hline $95 \%$ Confidence interval & {$[-0.02 ; 0.04]$} & {$[-0.01 ; 0.06]$} & {$[-0.02 ; 0.04]$} & {$[-0.00 ; 0.06]$} & {$[-1.50 ; 0.58]$} & {$[-1.58 ; 0.86]$} & {$[-49.45 ; 64.53]$} \\
\hline F-Stat & 25.31 & 116.23 & 25.57 & 116.82 & 25.30 & 52.17 & 74.65 \\
\hline P-Value & 0.000 & 0.000 & 0.000 & 0.000 & 0 & 0.000 & 0.000 \\
\hline \multicolumn{8}{|l|}{ 3- Drop if quality of match low } \\
\hline Accepted & 0.019 & 0.011 & 0.026 & 0.020 & -0.084 & 0.395 & 28.263 \\
\hline Clustered at county & $(0.035)$ & $(0.021)$ & $(0.027)$ & $(0.022)$ & $(0.948)$ & $(1.256)$ & $(38.861)$ \\
\hline Observations & 5589 & 4679 & 5589 & 4679 & 2035 & 1547 & 1237 \\
\hline
\end{tabular}

Note: please refer to Table 2 for a full description of the controls, restrictions and checks. Refer to Table 5 for a description of the quality measure.

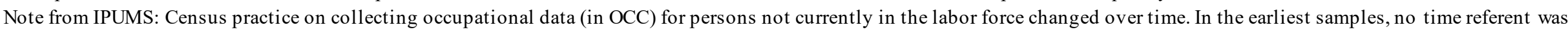

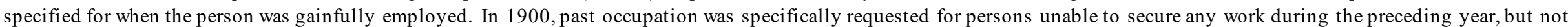

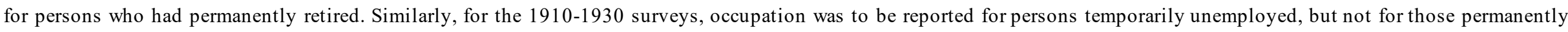

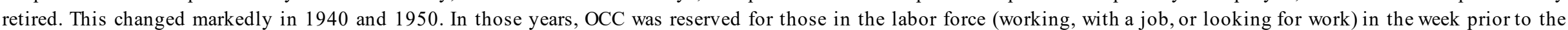

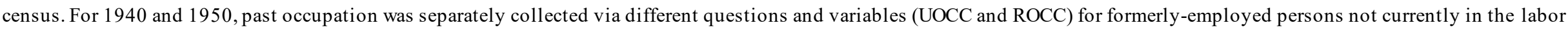
force. 
Table 7: Do the cash transfers affect geographic mobility?

Sample: all mothers in application

\begin{tabular}{|c|c|c|c|c|}
\hline \multirow{2}{*}{$\begin{array}{l}\text { Outcome: } \\
\text { Sample: }\end{array}$} & \multicolumn{4}{|c|}{ All mothers } \\
\hline & $\begin{array}{l}1930 \text { live in } \\
\text { MP county }\end{array}$ & $\begin{array}{c}1930 \text { live in } \\
\text { MP state }\end{array}$ & $\begin{array}{l}1940 \text { live in } \\
\text { MP county }\end{array}$ & $\begin{array}{c}1940 \text { live in } \\
\text { MP state }\end{array}$ \\
\hline Mean of Y for rejected & 0.65 & 0.85 & 0.59 & 0.83 \\
\hline \multicolumn{5}{|l|}{ Panel A: No controls } \\
\hline Accepted & 0.080 & 0.037 & 0.078 & 0.031 \\
\hline Robust standard errors & $(0.016)^{* * *}$ & $(0.012)^{* * *}$ & $(0.018)^{* * *}$ & $(0.014)^{* *}$ \\
\hline Clustered at county & {$[0.027]^{* * *}$} & {$[0.016]^{* *}$} & {$[0.028]^{* * *}$} & {$[0.020]$} \\
\hline Clustered at county*year & $\{0.019\} * * *$ & $\{0.013\}^{* * *}$ & $\{0.021\}^{* * *}$ & $\{0.015\}^{* *}$ \\
\hline Bounds for missing data(Lee 2009) & {$[0.04 ; 0.19]$} & {$[0.02 ; 0.15]$} & {$[0.00 ; 0.23]$} & {$[-0.00 ; 0.17]$} \\
\hline R-squared & 0.002 & 0.001 & 0.002 & 0.001 \\
\hline \multicolumn{5}{|l|}{ Panel B: Full controls } \\
\hline Accepted & 0.048 & 0.021 & 0.063 & 0.020 \\
\hline Robust standard errors & $(0.017)^{* * *}$ & $(0.013)^{*}$ & $(0.019)^{* * *}$ & $(0.015)$ \\
\hline Clustered at county & {$[0.024]^{* *}$} & [0.013] & {$[0.018]^{* * *}$} & [0.018] \\
\hline Clustered at county*year & $\{0.019\} * *$ & $\{0.013\}$ & $\{0.020\} * * *$ & $\{0.016\}$ \\
\hline R-squared & 0.176 & 0.099 & 0.114 & 0.090 \\
\hline Observations & 11178 & 11178 & 9358 & 9358 \\
\hline \multicolumn{5}{|l|}{ Panel C: Checks } \\
\hline 1- Correction for OVB (Oster 2017) & {$[0.04 ; 0.06]$} & {$[0.02 ; 0.03]$} & {$[0.06 ; 0.07]$} & {$[0.02 ; 0.02]$} \\
\hline \multicolumn{5}{|c|}{ 2- Semi-parametric sample selection correction (Newey, 2009) } \\
\hline Accepted & 0.049 & 0.021 & 0.063 & 0.020 \\
\hline $95 \%$ Confidence interval & {$[0.00 ; 0.10]$} & {$[-0.00 ; 0.05]$} & {$[0.03 ; 0.10]$} & {$[-0.02 ; 0.05]$} \\
\hline F-Stat & 25.57 & 25.57 & 116.82 & 116.82 \\
\hline P-Value & 0.000 & 0.000 & 0.000 & 0.000 \\
\hline \multicolumn{5}{|l|}{ 3- Drop if quality of match low } \\
\hline Accepted & $0.069 * * *$ & 0.017 & $0.053^{*}$ & 0.029 \\
\hline Clustered at county & $(0.026)$ & $(0.017)$ & $(0.028)$ & $(0.024)$ \\
\hline Observations & 5589 & 5589 & 4679 & 4679 \\
\hline
\end{tabular}


Table 7 Cont: Do the cash transfers affect geographic mobility?

\begin{tabular}{|c|c|c|c|c|c|c|}
\hline \multirow{2}{*}{$\begin{array}{l}\text { Outcome: } \\
\text { Sample: }\end{array}$} & \multicolumn{6}{|c|}{ All mothers who moved } \\
\hline & $\begin{array}{l}1930 \text { live in } \\
\text { more } \\
\text { educated } \\
\text { county }{ }^{1}\end{array}$ & $\begin{array}{l}1940 \text { live in } \\
\text { more } \\
\text { educated } \\
\text { county }{ }^{1}\end{array}$ & $\begin{array}{l}1930 \text { live in } \\
\text { higher sex } \\
\text { ratio county }{ }^{2}\end{array}$ & $\begin{array}{l}1940 \text { live in } \\
\text { higher sex } \\
\text { ratio county }\end{array}$ & $\begin{array}{l}1930 \text { live in } \\
\text { higher female } \\
\text { LFP county }{ }^{2}\end{array}$ & $\begin{array}{l}1940 \text { live in } \\
\text { higher female } \\
\text { LFP county }^{2}\end{array}$ \\
\hline Mean of Y for rejected & 0.5 & 0.51 & 0.5 & 0.54 & 0.67 & 0.63 \\
\hline \multicolumn{7}{|l|}{ Panel A: No controls } \\
\hline Accepted & 0.032 & 0.024 & 0.019 & -0.047 & -0.025 & 0.011 \\
\hline Robust standard errors & -0.029 & -0.03 & -0.037 & -0.03 & -0.035 & -0.029 \\
\hline Clustered at county & {$[0.048]$} & [0.044] & {$[0.053]$} & {$[0.050]$} & [0.039] & {$[0.034]$} \\
\hline Clustered at county*year & $\{0.034\}$ & $\{0.037\}$ & $\{0.041\}$ & $\{0.032\}$ & $\{0.036\}$ & $\{0.031\}$ \\
\hline Bounds for missing data(Lee 2009) & {$[-0.03 ; 0.09]$} & {$[0.02 ; 0.03]$} & {$[0.00 ; 0.03]$} & {$[-0.05 ;-0.04]$} & {$[-0.05 ;-0.02]$} & {$[0.00 ; 0.02]$} \\
\hline R-squared & 0 & 0 & 0 & 0.001 & 0 & 0 \\
\hline \multicolumn{7}{|l|}{ Panel B: Full controls } \\
\hline Accepted & 0.028 & 0.021 & 0.038 & -0.004 & -0.018 & 0.026 \\
\hline Robust standard errors & -0.026 & -0.026 & -0.036 & -0.029 & -0.035 & -0.027 \\
\hline Clustered at county & {$[0.024]$} & {$[0.024]$} & {$[0.031]$} & {$[0.032]$} & {$[0.034]$} & {$[0.026]$} \\
\hline Clustered at county*year & $\{0.027\}$ & $\{0.026\}$ & $\{0.036\}$ & $\{0.028\}$ & $\{0.032\}$ & $\{0.027\}$ \\
\hline R-squared & 0.399 & 0.405 & 0.333 & 0.289 & 0.328 & 0.275 \\
\hline Observations & 3123 & 3177 & 2009 & 3136 & 2009 & 3136 \\
\hline \multicolumn{7}{|l|}{ Panel C: Checks } \\
\hline 1- Correction for OVB (Oster 2017) & {$[0.03 ; 0.03]$} & {$[0.02 ; 0.02]$} & {$[0.03 ; 0.05]$} & {$[-0.02 ; 0.01]$} & {$[-0.02 ;-0.02]$} & {$[0.02 ; 0.03]$} \\
\hline \multicolumn{7}{|c|}{ 2- Semi-parametric sample selection correction (Newey, 2009) } \\
\hline Accepted & 0.028 & 0.022 & 0.037 & -0.003 & -0.019 & 0.025 \\
\hline $95 \%$ Confidence interval & {$[-0.02 ; 0.08]$} & {$[-0.03 ; 0.07]$} & {$[-0.02 ; 0.10]$} & {$[-0.07 ; 0.06]$} & {$[-0.09 ; 0.05]$} & {$[-0.03 ; 0.08]$} \\
\hline F-Stat & 22.13 & 29.86 & 27.58 & 27.52 & 27.58 & 27.52 \\
\hline P-Value & 0 & 0 & 0 & 0 & 0 & 0 \\
\hline \multicolumn{7}{|l|}{ 3- Drop if quality of match low } \\
\hline Accepted & -0.023 & -0.016 & 0.08 & 0.049 & -0.039 & -0.035 \\
\hline Clustered at county & -0.042 & -0.042 & -0.062 & -0.041 & -0.061 & -0.051 \\
\hline Observations & 1249 & 1362 & 775 & 1352 & 775 & 1352 \\
\hline
\end{tabular}

Note: Sample: all mothers in application. $R$ efer to Table 3 for a full description of the controls, restrictions and checks. ${ }^{1}$ Counties are ranked by the average schooling in the population between 18 and 55 years old in the 1940 census. ${ }^{2}$ Counties are ranked by the sex ratio (white married mother labor force participation) at the year of application (interpolated between 1910, 1920 and 1930 censuses). A Low quality match is a match with quality below the median. The quality measure uses the standardized jarowinkle for the 1930 and 1940 census matches respectively. 
Table 8: Does welfare benefit mothers in the long run?

Sample all women in application

\begin{tabular}{|c|c|c|}
\hline Data source & Family search & 1940 census \\
\hline Outcome & Mom longevity & $\begin{array}{c}\text { Household income } \\
\text { in } 1940 \\
\end{array}$ \\
\hline Mean of Y for rejected & 73.43 & 979.57 \\
\hline \multicolumn{3}{|l|}{ Panel A: No controls } \\
\hline Accepted & 0.950 & -9.027 \\
\hline Robust standard errors & $(0.456)^{* *}$ & $(42.631)$ \\
\hline Clustered at county & {$[0.404]^{* *}$} & {$[57.634]$} \\
\hline Clustered at county*year & $\{0.464\} * *$ & $\{44.757\}$ \\
\hline Bounds for missing data, no controls (Lee 2009) & {$[-0.53 ; 3.26]$} & [ -414.44;208.69] \\
\hline R-squared & 0.000 & 0.000 \\
\hline \multicolumn{3}{|l|}{ Panel B: Full controls } \\
\hline Accepted & 0.247 & -58.241 \\
\hline Robust standard errors & $(0.494)$ & $(44.585)$ \\
\hline Clustered at county & {$[0.567]$} & {$[31.877]^{*}$} \\
\hline Clustered at county*year & $\{0.490\}$ & $\{43.470\}$ \\
\hline R-squared & 0.028 & 0.080 \\
\hline Observations & 12989 & 9358 \\
\hline \multicolumn{3}{|l|}{ Panel C: Checks } \\
\hline 1- Correction for OVB (Oster 2017) & {$[-0.02 ; 0.49]$} & {$[-76.55 ;-41.74]$} \\
\hline \multicolumn{3}{|c|}{ 2- Semi-parametric sample selection correction (Newey, 2009) } \\
\hline Accepted & 0.254 & -59.762 \\
\hline $95 \%$ Confidence interval & {$[-0.86 ; 1.37]$} & {$[-122.81 ; 3.29]$} \\
\hline F-Stat & 46.25 & 116.82 \\
\hline P-Value & 0.000 & 0.000 \\
\hline \multicolumn{3}{|l|}{ 3- Drop if quality of match low } \\
\hline Accepted & 0.215 & -107.325 \\
\hline Clustered at county & $(0.742)$ & $(72.547)$ \\
\hline Observations & 8007 & 4679 \\
\hline
\end{tabular}

Note: please refer to Table 2 for a full description of the controls, restrictions and checks. The quality measure uses the standardized jarowinkle for longevity in column 1, and the standarized jarowinkle for the 1940 census match in column 2 . 
Table 9: Marginal Value of Public Funds

All values expressed in 2019 dollars

\begin{tabular}{|c|c|c|c|}
\hline & \multirow[t]{2}{*}{ Mothers } & \multicolumn{2}{|c|}{ Including Children Spillovers } \\
\hline & & $\begin{array}{c}\text { income and } \\
\text { longevity benefits on } \\
\text { kids } \\
\end{array}$ & $\begin{array}{l}\text { transfer not counted as a } \\
\text { benefit }\end{array}$ \\
\hline \multicolumn{4}{|c|}{ Panel A: computations based on the results of this paper and of Aizer et al. (2016) } \\
\hline $\begin{array}{l}\text { Dollar value of maternal behavioral response (marriage delay } \\
\text { and mobility decrease) }\end{array}$ & $3,660.68$ & $3,660.68$ & $3,660.68$ \\
\hline Dollar value of spillover for kids (mortality + income) & 0 & 61,481 & 61,481 \\
\hline Dollar value of increased income taxes from kids $(10 \%$ tax rate) & 0 & 5,225 & 5,225 \\
\hline Dollar value of increased income taxes from mom ( $10 \%$ tax rate) & 507.59 & 507.59 & 507.59 \\
\hline Total transfer & 20,715 & 20,715 & 20,715 \\
\hline $\begin{array}{l}\text { Total benefit or WTP (transfer + spillovers - cost of behavioral } \\
\text { responses) }\end{array}$ & 17,054 & 78,535 & 57,820 \\
\hline WTP excluding cost of behavioral responses & 20,715 & 82,196 & 61,481 \\
\hline Total cost (transfer - taxes from increased earnings) & 20,207 & 14,982 & 14,982 \\
\hline MVPF without behavioral responses from mother & 1.00 & 5.49 & 4.10 \\
\hline MVPF including behavioral responses & 0.84 & 5.24 & 3.86 \\
\hline \multicolumn{4}{|l|}{ Panel B: Minimum gains for children needed for an MVPF of 1} \\
\hline Minimum change in kids' life expectancy ${ }^{1}$ in years (for a MVPF $=$ & & 0.34 & 1.45 \\
\hline Minimum percentatge change in kids' income ${ }^{2}($ for a $M V P F=1)$ & & $0.75 \%$ & $5.67 \%$ \\
\hline
\end{tabular}

This table computes the Marginal Value of Public Funds (MVPF) using the methodology of Hendren and Sprung-Keyser (2019). We correct for discounting using a 3\% rate, and we do not consider the implications of life extensions on Medicare and SSA pensions. We ignore the effects of the pension on marriage rates, type of husband, and years of schooling of the children. These are treated as intermediate outcomes whose ultimate value is reflected in increases in income and longevity.

The dollar value of maternal behavioral response includes the discounted effects on marriage delay and mobility decrease. The value of spillover for kids includes the discounted effects on mortality from age 10 to 85 and discounted income effects for the children's average working period, 45 years. We assume a 10\% tax rate that is discounted for mothers and children average working periods (27 and 45 years, respectively). The total transfer takes into account that mothers are in the program, on average, for 3 years. ${ }^{1}$ Assumes no change in kids income. ${ }^{2}$ Assumes there is no change in kids longevity and takes into account the increase in income taxes from kids. 


\section{Appendix Figure 1: Census Figures}
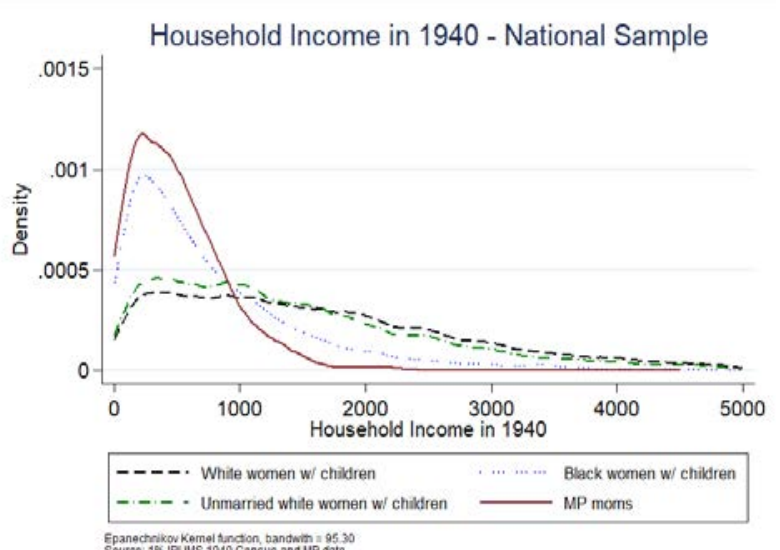

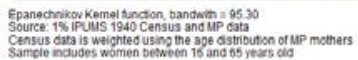

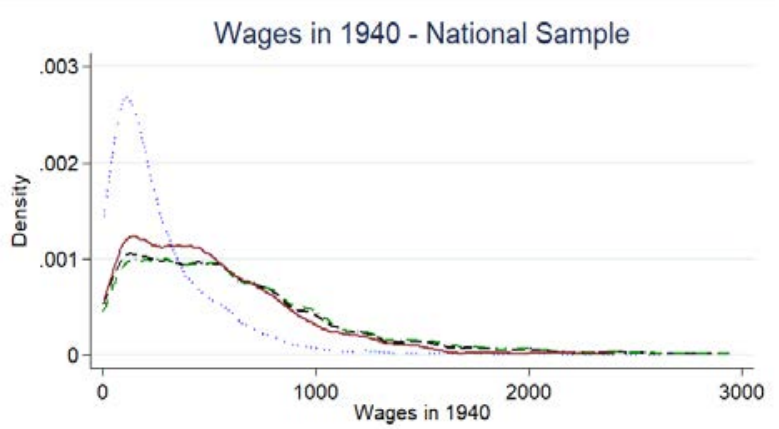

- - - - - Whito women w/ chiliren

- - -.- Unmarried white women w/ children _- MP mons

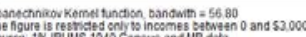

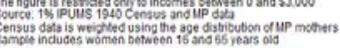
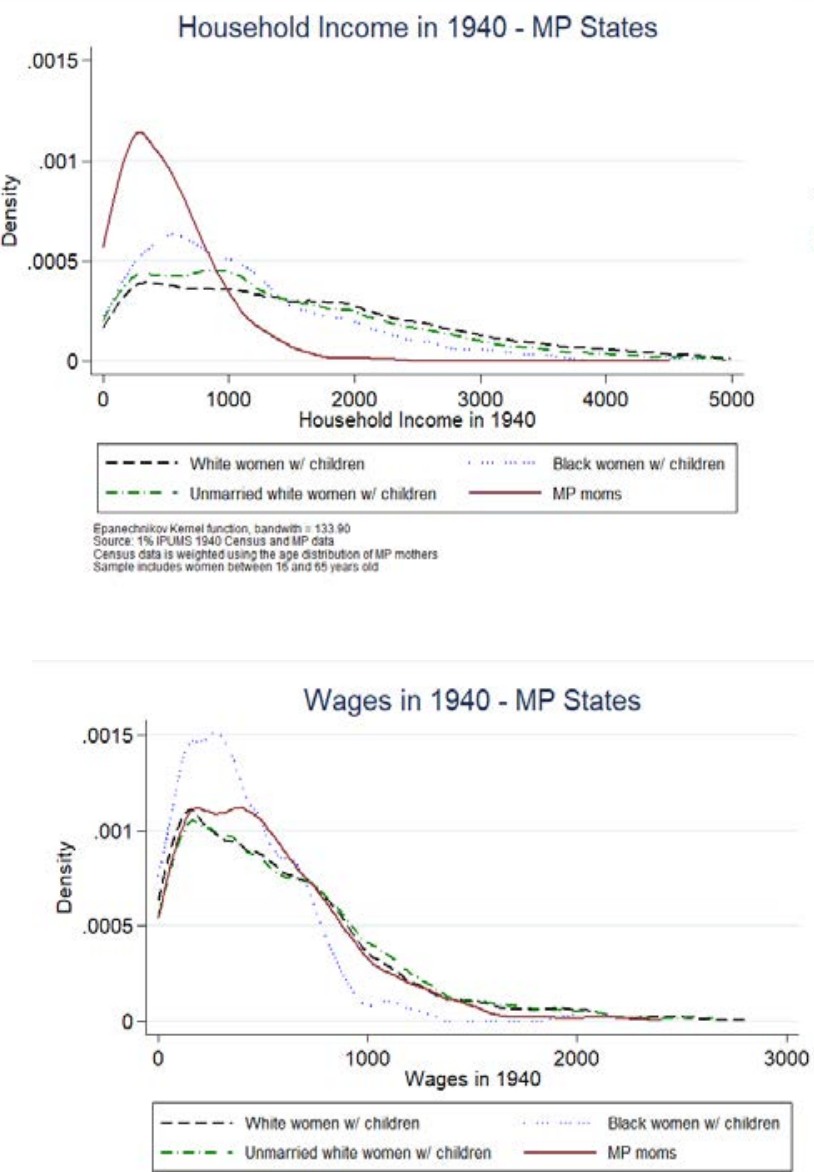

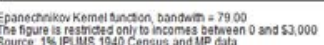

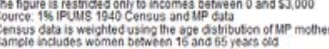

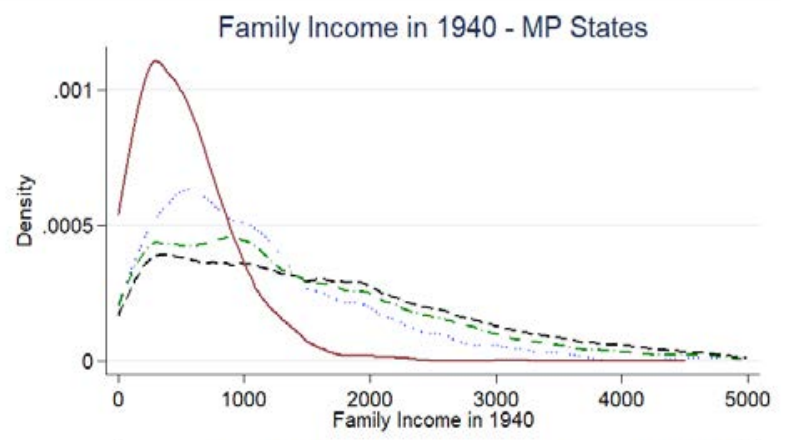

---.. White women w/ chibren

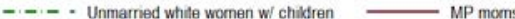

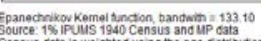

orup menters
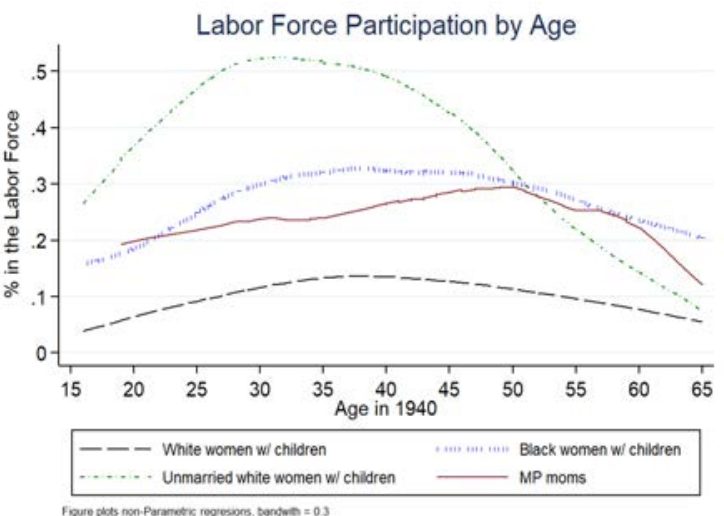

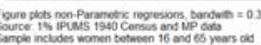


Appendix Figure 1 continued: Labor Force participation 1940 census

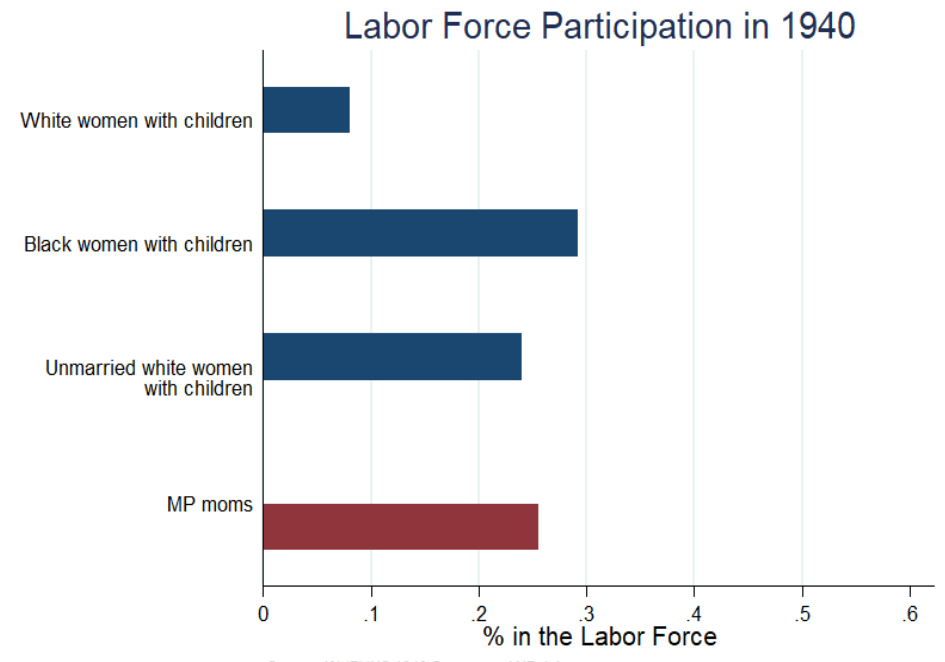

Source: $1 \%$ IPUMS 1940 Census and MP data

Census datais weighted using the age distribution of MP mothers
Sample includes women between 16 and 65 years old 


\section{Appendix Figure 2: Duration and Husband Quality}
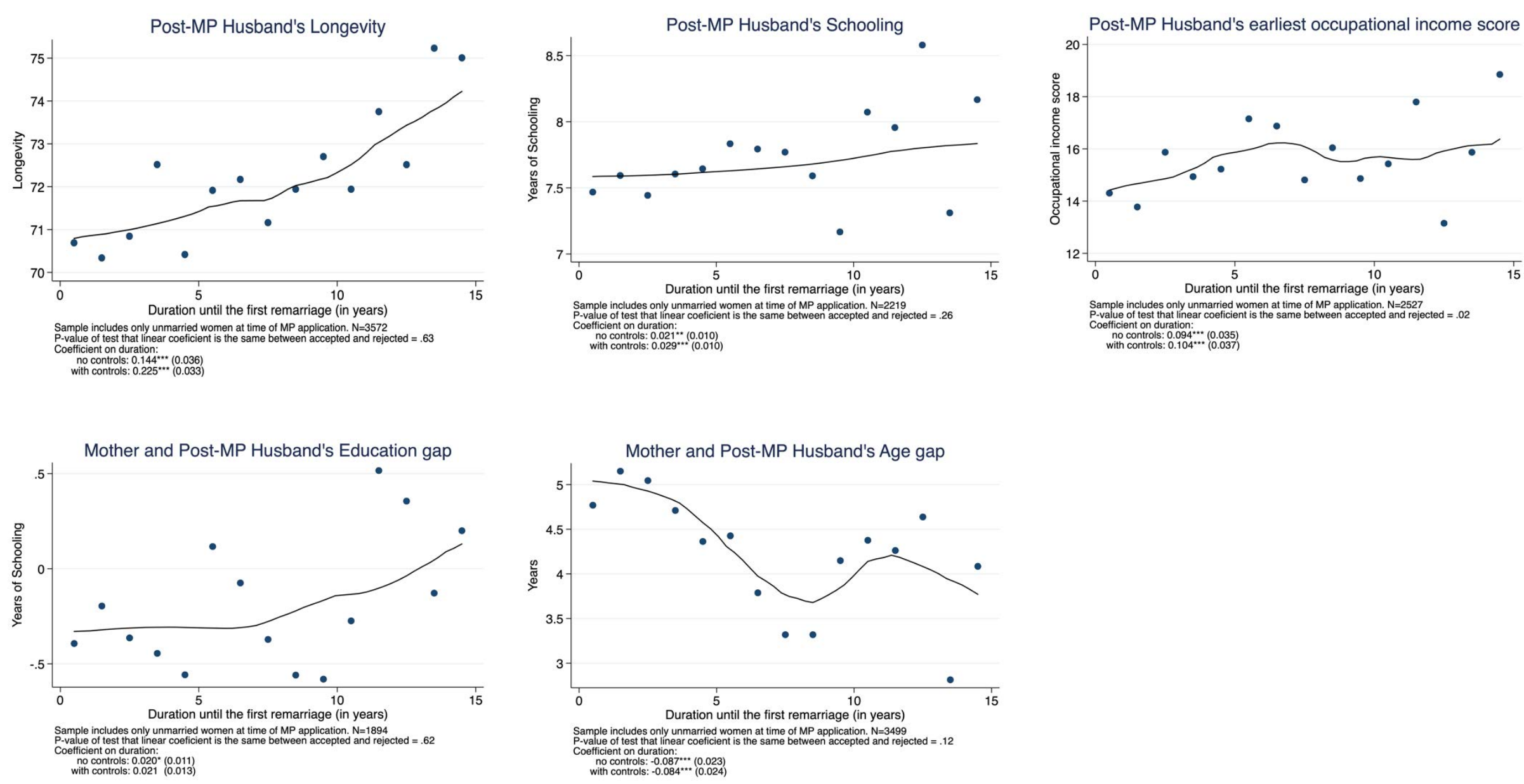
Appendix Figure 3: Cash transfers do not change the degree of assortative mating in education, longevity and age at marriage
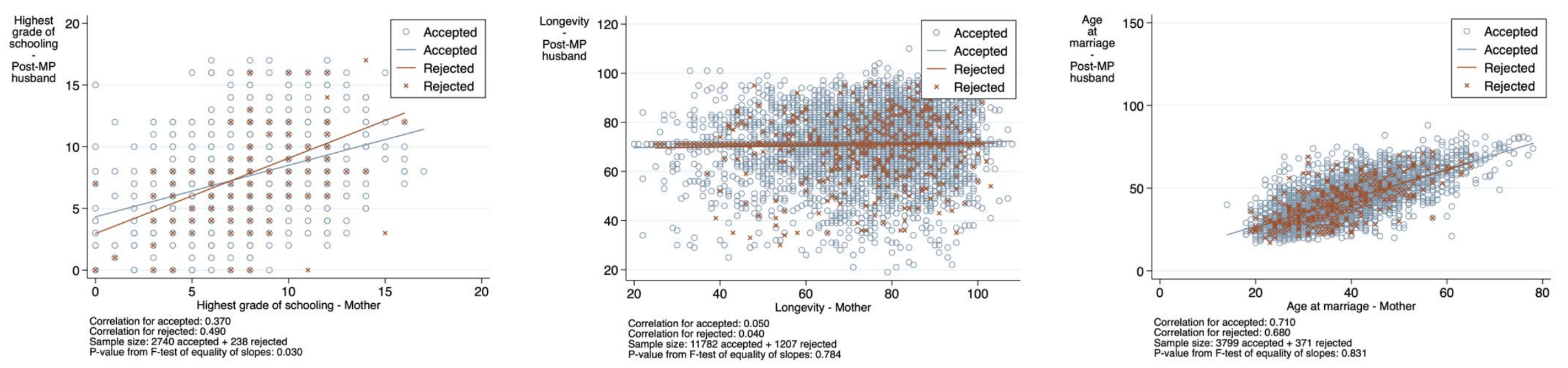


\section{Appendix Figure 4: Share of MP applicants remarrying by age}

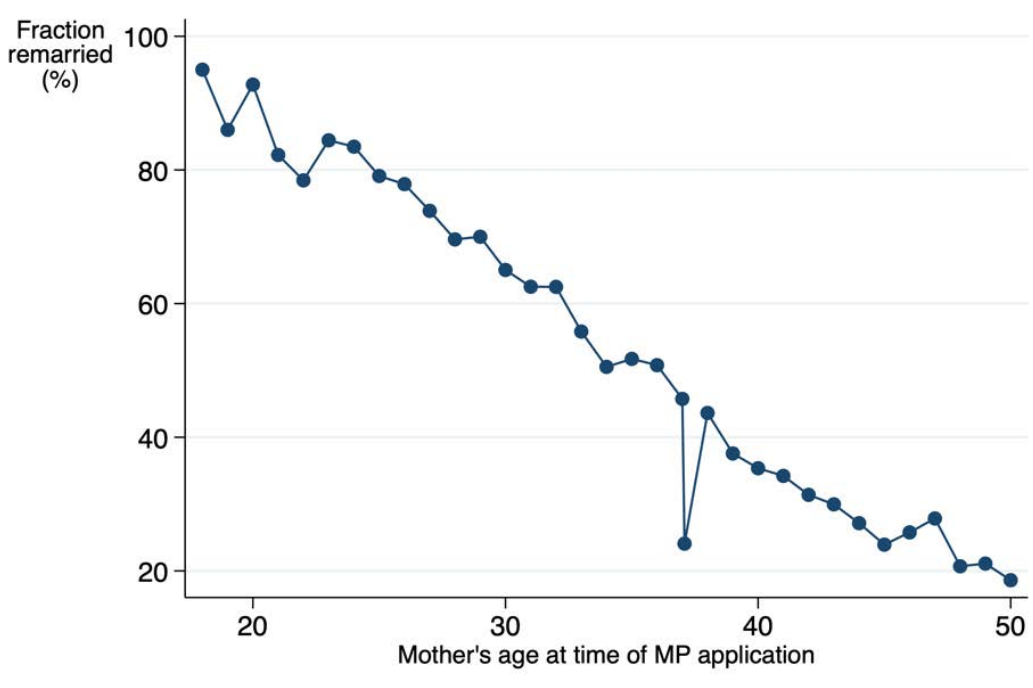

Figure is restricted to mothers between 18 and 50 years old at the time of application that had information on remarriage. $78.10000000000001 \%$ of the sample.

Note: the figure plots the fraction remarrying by age. The $5^{\text {th }}$ percentile of the age at remarriage is 24 and the $95^{\text {th }}$ is 52 . 
Appendix table 1: The status of poor women with children in 1910

Women ages $15-55$ in the $1 \% 1910$ IPUMS census data.

White Women with

children

Unmarried white women with children
Number of children ever had

3.873

\section{Married}

Married and working

House is a farm

Woman is the head of the household

Woman is head and male non-relatives are living at home

Woman is living with adult relatives

$\mathrm{N}$

Note: Author's computation using data from the 1910 census.
2.832

0.081

0.918

4.279

2.392

0.411

0.047

0.305

0.204

0.067

0.68

0.011

0.112

0.051

0.28

118,411 
Appendix Table 2: Accepted moms are slightly worse off at time of application

\begin{tabular}{|c|c|c|c|c|c|c|c|}
\hline \multirow[b]{2}{*}{ Outcome: } & \multirow{2}{*}{$\begin{array}{l}\text { MP admin data } \\
\text { Number of } \\
\text { kids on } \\
\text { application }\end{array}$} & \multicolumn{6}{|c|}{ Newly collected data } \\
\hline & & $\begin{array}{l}\text { Number } \\
\text { of kids } \\
\text { died } \\
\text { before MP } \\
\text { application }\end{array}$ & $\begin{array}{l}\text { Number } \\
\text { of live } \\
\text { kids } 14+ \\
\text { at MP } \\
\text { application }\end{array}$ & $\begin{array}{l}\text { Mom age } \\
\text { at } \\
\text { application }\end{array}$ & $\begin{array}{c}\text { Mom } \\
\text { number } \\
\text { of siblings }\end{array}$ & $\begin{array}{c}\text { Mom } \\
\text { foreign } \\
\text { born }\end{array}$ & $\begin{array}{c}\text { Mom is } \\
\text { black }\end{array}$ \\
\hline \multicolumn{8}{|c|}{ Panel A: All Moms (no controls) } \\
\hline Mean of outcome for rejected & 2.200 & 0.198 & 1.631 & 37.824 & 4.14 & 0.155 & 0.017 \\
\hline $\begin{array}{l}\text { Accepted } \\
\text { OLS (unadjusted se) } \\
\text { Robust standard errors } \\
\text { Clustered at county } \\
\text { Clustered at county*year }\end{array}$ & $\begin{array}{c}0.454 \\
(0.040)^{* * *} \\
{[0.037]^{* * *}} \\
\{0.071\}^{* * *} \\
(0.052)^{* * *}\end{array}$ & $\begin{array}{c}0.031 \\
(0.016)^{*} \\
{[0.015]^{* *}} \\
\{0.018\}^{*} \\
(0.015)^{* *}\end{array}$ & $\begin{array}{c}-0.132 \\
(0.060)^{* *} \\
{[0.064]^{* *}} \\
\{0.075\}^{*} \\
(0.071)^{*}\end{array}$ & $\begin{array}{c}-0.683 \\
(0.238)^{* * *} \\
{[0.253]^{* * *}} \\
\{0.309\}^{* *} \\
(0.290)^{* *}\end{array}$ & $\begin{array}{c}0.251 \\
(0.111)^{* *} \\
{[0.113]^{* *}} \\
\{0.191\} \\
(0.135)^{*}\end{array}$ & $\begin{array}{c}0.014 \\
-0.01 \\
{[0.010]} \\
\{0.019\} \\
-0.012\end{array}$ & $\begin{array}{c}0.002 \\
-0.004 \\
{[0.004]} \\
\{0.005\} \\
-0.004\end{array}$ \\
\hline $\begin{array}{l}\text { Observations } \\
\text { R-squared }\end{array}$ & $\begin{array}{l}16228 \\
0.008\end{array}$ & & & $\begin{array}{r}15313 \\
0.001\end{array}$ & $\begin{array}{c}16228 \\
0.000\end{array}$ & & $\begin{array}{r}14824 \\
0.000\end{array}$ \\
\hline \multicolumn{8}{|c|}{ Panel B: All Moms (County and Year of Application FE) } \\
\hline Mean of outcome for $r$ & 2.2000 & 0.198 & 1.631 & 37.824 & 4.14 & 0.155 & 0.017 \\
\hline $\begin{array}{l}\text { Accepted } \\
\text { OLS (unadjusted se) } \\
\text { Robust standard errors } \\
\text { Clustered at county } \\
\text { Clustered at county*year }\end{array}$ & $\begin{array}{l}0.421 \\
(0.042)^{* * *} \\
{[0.038]^{* * *}} \\
\{0.058\}^{* * *} \\
(0.045)^{* * *}\end{array}$ & $\begin{array}{c}0.023 \\
-0.017 \\
{[0.016]} \\
\{0.016\} \\
-0.016\end{array}$ & $\begin{array}{c}-0.193 \\
(0.063)^{* * *} \\
{[0.067]^{* * *}} \\
\{0.072\}^{* * *} \\
(0.069)^{* * *}\end{array}$ & $\begin{array}{l}-0.712 \\
(0.253)^{* * *} \\
{[0.267]^{* * *}} \\
\{0.272\}^{* * *} \\
(0.274)^{* * *}\end{array}$ & $\begin{array}{l}0.105 \\
-0.115 \\
{[0.117]} \\
\{0.130\} \\
-0.114\end{array}$ & $\begin{array}{c}0.006 \\
-0.01 \\
{[0.010]} \\
\{0.009\} \\
-0.01\end{array}$ & $\begin{array}{c}0.004 \\
-0.004 \\
{[0.004]} \\
\{0.004\} \\
-0.005\end{array}$ \\
\hline $\begin{array}{l}\text { Observations } \\
\text { R-squared }\end{array}$ & & & & $\begin{array}{r}15313 \\
0.033\end{array}$ & $\begin{array}{r}16228 \\
0.094\end{array}$ & & \\
\hline \multicolumn{8}{|c|}{ Panel C: Unmarried Moms (No Controls) } \\
\hline Mean of outcome for rejected & 2.182 & 0.196 & 1.727 & 38.372 & 4.22 & 0.159 & 0.018 \\
\hline $\begin{array}{l}\text { Accepted } \\
\text { OLS (unadjusted se) } \\
\text { Robust standard errors } \\
\text { Clustered at county } \\
\text { Clustered at county*year }\end{array}$ & $\begin{array}{l}0.471 \\
(0.044)^{* * *} \\
{[0.040]^{* * *}} \\
\{0.067\}^{* * *} \\
(0.053)^{* * *}\end{array}$ & $\begin{array}{c}0.043 \\
(0.018)^{* *} \\
{[0.017]^{* *}} \\
\{0.020\}^{* *} \\
(0.017)^{* *}\end{array}$ & $\begin{array}{c}-0.147 \\
(0.068)^{* *} \\
{[0.072]^{* *}} \\
\{0.094\} \\
(0.078)^{*}\end{array}$ & $\begin{array}{c}-0.81 \\
(0.263)^{* * *} \\
{[0.281]^{* * *}} \\
\{0.334\}^{* *} \\
(0.324)^{* *}\end{array}$ & $\begin{array}{c}0.253 \\
(0.124)^{* *} \\
{[0.127]^{* *}} \\
\{0.212\} \\
(0.146)^{*}\end{array}$ & $\begin{array}{c}0.009 \\
-0.011 \\
{[0.011]} \\
\{0.020\} \\
-0.013\end{array}$ & $\begin{array}{l}0.001 \\
-0.004 \\
{[0.004]} \\
0.005\} \\
-0.005\end{array}$ \\
\hline $\begin{array}{l}\text { Observations } \\
\text { R-squared }\end{array}$ & $\begin{array}{l}13383 \\
0.008\end{array}$ & $\begin{array}{r}13383 \\
0.000\end{array}$ & $\begin{array}{r}13383 \\
0.000\end{array}$ & $\begin{array}{r}12629 \\
0.001\end{array}$ & $\begin{array}{r}13383 \\
0.000\end{array}$ & $\begin{array}{r}12337 \\
0.000\end{array}$ & $\begin{array}{r}12205 \\
0.000\end{array}$ \\
\hline \multicolumn{8}{|c|}{ Panel D: Unmarried Moms (County and Year of Application FE) } \\
\hline Mean of outcome for rejected & 2.182 & 0.196 & 1.727 & 38.372 & 4.22 & 0.159 & 0.018 \\
\hline $\begin{array}{l}\text { Accepted } \\
\text { OLS (unadjusted se) } \\
\text { Robust standard errors } \\
\text { Clustered at county } \\
\text { Clustered at county*year }\end{array}$ & $\begin{array}{l}0.441 \\
(0.046)^{* * *} \\
{[0.042]^{* * *}} \\
\{0.057\}^{* * *} \\
(0.047)^{* * *}\end{array}$ & $\begin{array}{l}0.034 \\
(0.019)^{*} \\
{[0.018]^{*}} \\
\{0.019\}^{*} \\
(0.017)^{*}\end{array}$ & $\begin{array}{c}-0.224 \\
(0.071)^{* * *} \\
{[0.076]^{* * *}} \\
\{0.097\}^{* *} \\
(0.080)^{* * *}\end{array}$ & $\begin{array}{c}-0.779 \\
(0.278)^{* * *} \\
{[0.296]^{* * *}} \\
\{0.318\}^{* *} \\
(0.311)^{* *}\end{array}$ & $\begin{array}{c}0.049 \\
-0.127 \\
{[0.131]} \\
\{0.139\} \\
-0.133\end{array}$ & $\begin{array}{c}0.007 \\
-0.012 \\
{[0.012]} \\
\{0.009\} \\
-0.011\end{array}$ & $\begin{array}{c}0.003 \\
-0.004 \\
{[0.005]} \\
\{0.005\} \\
-0.005\end{array}$ \\
\hline $\begin{array}{l}\text { Observations } \\
\text { R-squared }\end{array}$ & $\begin{array}{l}13383 \\
0.092 \\
\end{array}$ & $\begin{array}{r}13383 \\
0.058 \\
\end{array}$ & $\begin{array}{r}13383 \\
0.047 \\
\end{array}$ & $\begin{array}{r}12629 \\
0.044 \\
\end{array}$ & $\begin{array}{r}13383 \\
0.101 \\
\end{array}$ & $\begin{array}{r}12337 \\
0.130 \\
\end{array}$ & $\begin{array}{r}12205 \\
0.063 \\
\end{array}$ \\
\hline
\end{tabular}


Appendix Table 2 cont: Accepted moms are slightly worse off at time of application

\begin{tabular}{|c|c|c|c|c|c|c|c|}
\hline \multirow[b]{2}{*}{ Outcome: } & \multicolumn{6}{|c|}{ Newly collected data } & \multirow{2}{*}{$\begin{array}{l}\text { Predicted } \\
\text { Income } \\
\text { (based on } \\
\text { Iowa } \\
\text { census }\end{array}$} \\
\hline & $\begin{array}{l}\text { In labor } \\
\text { force } 1910\end{array}$ & Work 1910 & $\begin{array}{c}\text { Occupationa } \\
1 \text { score } \\
1910^{2}\end{array}$ & $\begin{array}{c}\text { Mom } \\
\text { education } \\
1940\end{array}$ & $\begin{array}{c}\text { Years from } \\
\text { Pre-MP } \\
\text { husband death }\end{array}$ & $\begin{array}{c}\text { Longevity } \\
\text { of Pre-MP } \\
\text { husband }\end{array}$ & \\
\hline \multicolumn{8}{|c|}{ Panel A: All Moms (no controls) } \\
\hline Mean of outcome for rejected & 0.14 & 0.151 & 2.407 & 7.654 & 2.214 & 51.418 & 824.642 \\
\hline Accepted & -0.021 & -0.032 & -0.579 & 0.099 & -0.593 & -1.877 & -64.731 \\
\hline OLS (unadjusted se) & $(0.012)^{*}$ & $(0.011)^{* * *}$ & $(0.214)^{* * *}$ & -0.102 & $(0.119)^{* * *}$ & $(0.582)^{* * *}$ & $(34.086)^{*}$ \\
\hline Robust standard errors & [0.013] & {$[0.012]^{* * *}$} & {$[0.236]^{* *}$} & [0.099] & {$[0.134]^{* * *}$} & {$[0.609]^{* * *}$} & {$[33.450]^{*}$} \\
\hline Clustered at county & $\{0.012\}^{*}$ & $\{0.011\}^{* * *}$ & $\{0.336\}^{*}$ & $\{0.089\}$ & $\{0.148\} * * *$ & $\{0.742\} * *$ & $\{48.850\}$ \\
\hline Clustered at county*year & -0.013 & $(0.013)^{* *}$ & $(0.259)^{* *}$ & -0.108 & $(0.147)^{* * *}$ & $(0.674)^{* * *}$ & $(36.836)^{*}$ \\
\hline Observations & 7648 & 8953 & 8953 & 9222 & 7244 & 9938 & 5332 \\
\hline R-squared & 0.000 & 0.001 & 0.001 & 0.000 & 0.003 & 0.001 & 0.001 \\
\hline Mean of outcome for rejected & 0.14 & 0.151 & 2.407 & 7.654 & 2.214 & 51.418 & 824.642 \\
\hline \multicolumn{8}{|c|}{ Panel B: All Moms (County and Year of Application FE) } \\
\hline Accepted & -0.007 & -0.013 & -0.286 & 0.018 & -0.38 & -1.759 & -50.700 \\
\hline OLS (unadjusted se) & -0.013 & -0.012 & -0.228 & -0.107 & $(0.127)^{* * *}$ & $(0.608)^{* * *}$ & -34.287 \\
\hline Robust standard errors & [0.014] & {$[0.013]$} & {$[0.252]$} & {$[0.106]$} & {$[0.140]^{* * *}$} & {$[0.637]^{* * *}$} & {$[33.650]$} \\
\hline Clustered at county & $\{0.011\}$ & $\{0.010\}$ & $\{0.312\}$ & $\{0.102\}$ & $\{0.119\} * * *$ & $\{0.591\}^{* * *}$ & $\{29.663\}^{*}$ \\
\hline Clustered at county*year & -0.013 & -0.013 & -0.251 & -0.11 & $(0.132)^{* * *}$ & $(0.672)^{* * *}$ & -32.908 \\
\hline Observations & 7648 & 8953 & 8953 & 9222 & 7244 & 9938 & 5332 \\
\hline R-squared & 0.033 & 0.039 & 0.032 & 0.064 & 0.067 & 0.076 & 0.152 \\
\hline \multicolumn{8}{|c|}{ Panel C: Unmarried Moms (No Controls) } \\
\hline Mean of outcome for rejected & 0.141 & 0.153 & 2.515 & 7.712 & 2.222 & 49.083 & 768.819 \\
\hline $\begin{array}{l}\text { Accepted } \\
\text { OLS (ur }\end{array}$ & $\begin{array}{c}-0.023 \\
(0.013) *\end{array}$ & $\begin{array}{c}-0.033 \\
(0.013) * * *\end{array}$ & $\begin{array}{r}-0.648 \\
(0241) * *\end{array}$ & $\begin{array}{r}0.027 \\
-0.112\end{array}$ & $\begin{array}{c}-0.611 \\
(0.118) * * *\end{array}$ & $\begin{array}{c}-1.820 \\
(0.587) * * *\end{array}$ & $\begin{array}{c}-67.727 \\
(38.929) *\end{array}$ \\
\hline Robust standard errors & {$[0.014]$} & {$[0.014]^{* *}$} & {$[0.268]^{* *}$} & {$[0.109]$} & {$[0.135]^{* * *}$} & {$[0.629]^{* * *}$} & {$[38.478]^{*}$} \\
\hline Clustered at county & $\{0.013\}^{*}$ & $\{0.011\}^{* * *}$ & $\{0.326\}^{* *}$ & $\{0.111\}$ & $\{0.146\}^{* * *}$ & $\{0.885\} * *$ & $\{62.972\}$ \\
\hline Clustered at county*year & -0.015 & $(0.014)^{* *}$ & $(0.294)^{* *}$ & -0.114 & $(0.149)^{* * *}$ & $(0.704)^{* * *}$ & -44.261 \\
\hline Observations & 6507 & 7515 & 7515 & 7521 & 7067 & 8463 & 4453 \\
\hline R-squared & 0.000 & 0.001 & 0.001 & 0.000 & 0.004 & 0.001 & 0.001 \\
\hline \multicolumn{8}{|c|}{ Panel D: Unmarried Moms (County and Year of Application FE) } \\
\hline Mean of outcome for rejected & 0.141 & 0.153 & 2.515 & 7.712 & 2.222 & 49.083 & 768.819 \\
\hline Accepted & -0.006 & -0.01 & -0.309 & -0.051 & -0.395 & -1.672 & -52.257 \\
\hline OLS (unadjusted se) & -0.014 & -0.013 & -0.257 & -0.119 & $(0.125)^{* * *}$ & $(0.614)^{* * *}$ & -38.093 \\
\hline Robust standard errors & {$[0.015]$} & {$[0.014]$} & {$[0.283]$} & {$[0.115]$} & {$[0.141]^{* * *}$} & {$[0.656]^{* *}$} & [37.794] \\
\hline Clustered at county & $\{0.011\}$ & $\{0.010\}$ & $\{0.282\}$ & $\{0.112\}$ & $\{0.121\}^{* * *}$ & $\{0.717\}^{* *}$ & $\{37.969\}$ \\
\hline Clustered at county*year & -0.015 & -0.013 & -0.265 & -0.119 & $(0.134)^{* * *}$ & $(0.699)^{* *}$ & -38.244 \\
\hline Observations & 6507 & 7515 & 7515 & 7521 & 7067 & 8463 & 4453 \\
\hline R-squared & 0.039 & 0.044 & 0.037 & 0.063 & 0.071 & 0.076 & 0.207 \\
\hline
\end{tabular}

Note: Controls include county and year of application fixed effects. The sample drops mothers that applied after 1930, and applications made by a person who is not the mother, keeps only the observations of the firts successful attemp (It keeps the application with more children listed if multiple succesful applications in the same year. Keep the smallest fsid if applied successfully more than once the same year, with the same number of children.). The predicted income is obtained using the 1915 Iowa census to estimate the coefficients to predict income for all recipients. The regression includes only the covariates observed in both our data and the Iowa census. It includes widow status, mother's age, number of kids, number of kids at each age, age of youngest and oldest kid at application, number of kids over 14 years old at application, an indicator if the mother is foreign-born, and indicator of being black, schooling and occupation score. ${ }^{1}$ Only includes kids with elegible age. ${ }^{2}$ Occupational score inputs zeros for mothers out of the labor force. ${ }^{3}$ Death to MP application if $>0$. 
Appendix Table 3A: Does accepted status predict missing data for marriage outcomes?

\begin{tabular}{|c|c|c|c|c|}
\hline \multirow[b]{3}{*}{ Outcome: } & \multirow{3}{*}{$\begin{array}{c}\text { Remarriage } \\
\text { information } \\
\text { missing }\end{array}$} & \multicolumn{3}{|c|}{ Data for women known to have remarried } \\
\hline & & \multicolumn{3}{|c|}{ Missing Family Search variables } \\
\hline & & $\begin{array}{l}\text { Duration until } \\
\text { remarriage }\end{array}$ & Age gap & $\begin{array}{l}\text { Post-MP } \\
\text { Husband } \\
\text { Longevity }\end{array}$ \\
\hline \multicolumn{5}{|c|}{ Panel A: All Moms (No controls) } \\
\hline Mean of outcome for rejected & 0.205 & 0.355 & 0.121 & 0.298 \\
\hline Accepted & -0.051 & -0.024 & -0.028 & -0.060 \\
\hline OLS (unadjusted se) & $(0.010)^{* * *}$ & $(0.020)$ & $(0.013)^{* *}$ & $(0.018)^{* * *}$ \\
\hline Robust standard errors & {$[0.011]^{* * *}$} & [0.021] & {$[0.014]^{* *}$} & {$[0.020]^{* * *}$} \\
\hline Clustered at county & $\{0.009\} * * *$ & $\{0.024\}$ & $\{0.013\} * *$ & $\{0.018\}^{* * *}$ \\
\hline Clustered at county*year & $(0.010)^{* * *}$ & $(0.022)$ & $(0.016)^{*}$ & $(0.021)^{* * *}$ \\
\hline Observations & 16228 & 6384 & 6384 & 6384 \\
\hline R-squared & 0.002 & 0.000 & 0.001 & 0.002 \\
\hline \multicolumn{5}{|c|}{ Panel B: All Moms (All Controls) } \\
\hline Mean of outcome for rejected & 0.205 & 0.355 & 0.121 & 0.298 \\
\hline Accepted & -0.009 & -0.022 & -0.020 & -0.040 \\
\hline OLS (unadjusted se) & $(0.009)$ & $(0.020)$ & $(0.013)$ & $(0.020)^{* *}$ \\
\hline Robust standard errors & {$[0.010]$} & [0.021] & {$[0.015]$} & {$[0.021]^{*}$} \\
\hline Clustered at county & $\{0.011\}$ & $\{0.022\}$ & $\{0.014\}$ & $\{0.019\} * *$ \\
\hline Clustered at county*year & $(0.010)$ & $(0.022)$ & $(0.016)$ & $(0.021)^{*}$ \\
\hline Observations & 16228 & 6384 & 6384 & 6384 \\
\hline R-squared & 0.294 & 0.205 & 0.114 & 0.085 \\
\hline \multicolumn{5}{|c|}{ Panel C: Unmarried Moms (No Controls) } \\
\hline Mean of outcome for rejected & 0.203 & 0.370 & 0.127 & 0.300 \\
\hline Accepted & -0.051 & -0.030 & -0.026 & -0.060 \\
\hline OLS (unadjusted se) & $(0.011)^{* * *}$ & $(0.022)$ & $(0.014)^{*}$ & $(0.020)^{* * *}$ \\
\hline Robust standard errors & {$[0.012]^{* * *}$} & {$[0.023]$} & {$[0.016]^{*}$} & {$[0.021]^{* * *}$} \\
\hline Clustered at county & $\{0.009\} * * *$ & $\{0.027\}$ & $\{0.013\} *$ & $\{0.020\}^{* * *}$ \\
\hline Clustered at county*year & $(0.012)^{* * *}$ & $(0.022)$ & $(0.017)$ & $(0.022)^{* * *}$ \\
\hline Observations & 13383 & 5435 & 5435 & 5435 \\
\hline R-squared & 0.002 & 0.000 & 0.001 & 0.002 \\
\hline \multicolumn{5}{|c|}{ Panel D: Unmarried Moms (All Controls) } \\
\hline Mean of outcome for rejected & 0.203 & 0.370 & 0.127 & 0.300 \\
\hline Accepted & -0.009 & -0.039 & -0.019 & -0.045 \\
\hline OLS (unadjusted se) & $(0.010)$ & $(0.022)^{*}$ & $(0.015)$ & $(0.021)^{* *}$ \\
\hline Robust standard errors & {$[0.010]$} & {$[0.023]^{*}$} & {$[0.016]$} & {$[0.023]^{* *}$} \\
\hline Clustered at county & $\{0.013\}$ & $\{0.021\}^{*}$ & $\{0.015\}$ & $\{0.021\}^{* *}$ \\
\hline Clustered at county*year & $(0.012)$ & $(0.023)^{*}$ & $(0.016)$ & $(0.022)^{* *}$ \\
\hline Observations & 13383 & 5435 & 5435 & 5435 \\
\hline R-squared & 0.307 & 0.216 & 0.125 & 0.096 \\
\hline
\end{tabular}


Appendix Table 3B: Does accepted status predict missing data for marriage outcomes?

\begin{tabular}{|c|c|c|c|c|c|}
\hline \multirow[b]{3}{*}{ Outcome: } & \multicolumn{5}{|c|}{ Data for women known to have remarried } \\
\hline & \multicolumn{5}{|c|}{ Missing Post-MP census variables } \\
\hline & $\begin{array}{l}\text { Education } \\
\quad(1940)\end{array}$ & $\begin{array}{l}\text { Education } \\
\text { gap (1940) }\end{array}$ & $\begin{array}{c}\text { Occupational } \\
\text { score } \\
\text { (earliest) }\end{array}$ & $\begin{array}{l}\text { Farmer } \\
\text { (earliest) }\end{array}$ & $\begin{array}{l}\text { Income } \\
(1940)\end{array}$ \\
\hline \multicolumn{6}{|c|}{ Panel A: All Moms (No controls) } \\
\hline Mean of outcome for rejected & 0.513 & 0.599 & 0.325 & 0.199 & 0.539 \\
\hline Accepted & -0.061 & -0.073 & -0.015 & -0.026 & -0.062 \\
\hline OLS (unadjusted se) & $(0.021)^{* * *}$ & $(0.021)^{* * *}$ & $(0.020)$ & $(0.016)$ & $(0.022)^{* * *}$ \\
\hline Robust standard errors & {$[0.022]^{* * *}$} & {$[0.021]^{* * *}$} & {$[0.020]$} & {$[0.017]$} & {$[0.021]^{* * *}$} \\
\hline Clustered at county & $\{0.023\}^{* * *}$ & $\{0.020\}^{* * *}$ & $\{0.026\}$ & $\{0.014\}^{*}$ & $\{0.025\}^{* *}$ \\
\hline Clustered at county*year & $(0.023)^{* * *}$ & $(0.021)^{* * *}$ & $(0.025)$ & $(0.018)$ & $(0.023)^{* * *}$ \\
\hline Observations & 6384 & 6384 & 6384 & 6384 & 6384 \\
\hline R-squared & 0.001 & 0.002 & 0.000 & 0.000 & 0.001 \\
\hline \multicolumn{6}{|c|}{ Panel B: All Moms (All Controls) } \\
\hline Mean of outcome for rejected & 0.513 & 0.599 & 0.325 & 0.199 & 0.539 \\
\hline Accepted & -0.024 & -0.030 & -0.001 & -0.014 & -0.030 \\
\hline OLS (unadjusted se) & $(0.023)$ & $(0.023)$ & $(0.021)$ & $(0.017)$ & $(0.023)$ \\
\hline Robust standard errors & {$[0.022]$} & {$[0.022]$} & {$[0.021]$} & [0.018] & [0.023] \\
\hline Clustered at county & $\{0.020\}$ & $\{0.015\}^{*}$ & $\{0.021\}$ & $\{0.016\}$ & $\{0.023\}$ \\
\hline Clustered at county*year & $(0.021)$ & $(0.020)$ & $(0.024)$ & $(0.018)$ & $(0.022)$ \\
\hline Observations & 6384 & 6384 & 6384 & 6384 & 6384 \\
\hline R-squared & 0.102 & 0.102 & 0.079 & 0.079 & 0.098 \\
\hline \multicolumn{6}{|c|}{ Panel C: Unmarried Moms (No Controls) } \\
\hline Mean of outcome for rejected & 0.511 & 0.606 & 0.330 & 0.203 & 0.535 \\
\hline Accepted & -0.060 & -0.081 & -0.013 & -0.026 & -0.059 \\
\hline OLS (unadjusted se) & $(0.023)^{* *}$ & $(0.023)^{* * *}$ & $(0.022)$ & $(0.018)$ & $(0.024)^{* *}$ \\
\hline Robust standard errors & {$[0.024]^{* *}$} & {$[0.023]^{* * *}$} & {$[0.022]$} & {$[0.019]$} & {$[0.023]^{* *}$} \\
\hline Clustered at county & $\{0.023\} * * *$ & $\{0.018\}^{* * *}$ & $\{0.028\}$ & $\{0.017\}$ & $\{0.024\} * *$ \\
\hline Clustered at county*year & $(0.024)^{* *}$ & $(0.022)^{* * *}$ & $(0.026)$ & $(0.019)$ & $(0.024)^{* *}$ \\
\hline Observations & 5435 & 5435 & 5435 & 5435 & 5435 \\
\hline R-squared & 0.001 & 0.002 & 0.000 & 0.000 & 0.001 \\
\hline \multicolumn{6}{|c|}{ Panel D: Unmarried Moms (All Controls) } \\
\hline Mean of outcome for rejected & 0.511 & 0.606 & 0.330 & 0.203 & 0.535 \\
\hline Accepted & -0.027 & -0.038 & -0.005 & -0.015 & -0.029 \\
\hline OLS (unadjusted se) & $(0.025)$ & $(0.025)$ & $(0.023)$ & $(0.019)$ & $(0.025)$ \\
\hline Robust standard errors & {$[0.024]$} & {$[0.024]$} & {$[0.023]$} & {$[0.020]$} & {$[0.025]$} \\
\hline Clustered at county & $\{0.019\}$ & $\{0.017\}^{* *}$ & $\{0.022\}$ & $\{0.019\}$ & $\{0.022\}$ \\
\hline Clustered at county*year & $(0.022)$ & $(0.022)^{*}$ & $(0.023)$ & $(0.019)$ & $(0.022)$ \\
\hline Observations & 5435 & 5435 & 5435 & 5435 & 5435 \\
\hline R-squared & 0.117 & 0.115 & 0.087 & 0.088 & 0.108 \\
\hline
\end{tabular}


Appendix Table 4A: Does accepted predict missing data for MP mom's labor force outcomes?

\begin{tabular}{|c|c|c|c|c|c|c|c|c|c|}
\hline \multirow{2}{*}{ Outcome: } & \multicolumn{3}{|c|}{ Labor force participation } & \multicolumn{2}{|c|}{ Working } & \multicolumn{3}{|c|}{ Occupational Score } & \multirow{2}{*}{ - $\frac{\text { Aother's Incom }}{1940}$} \\
\hline & 1920 & 1930 & 1940 & 1930 & 1940 & 1920 & 1930 & 1940 & \\
\hline \multicolumn{10}{|c|}{ Panel A: All Moms (No controls) } \\
\hline Mean of outcome for rejected & 0.441 & 0.396 & 0.521 & 0.298 & 0.187 & 0.896 & 0.831 & 0.886 & 0.579 \\
\hline Accepted & -0.003 & -0.093 & -0.108 & 0.042 & 0.053 & -0.002 & -0.050 & -0.061 & -0.096 \\
\hline OLS (unadjusted se) & $(0.013)$ & $(0.012)^{* * *}$ & $(0.013)^{* * *}$ & $(0.016)^{* * *}$ & $(0.016)^{* * *}$ & $(0.008)$ & $(0.011)^{* * *}$ & $(0.010)^{* * *}$ & $(0.013)^{* * *}$ \\
\hline Robust standard errors & [0.013] & {$[0.013]^{* * *}$} & {$[0.013]^{* * *}$} & {$[0.015]^{* * *}$} & {$[0.015]^{* * *}$} & [0.008] & {$[0.010]^{* * *}$} & {$[0.009]^{* * *}$} & {$[0.013]^{* * *}$} \\
\hline Clustered at county & $\{0.026\}$ & $\{0.022\}^{* * *}$ & $\{0.022\}^{* * *}$ & $\{0.013\}^{* * *}$ & $\{0.018\}^{* * *}$ & $\{0.010\}$ & $\{0.012\}^{* * *}$ & $\{0.016\}^{* * *}$ & $\{0.024\}^{* * *}$ \\
\hline Clustered at county*year & $(0.017)$ & $(0.016)^{* * *}$ & $(0.016)^{* * *}$ & $(0.016)^{* * *}$ & $(0.016)^{* * *}$ & $(0.010)$ & $(0.010)^{* * *}$ & $(0.010)^{* * *}$ & $(0.017)^{* * *}$ \\
\hline Observations & 16228 & 16228 & 16228 & 11178 & 9358 & 16228 & 16228 & 16228 & 16228 \\
\hline R-squared & 0.000 & 0.004 & 0.004 & 0.001 & 0.001 & 0.000 & 0.001 & 0.002 & 0.003 \\
\hline \multicolumn{10}{|c|}{ Panel B: All Moms (All Controls) } \\
\hline Mean of outcome for rejected & 0.441 & 0.396 & 0.521 & 0.298 & 0.187 & 0.896 & 0.831 & 0.886 & 0.579 \\
\hline Accepted & -0.027 & -0.034 & -0.032 & 0.014 & 0.031 & -0.035 & -0.012 & -0.022 & -0.041 \\
\hline OLS (unadjusted se) & $(0.012)^{* *}$ & $(0.012)^{* * *}$ & $(0.013)^{* *}$ & (0.017) & $(0.017) *$ & $(0.008)^{* * *}$ & $(0.011)$ & $(0.010)^{* *}$ & $(0.013)^{* * *}$ \\
\hline Robust standard errors & {$[0.013]^{* *}$} & {$[0.013]^{* * *}$} & {$[0.013]^{* *}$} & [0.016] & {$[0.016]^{*}$} & {$[0.009]^{* * *}$} & {$[0.011]$} & {$[0.009]^{* *}$} & {$[0.013]^{* * *}$} \\
\hline Clustered at county & $\{0.012\}^{* *}$ & $\{0.013\}^{* *}$ & $\{0.013\}^{* *}$ & $\{0.015\}$ & $\{0.016\}^{* *}$ & $\{0.008\}^{* * *}$ & $\{0.010\}$ & $\{0.009\}^{* *}$ & $\{0.014\}^{* * *}$ \\
\hline Clustered at county*year & $(0.013)^{* *}$ & $(0.013)^{* * *}$ & $(0.013)^{* *}$ & $(0.016)$ & $(0.016)^{*}$ & $(0.009)^{* * *}$ & $(0.011)$ & $(0.009)^{* *}$ & $(0.013)^{* * *}$ \\
\hline Observations & 16228 & 16228 & 16228 & 11178 & 9358 & 16228 & 16228 & 16228 & 16228 \\
\hline R-squared & 0.287 & 0.215 & 0.157 & 0.057 & 0.062 & 0.103 & 0.071 & 0.075 & 0.129 \\
\hline
\end{tabular}


Appendix Table 4B: Does accepted predict missing data for MP mom's labor force outcomes?

\begin{tabular}{|c|c|c|c|c|c|c|c|c|c|}
\hline \multirow{2}{*}{ Outcome: } & \multicolumn{3}{|c|}{ Labor force participation } & \multicolumn{2}{|c|}{ Working } & \multicolumn{3}{|c|}{ Occupational Score } & \multirow{2}{*}{$\begin{array}{c}\text { Mom's Income } \\
1940\end{array}$} \\
\hline & 1920 & 1930 & 1940 & 1930 & 1940 & 1920 & 1930 & 1940 & \\
\hline \multicolumn{10}{|c|}{ Panel C: Unmarried Moms (No Controls) } \\
\hline Mean of outcome for rejected & 0.426 & 0.401 & 0.529 & 0.303 & 0.190 & 0.891 & 0.830 & 0.888 & 0.584 \\
\hline Accepted & 0.008 & -0.096 & -0.110 & 0.034 & 0.044 & 0.000 & -0.046 & -0.056 & -0.093 \\
\hline OLS (unadjusted se) & $(0.014)$ & $(0.013)^{* * *}$ & $(0.014)^{* * *}$ & $(0.018)^{*}$ & $(0.018)^{* *}$ & $(0.009)$ & $(0.012)^{* * *}$ & $(0.011)^{* * *}$ & $(0.014)^{* * *}$ \\
\hline Robust standard errors & {$[0.014]$} & {$[0.014]^{* * *}$} & {$[0.014]^{* * *}$} & {$[0.017]^{*}$} & {$[0.017]^{* * *}$} & [0.009] & {$[0.011]^{* * *}$} & {$[0.009]^{* * *}$} & {$[0.014]^{* * *}$} \\
\hline Clustered at county & $\{0.026\}$ & $\{0.021\}^{* * *}$ & $\{0.022\}^{* * *}$ & $\{0.013\}^{* *}$ & $\{0.017\}^{* *}$ & $\{0.011\}$ & $\{0.012\}^{* * *}$ & $\{0.013\}^{* * *}$ & $\{0.022\}^{* * *}$ \\
\hline Clustered at county*year & $(0.018)$ & $(0.017)^{* * *}$ & $(0.018)^{* * *}$ & $(0.017)^{*}$ & $(0.018)^{* *}$ & $(0.010)$ & $(0.012)^{* * *}$ & $(0.011)^{* * *}$ & $(0.018)^{* * *}$ \\
\hline Observations & 13383 & 13383 & 13383 & 9174 & 7635 & 13383 & 13383 & 13383 & 13383 \\
\hline R-squared & 0.000 & 0.004 & 0.004 & 0.000 & 0.001 & 0.000 & 0.001 & 0.002 & 0.003 \\
\hline \multicolumn{10}{|c|}{ Panel D: Unmarried Moms (All Controls) } \\
\hline Mean of outcome for rejected & 0.426 & 0.401 & 0.529 & 0.303 & 0.190 & 0.891 & 0.830 & 0.888 & 0.584 \\
\hline Accepted & -0.018 & -0.035 & -0.041 & 0.007 & 0.027 & -0.035 & -0.007 & -0.021 & -0.047 \\
\hline OLS (unadjusted se) & $(0.013)$ & $(0.013)^{* * *}$ & $(0.014)^{* * *}$ & (0.019) & (0.019) & $(0.009)^{* * *}$ & $(0.012)$ & $(0.011)^{*}$ & $(0.015)^{* * *}$ \\
\hline Robust standard errors & {$[0.014]$} & {$[0.014]^{* *}$} & {$[0.014]^{* * *}$} & {$[0.018]$} & {$[0.018]$} & {$[0.010]^{* * *}$} & [0.012] & {$[0.010]^{* *}$} & {$[0.015]^{* * *}$} \\
\hline Clustered at county & $\{0.013\}$ & $\{0.014\}^{* *}$ & $\{0.014\}^{* * *}$ & $\{0.017\}$ & $\{0.014\}^{*}$ & $\{0.010\}^{* * *}$ & $\{0.010\}$ & $\{0.008\}^{* *}$ & $\{0.015\}^{* * *}$ \\
\hline Clustered at county*year & $(0.014)$ & $(0.015)^{* *}$ & $(0.014)^{* * *}$ & $(0.018)$ & (0.019) & $(0.010)^{* * *}$ & $(0.012)$ & $(0.010)^{* *}$ & $(0.014)^{* * *}$ \\
\hline Observations & 13383 & 13383 & 13383 & 9174 & 7635 & 13383 & 13383 & 13383 & 13383 \\
\hline R-squared & 0.299 & 0.218 & 0.159 & 0.061 & 0.067 & 0.105 & 0.075 & 0.077 & 0.128 \\
\hline
\end{tabular}

Note: Refer to Table 2 for a description of the controls and checks. The sample drops mothers that applied after 1930, and applications made by a person who is not the mother, keeps only the observations of the firts successful attemp (It keeps the application with more children listed if multiple succesful applications in the same year. Keep the smallest fsid if applied successfully more than once the same year, with the same number of children. ). Panel D drons mother with missing marital status. 
Appendix Table 5: Does accepted predict missing data for mobility and well-being outcomes?

\begin{tabular}{|c|c|c|c|c|c|c|}
\hline \multirow[b]{2}{*}{ Outcome: } & \multicolumn{3}{|c|}{ County of residence missing } & \multicolumn{3}{|c|}{ Long Run mother outcomes missing } \\
\hline & 1920 & 1930 & 1940 & Longevity & $\begin{array}{c}\text { Died } \\
\text { before } \\
1940 \\
\end{array}$ & $\begin{array}{r}\text { Family } \\
\text { income } \\
(1940)\end{array}$ \\
\hline \multicolumn{7}{|c|}{ Panel A: All Moms (No controls) } \\
\hline Mean of outcome for rejected & 0.435 & 0.396 & 0.520 & 0.244 & 0.237 & 0.520 \\
\hline Accepted & -0.005 & -0.094 & -0.108 & -0.049 & -0.046 & -0.108 \\
\hline OLS (unadjusted se) & $(0.013)$ & $(0.012)^{* * *}$ & $(0.013)^{* * *}$ & $(0.011)^{* * *}$ & $(0.010)^{* * *}$ & $(0.013)^{* * *}$ \\
\hline Robust standard errors & {$[0.013]$} & {$[0.013]^{* * *}$} & {$[0.013]^{* * *}$} & {$[0.011]^{* * *}$} & {$[0.011]^{* * *}$} & {$[0.013]^{* * *}$} \\
\hline Clustered at county & $\{0.027\}$ & $\{0.022\} * * *$ & $\{0.022\} * * *$ & $\{0.016\} * * *$ & $\{0.016\}^{* * *}$ & $\{0.022\} * * *$ \\
\hline Clustered at county*year & $(0.017)$ & $(0.016)^{* * *}$ & $(0.016)^{* * *}$ & $(0.013)^{* * *}$ & $(0.013)^{* * *}$ & $(0.016)^{* * *}$ \\
\hline Observations & 16228 & 16228 & 16228 & 16228 & 16228 & 16228 \\
\hline R-squared & 0.000 & 0.004 & 0.004 & 0.001 & 0.001 & 0.004 \\
\hline \multicolumn{7}{|c|}{ Panel B: All Moms (All Controls) } \\
\hline Mean of outcome for rejected & 0.435 & 0.396 & 0.520 & 0.244 & 0.237 & 0.520 \\
\hline Accepted & -0.028 & -0.034 & -0.032 & -0.006 & -0.003 & -0.032 \\
\hline OLS (unadjusted se) & $(0.012)^{* *}$ & $(0.012)^{* * *}$ & $(0.013)^{* *}$ & $(0.009)$ & $(0.009)$ & $(0.013)^{* *}$ \\
\hline Robust standard errors & {$[0.013]^{* *}$} & {$[0.013]^{* * *}$} & {$[0.013]^{* *}$} & {$[0.010]$} & {$[0.010]$} & {$[0.013]^{* *}$} \\
\hline Clustered at county & $\{0.012\} * *$ & $\{0.013\}^{* *}$ & $\{0.013\} * *$ & $\{0.013\}$ & $\{0.014\}$ & $\{0.013\}^{* *}$ \\
\hline Clustered at county*year & $(0.013)^{* *}$ & $(0.013)^{* * *}$ & $(0.013)^{* *}$ & $(0.011)$ & $(0.011)$ & $(0.013)^{* *}$ \\
\hline Observations & 16228 & 16228 & 16228 & 16228 & 16228 & 16228 \\
\hline R-squared & 0.287 & 0.216 & 0.157 & 0.352 & 0.324 & 0.157 \\
\hline \multicolumn{7}{|c|}{ Panel C: Unmarried Moms (No Controls) } \\
\hline Mean of outcome for rejected & 0.420 & 0.401 & 0.529 & 0.242 & 0.235 & 0.529 \\
\hline Accepted & 0.007 & -0.096 & -0.110 & -0.051 & -0.047 & -0.110 \\
\hline OLS (unadjusted se) & $(0.014)$ & $(0.013)^{* * *}$ & $(0.014)^{* * *}$ & $(0.012)^{* * *}$ & $(0.011)^{* * *}$ & $(0.014)^{* * *}$ \\
\hline Robust standard errors & {$[0.014]$} & {$[0.014]^{* * *}$} & {$[0.014]^{* * *}$} & {$[0.012]^{* * *}$} & {$[0.012]^{* * *}$} & {$[0.014]^{* * *}$} \\
\hline Clustered at county & $\{0.026\}$ & $\{0.021\}^{* * *}$ & $\{0.022\} * * *$ & $\{0.016\} * * *$ & $\{0.016\}^{* * *}$ & $\{0.022\} * * *$ \\
\hline Clustered at county*year & $(0.018)$ & $(0.017)^{* * *}$ & $(0.018)^{* * *}$ & $(0.014)^{* * *}$ & $(0.014)^{* * *}$ & $(0.018)^{* * *}$ \\
\hline Observations & 13383 & 13383 & 13383 & 13383 & 13383 & 13383 \\
\hline R-squared & 0.000 & 0.004 & 0.004 & 0.001 & 0.001 & 0.004 \\
\hline \multicolumn{7}{|c|}{ Panel D: Unmarried Moms (All Controls) } \\
\hline Mean of outcome for rejected & 0.420 & 0.401 & 0.529 & 0.242 & 0.235 & 0.529 \\
\hline Accepted & -0.018 & -0.035 & -0.041 & -0.006 & -0.003 & -0.041 \\
\hline OLS (unadjusted se) & $(0.013)$ & $(0.013)^{* * *}$ & $(0.014)^{* * *}$ & $(0.010)$ & $(0.010)$ & $(0.014)^{* * *}$ \\
\hline Robust standard errors & {$[0.014]$} & {$[0.014]^{* *}$} & {$[0.014]^{* * *}$} & [0.011] & {$[0.011]$} & {$[0.014]^{* * *}$} \\
\hline Clustered at county & $\{0.013\}$ & $\{0.014\} * *$ & $\{0.014\}^{* * *}$ & $\{0.014\}$ & $\{0.016\}$ & $\{0.014\} * * *$ \\
\hline Clustered at county*year & $(0.014)$ & $(0.015)^{* *}$ & $(0.014)^{* * *}$ & $(0.012)$ & $(0.012)$ & $(0.014)^{* * *}$ \\
\hline Observations & 13383 & 13383 & 13383 & 13383 & 13383 & 13383 \\
\hline R-squared & 0.299 & 0.219 & 0.159 & 0.361 & 0.332 & 0.159 \\
\hline
\end{tabular}

Note: Refer to Table 2 for a description of the controls and checks. 
Appendix Table 6: Does welfare increase quality of Post-MP husband? Results for additional quality measures

Sample women who were unmarried at the time of application

\begin{tabular}{|c|c|c|c|c|c|c|c|c|c|c|}
\hline Outcome: & $\begin{array}{l}\text { Post-MP } \\
\text { husband is } \\
\text { foreign } \\
\text { (1) }\end{array}$ & $\begin{array}{c}\text { Post-MP } \\
\text { Husband's } \\
\text { kids at } \\
\text { marriage } \\
(2)\end{array}$ & $\begin{array}{c}\text { Post-MP } \\
\text { Husband } \\
\text { is a } \\
\text { farmer* } \\
\text { (3) }\end{array}$ & $\begin{array}{c}\text { Post-MP } \\
\text { Husband } \\
1940 \\
\text { income } \\
(4)\end{array}$ & $\begin{array}{c}1939 \\
\text { earnings } \\
\text { occupation } \\
\text { score } \\
(5)\end{array}$ & $\begin{array}{c}\text { Husband's } \\
\text { age at } \\
\text { marriage } \\
\text { (6) }\end{array}$ & $\begin{array}{c}\text { Mom's } \\
\text { Education } \\
\text { (7) }\end{array}$ & $\begin{array}{l}\text { Mom's } \\
\text { age at } \\
\text { marriage } \\
(8)\end{array}$ & \multicolumn{2}{|c|}{$\begin{array}{l}\text { Mom and Husband } \\
\text { live together }\end{array}$} \\
\hline \multicolumn{11}{|l|}{ Panel A: No Controls } \\
\hline Mean of outcome for rejected & 0.683 & 0.607 & 0.106 & 751.3 & 43.17 & 44.670 & 7.801 & 38.240 & 0.827 & 0.920 \\
\hline \multirow[t]{2}{*}{ Accepted } & 0.043 & -0.042 & 0.011 & -83.318 & $-3.833^{*}$ & 0.770 & -0.059 & 0.582 & $-0.051 * *$ & $-0.036^{*}$ \\
\hline & $(0.028)$ & $(0.066)$ & $(0.016)$ & $(73.331)$ & $(2.079)$ & $(0.846)$ & $(0.149)$ & $(0.544)$ & $(0.023)$ & $(0.019)$ \\
\hline Observations & 4,266 & 3,572 & 4,457 & 2,815 & 3,328 & 2,637 & 3,759 & 3,558 & 2,987 & 2,612 \\
\hline \multicolumn{11}{|c|}{ Panel B: control for predetermined variables } \\
\hline \multirow[t]{2}{*}{ Accepted } & 0.000 & -0.029 & 0.014 & -65.456 & -3.002 & $1.140^{*}$ & -0.021 & $0.995 * * *$ & $-0.041 * *$ & -0.012 \\
\hline & $(0.027)$ & $(0.069)$ & $(0.017)$ & $(80.028)$ & $(2.102)$ & $(0.627)$ & $(0.141)$ & $(0.346)$ & $(0.019)$ & $(0.024)$ \\
\hline \multicolumn{11}{|c|}{ Panel C: control for pre-determined variables and other inputs } \\
\hline Mean of outcome for rejected & 0.446 & 0.698 & 0.142 & 804.6 & 41.84 & 40.92 & 8.169 & 36.69 & 0.788 & 0.919 \\
\hline \multirow[t]{2}{*}{ Accepted } & -0.008 & 0.032 & -0.010 & -87.459 & 0.566 & $2.452 * *$ & -0.108 & $1.761 * * *$ & -0.031 & -0.028 \\
\hline & $(0.049)$ & $(0.098)$ & $(0.027)$ & $(109.735)$ & $(0.804)$ & $(0.944)$ & $(0.172)$ & $(0.548)$ & $(0.031)$ & $(0.031)$ \\
\hline Observations & 1,887 & 1,363 & 1,887 & 1,755 & 1,755 & 998 & 1,887 & 1,363 & 1,431 & 1,887 \\
\hline \multicolumn{11}{|c|}{ Panel D: control for pre-determined variables and mom's age at marriage } \\
\hline Mean of outcome for rejected & 0.673 & 0.607 & 0.107 & 758.6 & 41.54 & 44.67 & 7.902 & 38.24 & 0.817 & 0.912 \\
\hline \multirow[t]{2}{*}{ Accepted } & -0.003 & -0.029 & 0.004 & -90.378 & -2.877 & $1.140 *$ & -0.095 & $0.995 * * *$ & -0.024 & -0.020 \\
\hline & $(0.028)$ & $(0.069)$ & $(0.020)$ & (109.387) & $(2.893)$ & $(0.627)$ & $(0.178)$ & $(0.346)$ & $(0.024)$ & $(0.033)$ \\
\hline Observations & 3,177 & 3,572 & 3,276 & 2,108 & 2,215 & 2,637 & 2,512 & 3,558 & 2,250 & 1,948 \\
\hline
\end{tabular}

Note: Standard errors are clustered at the county level. Please refer to Table 2 for a full description of the controls, restrictions and checks. Panel $\mathrm{C}$ includes the other inputs (Post-MP Husband longevity, age gap, Post-MP Husband latest occupational score, Post-MP Husband 1940 education and education gap) as controls. *Defined from pre marriage data: uses 1910 if available, then 1920, then 1930, then 1940. Never uses a measure that is observed post-MP marriage. 
Appendix Table 7: Determinants of remarriage and time to remarriage

\begin{tabular}{|c|c|c|c|c|c|c|}
\hline \multirow{2}{*}{$\begin{array}{l}\text { Dependent variable: } \\
\text { Sample: }\end{array}$} & \multicolumn{3}{|c|}{ Remarried $=1$} & \multicolumn{3}{|c|}{ Duration to remarriage } \\
\hline & All & Accepted & Rejected & All & Accepted & Rejected \\
\hline Mean of dependent variable & 0.482 & 0.482 & 0.474 & 6.357 & 6.442 & 5.471 \\
\hline Accepted & $\begin{array}{l}-0.014 \\
(0.020)\end{array}$ & & & $\begin{array}{l}1.275 * * * \\
(0.444)\end{array}$ & & \\
\hline MP age of youngest sibling & $\begin{array}{c}-0.005^{* *} \\
(0.002)\end{array}$ & $\begin{array}{c}-0.005 * * \\
(0.002)\end{array}$ & $\begin{array}{l}-0.004 \\
(0.005)\end{array}$ & $\begin{array}{l}-0.047 \\
(0.059)\end{array}$ & $\begin{array}{l}-0.080 \\
(0.061)\end{array}$ & $\begin{array}{c}0.101 \\
(0.195)\end{array}$ \\
\hline MP age of oldest sibling & $\begin{array}{c}0.003 \\
(0.002)\end{array}$ & $\begin{array}{l}0.004^{*} \\
(0.003)\end{array}$ & $\begin{array}{l}-0.009 \\
(0.006)\end{array}$ & $\begin{array}{l}-0.010 \\
(0.059)\end{array}$ & $\begin{array}{c}0.014 \\
(0.063)\end{array}$ & $\begin{array}{l}-0.087 \\
(0.201)\end{array}$ \\
\hline \# of kids in the application ( $7+$ omitted): & $0.080^{*}$ & $0.086^{*}$ & 0.059 & -1.713 & -1.473 & -0.038 \\
\hline 1 & $\begin{array}{c}(0.045) \\
0.065\end{array}$ & $\begin{array}{c}(0.047) \\
0.063\end{array}$ & $\begin{array}{c}(0.151) \\
0.129\end{array}$ & $\begin{array}{l}(1.258) \\
-1.864^{*}\end{array}$ & $\begin{array}{l}(1.308) \\
-1.671\end{array}$ & $\begin{array}{l}(3.995) \\
-0.006\end{array}$ \\
\hline 2 & $\begin{array}{c}(0.040) \\
0.029\end{array}$ & $\begin{array}{c}(0.041) \\
0.030\end{array}$ & $\begin{array}{c}(0.137) \\
0.062\end{array}$ & $\begin{array}{l}(1.101) \\
-1.328\end{array}$ & $\begin{array}{l}(1.157) \\
-1.169\end{array}$ & $\begin{array}{c}(3.450) \\
2.174\end{array}$ \\
\hline 3 & $\begin{array}{c}(0.040) \\
0.003\end{array}$ & $\begin{array}{c}(0.041) \\
0.004\end{array}$ & $\begin{array}{c}(0.153) \\
0.017\end{array}$ & $\begin{array}{l}(1.226) \\
-0.827\end{array}$ & $\begin{array}{l}(1.242) \\
-0.729\end{array}$ & $\begin{array}{c}(3.486) \\
2.857\end{array}$ \\
\hline 4 & $\begin{array}{l}(0.039) \\
-0.028\end{array}$ & $\begin{array}{l}(0.041) \\
-0.030\end{array}$ & $\begin{array}{c}(0.131) \\
0.038\end{array}$ & $\begin{array}{l}(1.094) \\
-0.782\end{array}$ & $\begin{array}{l}(1.133) \\
-0.777\end{array}$ & $\begin{array}{c}(3.695) \\
0.475\end{array}$ \\
\hline 5 & $\begin{array}{l}(0.037) \\
-0.030 \\
(0.045)\end{array}$ & $\begin{array}{l}(0.039) \\
-0.037 \\
(0.047)\end{array}$ & $\begin{array}{c}(0.134) \\
0.129 \\
(0.150)\end{array}$ & $\begin{array}{l}(1.243) \\
-0.807 \\
(1.078)\end{array}$ & $\begin{array}{c}(1.311) \\
-0.774 \\
(1.164)\end{array}$ & $\begin{array}{c}(4.122) \\
1.812 \\
(4.379)\end{array}$ \\
\hline Length of mother's last name & $\begin{array}{c}0.000 \\
(0.002)\end{array}$ & $\begin{array}{c}0.001 \\
(0.002)\end{array}$ & $\begin{array}{l}-0.010 \\
(0.009)\end{array}$ & $\begin{array}{l}-0.064 \\
(0.066)\end{array}$ & $\begin{array}{l}-0.067 \\
(0.072)\end{array}$ & $\begin{array}{l}-0.107 \\
(0.223)\end{array}$ \\
\hline Divorced mother (MP) & $\begin{array}{c}0.372 * * * \\
(0.023)\end{array}$ & $\begin{array}{c}0.382 * * * \\
(0.026)\end{array}$ & $\begin{array}{l}-0.003 \\
(0.130)\end{array}$ & $\begin{array}{l}-0.401 \\
(0.789)\end{array}$ & $\begin{array}{l}-0.246 \\
(0.884)\end{array}$ & $\begin{array}{c}-2.360 \\
(2.946)\end{array}$ \\
\hline Widow mother (MP) & $\begin{array}{c}0.418^{* * *} \\
(0.023)\end{array}$ & $\begin{array}{c}0.432 * * * \\
(0.023)\end{array}$ & $\begin{array}{c}0.020 \\
(0.131)\end{array}$ & $\begin{array}{l}-0.950 \\
(0.746)\end{array}$ & $\begin{array}{l}-1.027 \\
(0.802)\end{array}$ & $\begin{array}{l}-1.863 \\
(2.573)\end{array}$ \\
\hline MP Marital status is missing & $\begin{array}{c}0.316^{* * *} * \\
(0.032)\end{array}$ & $\begin{array}{c}0.329 * * * \\
(0.036)\end{array}$ & & & & \\
\hline Mother's age at application & $\begin{array}{c}-0.028^{* * *} \\
(0.001)\end{array}$ & $\begin{array}{c}-0.029 * * * \\
(0.001)\end{array}$ & $\begin{array}{c}-0.022 * * * \\
(0.002)\end{array}$ & $\begin{array}{c}0.048^{* *} \\
(0.022)\end{array}$ & $\begin{array}{c}0.060^{* *} \\
(0.024)\end{array}$ & $\begin{array}{c}-0.043 \\
(0.076)\end{array}$ \\
\hline Missing mother's age at application & $\begin{array}{l}-0.155^{*} \\
(0.080)\end{array}$ & $\begin{array}{c}-0.136^{*} \\
(0.081)\end{array}$ & $\begin{array}{c}-0.309^{* *} \\
(0.136)\end{array}$ & $\begin{array}{c}62.227 * * * \\
\quad(6.606)\end{array}$ & $\begin{array}{c}66.624 * * * \\
(7.482)\end{array}$ & $\begin{array}{c}-8.601 * * \\
(3.784)\end{array}$ \\
\hline Number of siblings of the mother & $\begin{array}{c}0.009 * * * \\
(0.001)\end{array}$ & $\begin{array}{c}0.009 * * * \\
(0.001)\end{array}$ & $\begin{array}{c}0.006 \\
(0.004)\end{array}$ & $\begin{array}{l}-0.013 \\
(0.028)\end{array}$ & $\begin{array}{l}-0.018 \\
(0.030)\end{array}$ & $\begin{array}{c}0.078 \\
(0.123)\end{array}$ \\
\hline Mother is foreign born (FS) & $\begin{array}{l}-0.018^{*} \\
(0.011)\end{array}$ & $\begin{array}{c}-0.021^{*} \\
(0.013)\end{array}$ & $\begin{array}{l}-0.014 \\
(0.044)\end{array}$ & $\begin{array}{c}0.105 \\
(0.387)\end{array}$ & $\begin{array}{c}0.144 \\
(0.415)\end{array}$ & $\begin{array}{c}0.143 \\
(0.925)\end{array}$ \\
\hline Mother's foreign status is missing & $\begin{array}{c}-0.055^{* *} \\
(0.023)\end{array}$ & $\begin{array}{c}-0.051^{*} \\
(0.026)\end{array}$ & $\begin{array}{l}-0.098 \\
(0.068)\end{array}$ & $\begin{array}{l}-1.701 \\
(1.462)\end{array}$ & $\begin{array}{l}-1.161 \\
(2.111)\end{array}$ & $\begin{array}{c}2.964 \\
(3.180)\end{array}$ \\
\hline Pre-MP husband's longevity & $\begin{array}{c}0.003 * * * \\
(0.001)\end{array}$ & $\begin{array}{c}0.003 * * * \\
(0.001)\end{array}$ & $\begin{array}{c}0.000 \\
(0.001)\end{array}$ & $\begin{array}{c}0.014 \\
(0.012)\end{array}$ & $\begin{array}{c}0.013 \\
(0.014)\end{array}$ & $\begin{array}{c}-0.024 \\
(0.033)\end{array}$ \\
\hline Pre-MP husband's longevity is missing & $\begin{array}{c}0.047 * * * \\
(0.011)\end{array}$ & $\begin{array}{c}0.049 * * * \\
(0.012)\end{array}$ & $\begin{array}{c}0.047 \\
(0.028)\end{array}$ & $\begin{array}{c}-0.132 \\
(0.182)\end{array}$ & $\begin{array}{l}-0.233 \\
(0.188)\end{array}$ & $\begin{array}{c}-0.604 \\
(1.161)\end{array}$ \\
\hline Number of kids older than 14 (FS) & $\begin{array}{c}0.015 * * * \\
(0.003)\end{array}$ & $\begin{array}{c}0.015 * * * \\
(0.003)\end{array}$ & $\begin{array}{c}0.008 \\
(0.007)\end{array}$ & $\begin{array}{c}-0.165^{* *} \\
(0.071)\end{array}$ & $\begin{array}{c}-0.187 * * \\
(0.077)\end{array}$ & $\begin{array}{c}0.110 \\
(0.343)\end{array}$ \\
\hline Number of kids that died before applicatior & $\begin{array}{c}0.003 \\
(0.007)\end{array}$ & $\begin{array}{c}0.003 \\
(0.007)\end{array}$ & $\begin{array}{c}0.020 \\
(0.021)\end{array}$ & $\begin{array}{c}-0.042 \\
(0.146)\end{array}$ & $\begin{array}{c}0.027 \\
(0.149)\end{array}$ & $\begin{array}{c}-1.097 * * \\
(0.521)\end{array}$ \\
\hline Number with missing dates of birth/death ( & $\begin{array}{l}-0.005 \\
(0.014)\end{array}$ & $\begin{array}{c}0.005 \\
(0.014)\end{array}$ & $\begin{array}{c}-0.093 * * * \\
(0.035)\end{array}$ & $\begin{array}{c}0.455 \\
(0.299)\end{array}$ & $\begin{array}{c}0.301 \\
(0.318)\end{array}$ & $\begin{array}{l}2.519^{*} \\
(1.354)\end{array}$ \\
\hline Observations & 11,286 & 10,237 & 1,049 & 3,572 & 3,259 & 313 \\
\hline
\end{tabular}

Note: OLS regressions. Standard errors clustered at the county level. The specifications also include year of application FE. State and county covariates not shown. 


\begin{tabular}{|c|c|c|c|c|c|c|c|c|c|c|}
\hline \multirow{2}{*}{$\begin{array}{l}\text { Sample } \\
\qquad \text { Outcome (Y): }\end{array}$} & \multicolumn{2}{|c|}{ All } & \multicolumn{8}{|c|}{ Among remarried women only } \\
\hline & $\begin{array}{c}\text { Ever } \\
\text { remarried? }\end{array}$ & $\begin{array}{c}\text { \# kids post } \\
\text { MP }\end{array}$ & $\begin{array}{l}\text { Years to } \\
\text { remarriage }\end{array}$ & $\begin{array}{c}\text { Equal } \\
\text { weights }{ }^{4}\end{array}$ & $\begin{array}{c}\text { Utility } \\
\text { weighted } \\
\text { index } \\
\end{array}$ & $\begin{array}{l}\text { Post-MP } \\
\text { Husband } \\
\text { Longevity }\end{array}$ & $\begin{array}{l}\text { Post-MP } \\
\text { Husband } \\
\text { Occ Score } \\
\end{array}$ & $\begin{array}{l}\text { Post-MP } \\
\text { Husband } \\
\text { Education }\end{array}$ & $\begin{array}{c}\text { Age gap } \\
\text { (shifted by } \\
2.5 \text { years) }^{1}\end{array}$ & $\begin{array}{c}\text { Education } \\
\text { gap }^{3}\end{array}$ \\
\hline \multicolumn{11}{|l|}{ A.All moms } \\
\hline Accepted & -0.013 & -0.023 & 1.296 & 0.945 & -0.005 & 1.752 & -0.327 & -0.115 & 0.390 & -0.039 \\
\hline Clustered at county level & $(0.018)$ & $(0.018)$ & $(0.398)^{* * *}$ & $(0.429)^{* *}$ & $(0.018)$ & $(0.899)^{*}$ & $(0.461)$ & $(0.219)$ & $(0.235)^{*}$ & $(0.174)$ \\
\hline R-squared & 0.212 & 0.160 & 0.315 & 0.058 & 0.076 & 0.052 & 0.089 & 0.119 & 0.044 & 0.068 \\
\hline Mean of outcome for rejected & 0.468 & 0.246 & 5.719 & 23.123 & 0.360 & 70.242 & 21.095 & 7.709 & 6.557 & 1.950 \\
\hline Observations & 13638 & 16228 & 4255 & 5792 & 2973 & 4830 & 4206 & 3460 & 5771 & 2978 \\
\hline \multicolumn{11}{|l|}{ B. all unmarried moms } \\
\hline Accepted & -0.014 & -0.009 & 1.275 & 0.921 & -0.006 & 1.821 & -0.828 & -0.226 & 0.275 & -0.064 \\
\hline Clustered at county level & $(0.020)$ & $(0.021)$ & $(0.444) * * *$ & $(0.448)^{* *}$ & $(0.021)$ & $(0.903)^{* *}$ & $(0.574)$ & $(0.228)$ & $(0.289)$ & $(0.185)$ \\
\hline R-squared & 0.228 & 0.162 & 0.338 & 0.068 & 0.085 & 0.056 & 0.095 & 0.122 & 0.049 & 0.081 \\
\hline Mean of outcome for rejected & 0.474 & 0.224 & 5.471 & 23.153 & 0.361 & 70.129 & 21.220 & 7.798 & 6.661 & 1.821 \\
\hline Observations & 11286 & 13383 & 3572 & 4894 & 2540 & 4104 & 3556 & 2955 & 4874 & 2545 \\
\hline \multicolumn{11}{|c|}{ C. (unmarried moms?) drop if marital status missing at application } \\
\hline Accepted & -0.048 & -0.032 & 1.112 & 1.366 & -0.018 & 2.577 & -0.542 & -0.393 & 0.323 & -0.258 \\
\hline Clustered at county level & $(0.020) * *$ & $(0.030)$ & $(0.573)^{*}$ & $(0.467)^{* * *}$ & $(0.023)$ & $(1.011)^{* *}$ & $(0.677)$ & $(0.297)$ & $(0.313)$ & $(0.199)$ \\
\hline R-squared & 0.241 & 0.174 & 0.331 & 0.076 & 0.094 & 0.066 & 0.095 & 0.117 & 0.053 & 0.108 \\
\hline Mean of outcome for rejected & 0.529 & 0.252 & 5.232 & 22.960 & 0.368 & 69.428 & 21.162 & 7.915 & 6.559 & 1.885 \\
\hline Observations & 7925 & 9171 & 2620 & 3524 & 1794 & 2965 & 2549 & 2094 & 3511 & 1797 \\
\hline \multicolumn{11}{|l|}{ D. states that only admit widows } \\
\hline Accepted & -0.006 & 0.000 & 1.467 & 1.571 & 0.003 & 1.587 & 0.272 & -0.457 & 0.529 & -0.212 \\
\hline Clustered at county level & $(0.026)$ & $(0.030)$ & $(0.696)^{* *}$ & $(0.494)^{* * *}$ & $(0.023)$ & (1.908) & $(0.837)$ & $(0.330)$ & $(0.235)^{* *}$ & $(0.196)$ \\
\hline R-squared & 0.206 & 0.156 & 0.319 & 0.060 & 0.094 & 0.060 & 0.101 & 0.106 & 0.050 & 0.101 \\
\hline Mean of outcome for rejected & 0.491 & 0.222 & 5.471 & 23.028 & 0.371 & 69.582 & 20.867 & 8.193 & 6.335 & 2.229 \\
\hline Observations & 4128 & 4906 & 1395 & 1795 & 920 & 1507 & 1199 & 1053 & 1790 & 921 \\
\hline \multicolumn{11}{|c|}{ E. states that admit more than just widows (all other states?) } \\
\hline Accepted & -0.013 & -0.025 & 1.096 & 0.644 & -0.010 & 1.547 & -0.612 & 0.056 & 0.333 & 0.037 \\
\hline Clustered at county level & $(0.020)$ & $(0.022)$ & $(0.430)^{* *}$ & $(0.529)$ & $(0.025)$ & $(0.892)^{*}$ & $(0.606)$ & $(0.210)$ & $(0.314)$ & $(0.236)$ \\
\hline R-squared & 0.220 & 0.165 & 0.333 & 0.070 & 0.089 & 0.063 & 0.097 & 0.147 & 0.054 & 0.076 \\
\hline Mean of outcome for rejected & 0.458 & 0.257 & 5.858 & 23.170 & 0.355 & 70.555 & 21.180 & 7.515 & 6.665 & 1.833 \\
\hline Observations & 9510 & 11322 & 2860 & 3997 & 2053 & 3323 & 3007 & 2407 & 3981 & 2057 \\
\hline P-value of test that $D=E$ & 0.869 & 0.804 & 0.767 & 0.191 & 0.642 & 0.741 & 0.295 & 0.253 & 0.758 & 0.616 \\
\hline \multicolumn{11}{|c|}{ F. states that regulated/required work } \\
\hline Accepted & -0.006 & -0.012 & 1.244 & 0.852 & -0.002 & 1.641 & -0.347 & 0.082 & 0.488 & -0.095 \\
\hline Clustered at county level & $(0.023)$ & $(0.024)$ & $(0.468)^{* *}$ & $(0.582)$ & $(0.028)$ & $(1.021)$ & $(0.715)$ & $(0.253)$ & $(0.358)$ & $(0.272)$ \\
\hline R-squared & 0.212 & 0.149 & 0.316 & 0.068 & 0.092 & 0.060 & 0.086 & 0.144 & 0.049 & 0.086 \\
\hline Mean of outcome for rejected & 0.444 & 0.229 & 6.130 & 23.011 & 0.364 & 70.188 & 21.763 & 7.530 & 6.421 & 1.918 \\
\hline Observations & 6657 & 8015 & 2046 & 2804 & 1432 & 2351 & 2144 & 1691 & 2795 & 1435 \\
\hline \multicolumn{11}{|c|}{ G. states that required women to stay } \\
\hline Accepted & -0.017 & -0.030 & 1.265 & 1.127 & -0.010 & 1.559 & -0.083 & -0.245 & 0.333 & -0.034 \\
\hline Clustered at county level & $(0.025)$ & $(0.029)$ & $(0.604)^{* *}$ & $(0.556)^{* *}$ & $(0.019)$ & $(1.492)$ & $(0.599)$ & $(0.327)$ & $(0.296)$ & $(0.214)$ \\
\hline R-squared & 0.219 & 0.180 & 0.343 & 0.068 & 0.098 & 0.070 & 0.112 & 0.124 & 0.058 & 0.095 \\
\hline Mean of outcome for rejected & 0.501 & 0.270 & 5.270 & 23.252 & 0.355 & 70.304 & 20.231 & 7.951 & 6.714 & 1.990 \\
\hline Observations & 6981 & 8213 & 2209 & 2988 & 1541 & 2479 & 2062 & 1769 & 2976 & 1543 \\
\hline$P$-value of test that $F=G$ & 0.651 & 0.511 & 0.997 & 0.526 & 0.919 & 0.916 & 0.722 & 0.445 & 0.883 & 0.700 \\
\hline
\end{tabular}


Appendix Table 8b: Heterogeneity in results - controls

\begin{tabular}{|c|c|c|c|c|c|c|c|c|c|c|}
\hline Outcome (Y): & $\begin{array}{c}\text { Ever } \\
\text { remarried? }\end{array}$ & \# kids post MP & $\begin{array}{l}\text { Years to } \\
\text { remarriage }\end{array}$ & Equal weights ${ }^{4}$ & $\begin{array}{c}\text { Utility } \\
\text { weighted } \\
\text { quality index } \\
\end{array}$ & $\begin{array}{l}\text { Post-MP } \\
\text { Husband } \\
\text { Longevity }\end{array}$ & $\begin{array}{l}\text { Post-MP } \\
\text { Husband } \\
\text { Occ Score }^{2} \\
\end{array}$ & $\begin{array}{l}\text { Post-MP } \\
\text { Husband } \\
\text { Education }\end{array}$ & $\begin{array}{c}\text { Age gap } \\
\text { (shifted by } 2.5 \\
\text { years) }^{1}\end{array}$ & Education gap ${ }^{3}$ \\
\hline \multicolumn{11}{|c|}{ H. counties with high share males (sex ratio above median) } \\
\hline Accepted & 0.001 & -0.002 & 1.642 & 1.183 & 0.014 & 2.154 & -0.347 & -0.292 & 0.259 & 0.012 \\
\hline Clustered at county level & $(0.020)$ & $(0.022)$ & $(0.475)^{* * *}$ & $(0.477)^{* *}$ & $(0.026)$ & $(1.224)^{*}$ & $(0.642)$ & $(0.320)$ & $(0.276)$ & $(0.226)$ \\
\hline R-squared & 0.225 & 0.181 & 0.282 & 0.075 & 0.100 & 0.063 & 0.109 & 0.147 & 0.059 & 0.089 \\
\hline Mean of outcome for rejected & 0.472 & 0.228 & 5.751 & 23.154 & 0.351 & 69.876 & 21.106 & 7.965 & 6.549 & 2.083 \\
\hline Observations & 6778 & 8095 & 2228 & 2995 & 1544 & 2511 & 2089 & 1787 & 2983 & 1547 \\
\hline \multicolumn{11}{|c|}{ I. counties with low share males (sex ratio below median) } \\
\hline Accepted & -0.022 & -0.050 & 1.042 & 0.505 & -0.021 & 1.051 & -0.242 & 0.034 & 0.543 & -0.253 \\
\hline Clustered at county level & $(0.027)$ & $(0.029)^{*}$ & $(0.544)^{*}$ & $(0.598)$ & $(0.027)$ & $(1.016)$ & $(0.747)$ & $(0.252)$ & $(0.382)$ & $(0.238)$ \\
\hline R-squared & 0.208 & 0.144 & 0.377 & 0.068 & 0.115 & 0.073 & 0.100 & 0.126 & 0.065 & 0.084 \\
\hline Mean of outcome for rejected & 0.464 & 0.268 & 5.679 & 23.086 & 0.369 & 70.675 & 21.085 & 7.459 & 6.568 & 1.814 \\
\hline Observations & 6860 & 8133 & 2027 & 2797 & 1429 & 2319 & 2117 & 1673 & 2788 & 1431 \\
\hline $\mathrm{P}$-value of test that $\mathrm{H}=\mathrm{I}$ & 0.746 & 0.104 & 0.636 & 0.415 & 0.296 & 0.691 & 0.961 & 0.411 & 0.786 & 0.443 \\
\hline \multicolumn{11}{|c|}{ J. counties with high female labor force participation (LFP above median) } \\
\hline Accepted & -0.020 & -0.021 & 0.994 & 0.678 & 0.019 & 2.338 & 0.201 & -0.401 & 0.346 & -0.127 \\
\hline Clustered at county level & $(0.028)$ & $(0.020)$ & $(0.873)$ & $(0.694)$ & $(0.022)$ & $(1.384)^{*}$ & $(0.721)$ & $(0.265)$ & $(0.321)$ & $(0.228)$ \\
\hline $\mathrm{R}$-squared & 0.203 & 0.130 & 0.359 & 0.060 & 0.099 & 0.064 & 0.105 & 0.142 & 0.055 & 0.115 \\
\hline Mean of outcome for rejected & 0.442 & 0.200 & 6.076 & 23.224 & 0.357 & 69.557 & 21.795 & 8.105 & 6.583 & 2.000 \\
\hline Observations & 6766 & 8108 & 1980 & 2741 & 1426 & 2245 & 1940 & 1633 & 2733 & 1427 \\
\hline \multicolumn{11}{|c|}{ K. counties with low female labor force participation (LFP below median) } \\
\hline Accepted & -0.005 & -0.026 & 1.468 & 1.305 & -0.021 & 1.373 & -0.466 & 0.141 & 0.429 & 0.101 \\
\hline Clustered at county level & $(0.015)$ & $(0.030)$ & $(0.435)^{* * *}$ & $(0.618)^{* *}$ & $(0.026)$ & (1.210) & $(0.715)$ & $(0.282)$ & $(0.333)$ & $(0.236)$ \\
\hline $\mathrm{K}$-squared & 0.232 & 0.188 & 0.288 & 0.094 & 0.113 & 0.084 & 0.114 & 0.154 & 0.065 & 0.122 \\
\hline Mean of outcome for rejected & 0.493 & 0.290 & 5.413 & 23.037 & 0.362 & 70.839 & 20.544 & 7.372 & 6.535 & 1.908 \\
\hline Observations & 6872 & 8120 & 2275 & 3051 & 1547 & 2585 & 2266 & 1827 & 3038 & 1551 \\
\hline$P$-value of test that $\mathrm{J}=\mathrm{K}$ & 0.601 & 0.741 & 0.573 & 0.585 & 0.231 & 0.634 & 0.593 & 0.186 & 0.453 & 0.763 \\
\hline \multicolumn{11}{|l|}{ L. moms above median age } \\
\hline Accepted & -0.010 & -0.007 & 2.470 & 0.876 & -0.010 & 3.022 & -2.963 & -0.237 & 1.166 & -0.292 \\
\hline Clustered at county level & $(0.021)$ & $(0.010)$ & $(0.659)^{* * *}$ & $(0.919)$ & $(0.043)$ & (2.199) & $(1.567)^{*}$ & $(0.395)$ & $(0.656)^{*}$ & $(0.318)$ \\
\hline R-squared & 0.096 & 0.060 & 0.181 & 0.143 & 0.274 & 0.130 & 0.189 & 0.243 & 0.137 & 0.298 \\
\hline Mean of outcome for rejected & 0.282 & 0.032 & 5.083 & 24.781 & 0.387 & 70.583 & 23.587 & 7.354 & 6.146 & 2.200 \\
\hline Observations & 6407 & 7214 & 1091 & 1594 & 606 & 1267 & 1113 & 753 & 1590 & 607 \\
\hline \multicolumn{11}{|l|}{ M. moms below median age } \\
\hline Accepted & -0.016 & -0.032 & 0.924 & 1.160 & 0.001 & 1.346 & 0.803 & -0.132 & 0.101 & 0.075 \\
\hline Clustered at county level & $(0.021)$ & $(0.036)$ & $(0.531)^{*}$ & $(0.567)^{* *}$ & $(0.022)$ & $(0.916)$ & $(0.742)$ & $(0.243)$ & $(0.381)$ & $(0.195)$ \\
\hline $\mathrm{R}$-squared & 0.150 & 0.157 & 0.370 & 0.059 & 0.096 & 0.064 & 0.107 & 0.124 & 0.057 & 0.078 \\
\hline Mean of outcome for rejected & 0.644 & 0.420 & 5.932 & 22.491 & 0.353 & 70.113 & 20.122 & 7.812 & 6.714 & 1.883 \\
\hline Observations & 7231 & 9014 & 3164 & 4198 & 2367 & 3563 & 3093 & 2707 & 4181 & 2371 \\
\hline $\mathrm{P}$-value of test that $\mathrm{L}=\mathrm{M}$ & 0.699 & 0.559 & 0.187 & 0.521 & 0.164 & 0.413 & 0.041 & 0.773 & 0.163 & 0.208 \\
\hline \multicolumn{11}{|c|}{ N. moms above median age of youngest } \\
\hline Accepted & 0.002 & -0.002 & 0.684 & 1.637 & 0.001 & 2.590 & -0.832 & -0.213 & 0.795 & 0.200 \\
\hline Clustered at county level & $(0.020)$ & $(0.013)$ & $(0.568)$ & $(0.675)^{* *}$ & $(0.027)$ & $(1.222)^{* *}$ & $(0.932)$ & $(0.367)$ & $(0.470)^{*}$ & $(0.309)$ \\
\hline $\mathrm{R}$-squared & 0.177 & 0.096 & 0.347 & 0.116 & 0.222 & 0.117 & 0.178 & 0.212 & 0.126 & 0.232 \\
\hline Mean of outcome for rejected & 0.348 & 0.078 & 5.857 & 23.737 & 0.381 & 70.597 & 22.240 & 7.630 & 6.425 & 1.800 \\
\hline Observations & 5672 & 6886 & 1296 & 1804 & 802 & 1470 & 1283 & 965 & 1797 & 803 \\
\hline \multicolumn{11}{|c|}{$O$. moms below median age if youngest } \\
\hline Accepted & -0.029 & -0.037 & 1.377 & 0.659 & -0.003 & 1.557 & 0.033 & -0.139 & 0.151 & -0.152 \\
\hline Clustered at county level & $(0.023)$ & $(0.033)$ & $(0.512)^{* * *}$ & $(0.629)$ & $(0.023)$ & $(1.076)$ & $(0.754)$ & $(0.285)$ & $(0.328)$ & $(0.219)$ \\
\hline $\mathrm{R}$-squared & 0.213 & 0.169 & 0.344 & 0.073 & 0.104 & 0.072 & 0.104 & 0.135 & 0.055 & 0.078 \\
\hline Mean of outcome for rejected & 0.594 & 0.422 & 5.638 & 22.781 & 0.351 & 70.055 & 20.551 & 7.746 & 6.631 & 2.012 \\
\hline Observations & 7966 & 9342 & 2959 & 3988 & 2171 & 3360 & 2923 & 2495 & 3974 & 2175 \\
\hline$P$-value of test that $\mathrm{N}=\mathrm{O}$ & 0.279 & 0.744 & 0.438 & 0.688 & 0.548 & 0.748 & 0.998 & 0.998 & 0.307 & 0.402 \\
\hline
\end{tabular}


Appendix Table 8c: Heterogeneity in results - controls (All Sample)

\begin{tabular}{|c|c|c|c|c|c|c|c|c|c|c|c|c|c|}
\hline \multirow[t]{2}{*}{ Outcome (Y): } & \multicolumn{3}{|c|}{ Labor force participation } & \multicolumn{3}{|c|}{$\begin{array}{c}\text { Occupation Score | occupation } \\
\text { not missing }\end{array}$} & \multirow{2}{*}{$\begin{array}{c}\text { Earned } \\
\text { Income } \mid \\
\text { income }>0\end{array}$} & \multicolumn{2}{|c|}{$\begin{array}{c}\text { Lives in same } \\
\text { county }\end{array}$} & \multicolumn{2}{|c|}{$\begin{array}{c}\text { Lives in more } \\
\text { educated county }\end{array}$} & \multirow{2}{*}{ Longevity } & \multirow{2}{*}{$\begin{array}{c}\text { Household } \\
\text { income } \\
1940\end{array}$} \\
\hline & $\begin{array}{c}\text { applied } \\
\text { pre } 1920\end{array}$ & 1930 & 1940 & $\begin{array}{c}\text { applied } \\
\text { pre } 1920 \\
\end{array}$ & 1930 & 1940 & & 1930 & 1940 & 1930 & 1940 & & \\
\hline \multicolumn{14}{|l|}{ A.All moms } \\
\hline Accepted & 0.067 & 0.012 & 0.027 & 0.713 & -0.487 & -0.349 & 5.434 & 0.048 & 0.063 & 0.028 & 0.021 & 0.247 & -58.241 \\
\hline Clustered at county level & $(0.025)^{* * *}$ & $(0.016)$ & $(0.017)$ & $(0.714)$ & $(0.522)$ & $(0.614)$ & $(28.688)$ & $(0.024)^{* *}$ & $(0.018)^{* * *}$ & $(0.024)$ & $(0.024)$ & $(0.567)$ & $(31.877)^{*}$ \\
\hline R-squared & 0.083 & 0.072 & 0.067 & 0.159 & 0.097 & 0.108 & 0.160 & 0.176 & 0.114 & 0.399 & 0.405 & 0.028 & 0.080 \\
\hline Mean outcome for rejected & 0.356 & 0.327 & 0.209 & 14.500 & 15.852 & 15.786 & 479.083 & 0.648 & 0.589 & 0.497 & 0.508 & 73.432 & 979.570 \\
\hline Observations & 4127 & 11170 & 9351 & 1313 & 3472 & 2737 & 2083 & 11178 & 9358 & 3123 & 3177 & 12989 & 9358 \\
\hline \multicolumn{14}{|l|}{ B. all unmarried moms } \\
\hline Accepted & 0.058 & 0.005 & 0.021 & 0.865 & -0.805 & -0.133 & 1.527 & 0.053 & 0.071 & 0.025 & 0.022 & 0.397 & -80.179 \\
\hline Clustered at county level & $(0.027)^{* *}$ & $(0.017)$ & $(0.014)$ & $(0.741)$ & $(0.581)$ & $(0.756)$ & $(50.856)$ & $(0.025)^{* *}$ & $(0.023)^{* * *}$ & $(0.026)$ & $(0.029)$ & $(0.657)$ & $(38.347)^{* *}$ \\
\hline R-squared & 0.090 & 0.075 & 0.071 & 0.186 & 0.109 & 0.131 & 0.175 & 0.173 & 0.116 & 0.413 & 0.418 & 0.030 & 0.083 \\
\hline Mean outcome for rejected & 0.367 & 0.332 & 0.211 & 14.568 & 16.308 & 15.284 & 490.283 & 0.646 & 0.585 & 0.509 & 0.525 & 73.467 & 1013.223 \\
\hline Observations & 3523 & 9166 & 7630 & 1136 & 2833 & 2185 & 1644 & 9174 & 7635 & 2581 & 2608 & 10749 & 7635 \\
\hline \multicolumn{14}{|c|}{ C. (unmarried moms?) drop if marital status missing at application } \\
\hline Accepted & 0.054 & 0.020 & 0.021 & 0.986 & -0.846 & -0.871 & -1.899 & 0.076 & 0.087 & 0.030 & 0.064 & -0.268 & -10.464 \\
\hline Clustered at county level & $(0.036)$ & $(0.021)$ & $(0.015)$ & $(0.963)$ & $(0.820)$ & $(0.925)$ & $(72.490)$ & $(0.031)^{* *}$ & $(0.025)^{* * *}$ & $(0.033)$ & $(0.033)^{*}$ & $(0.791)$ & $(45.632)$ \\
\hline R-squared & 0.087 & 0.085 & 0.083 & 0.171 & 0.120 & 0.144 & 0.197 & 0.198 & 0.131 & 0.416 & 0.432 & 0.031 & 0.079 \\
\hline Mean outcome for rejected & 0.366 & 0.339 & 0.211 & 13.603 & 16.613 & 15.625 & 442.130 & 0.644 & 0.576 & 0.500 & 0.509 & 73.786 & 923.520 \\
\hline Observations & 2448 & 6399 & 5255 & 792 & 2023 & 1558 & 1156 & 6405 & 5256 & 1757 & 1762 & 7484 & 5256 \\
\hline \multicolumn{14}{|c|}{ D. states that only admit widows } \\
\hline Accepted & 0.075 & -0.024 & 0.039 & -0.013 & -1.483 & -0.732 & 26.339 & 0.076 & 0.074 & 0.045 & 0.025 & -0.179 & -51.370 \\
\hline Clustered at county level & $(0.047)$ & $(0.038)$ & $(0.030)$ & $(1.357)$ & $(0.610)^{* *}$ & $(0.590)$ & $(51.596)$ & $(0.031)^{* *}$ & $(0.027)^{* * *}$ & $(0.034)$ & $(0.049)$ & $(0.978)$ & $(41.588)$ \\
\hline R-squared & 0.085 & 0.069 & 0.086 & 0.224 & 0.128 & 0.138 & 0.179 & 0.223 & 0.183 & 0.394 & 0.358 & 0.033 & 0.066 \\
\hline Mean outcome for rejected & 0.350 & 0.403 & 0.228 & 13.610 & 16.687 & 16.056 & 536.762 & 0.618 & 0.557 & 0.364 & 0.386 & 73.897 & 1021.553 \\
\hline Observations & 1030 & 3496 & 2960 & 327 & 1223 & 940 & 760 & 3497 & 2962 & 928 & 986 & 3841 & 2962 \\
\hline \multicolumn{14}{|c|}{ E. states that admit more than just widows (all other states?) } \\
\hline Accepted & 0.060 & 0.030 & 0.023 & 0.756 & -0.060 & -0.373 & -20.359 & 0.041 & 0.062 & 0.019 & 0.015 & 0.430 & -58.852 \\
\hline Clustered at county level & $(0.028)^{* *}$ & $(0.015)^{* *}$ & $(0.018)$ & $(1.019)$ & $(0.709)$ & $(0.840)$ & $(26.588)$ & $(0.030)$ & $(0.022)^{* * *}$ & $(0.032)$ & $(0.026)$ & $(0.696)$ & $(41.529)$ \\
\hline R-squared & 0.091 & 0.072 & 0.060 & 0.168 & 0.096 & 0.110 & 0.185 & 0.160 & 0.091 & 0.416 & 0.445 & 0.031 & 0.092 \\
\hline Mean outcome for rejected & 0.358 & 0.295 & 0.201 & 14.884 & 15.368 & 15.672 & 452.462 & 0.660 & 0.602 & 0.561 & 0.565 & 73.242 & 961.779 \\
\hline Observations & 3097 & 7674 & 6391 & 986 & 2249 & 1797 & 1323 & 7681 & 6396 & 2195 & 2191 & 9148 & 6396 \\
\hline P-value of test that $D=E$ & 0.574 & 0.153 & 0.772 & 0.817 & 0.223 & 0.943 & 0.324 & 0.538 & 0.743 & 0.712 & 0.757 & 0.634 & 0.625 \\
\hline \multicolumn{14}{|c|}{ F. states that regulated/required work } \\
\hline Accepted & 0.058 & 0.034 & 0.014 & 0.604 & 0.147 & 0.159 & -22.365 & 0.053 & 0.049 & 0.009 & -0.019 & 0.526 & -61.801 \\
\hline Clustered at county level & $(0.030)^{*}$ & $(0.016)^{* *}$ & $(0.020)$ & $(1.172)$ & $(0.821)$ & $(0.869)$ & $(26.738)$ & $(0.035)$ & $(0.024)^{* *}$ & $(0.035)$ & $(0.028)$ & $(0.803)$ & $(44.188)$ \\
\hline R-squared & 0.071 & 0.070 & 0.065 & 0.170 & 0.111 & 0.110 & 0.183 & 0.148 & 0.076 & 0.423 & 0.455 & 0.032 & 0.071 \\
\hline Mean outcome for rejected & 0.372 & 0.291 & 0.209 & 15.128 & 15.338 & 15.355 & 477.397 & 0.664 & 0.640 & 0.557 & 0.590 & 72.855 & 1008.257 \\
\hline Observations & 2500 & 5377 & 4501 & 834 & 1537 & 1265 & 947 & 5380 & 4506 & 1509 & 1458 & 6569 & 4506 \\
\hline \multicolumn{14}{|c|}{ G. states that required women to stay home (all other states?) } \\
\hline Accepted & 0.077 & -0.018 & 0.042 & 0.471 & -1.381 & -0.874 & 16.405 & 0.048 & 0.092 & 0.058 & 0.057 & -0.163 & -32.908 \\
\hline Clustered at county level & $(0.033)^{* *}$ & $(0.028)$ & $(0.025)^{*}$ & $(0.832)$ & $(0.546)^{* *}$ & $(0.764)$ & $(48.235)$ & $(0.031)$ & $(0.023)^{* * *}$ & $(0.035)$ & $(0.040)$ & $(0.774)$ & $(41.579)$ \\
\hline R-squared & 0.117 & 0.075 & 0.077 & 0.207 & 0.118 & 0.135 & 0.186 & 0.209 & 0.154 & 0.395 & 0.386 & 0.032 & 0.097 \\
\hline Mean outcome for rejected & 0.330 & 0.381 & 0.210 & 13.420 & 16.422 & 16.400 & 481.133 & 0.624 & 0.517 & 0.419 & 0.422 & 74.317 & 939.373 \\
\hline Observations & 1627 & 5793 & 4850 & 479 & 1935 & 1472 & 1136 & 5798 & 4852 & 1614 & 1719 & 6420 & 4852 \\
\hline P-value of test that $F=G$ & 0.535 & 0.101 & 0.403 & 0.560 & 0.131 & 0.424 & 0.617 & 0.990 & 0.128 & 0.503 & 0.155 & 0.454 & 0.523 \\
\hline
\end{tabular}


Appendix Table 8d: Heterogeneity in results - controls (All Sample)

\begin{tabular}{|c|c|c|c|c|c|c|c|c|c|c|c|c|c|}
\hline \multirow[t]{3}{*}{ Outcome (Y): } & \multicolumn{3}{|c|}{ Labor force participation } & \multicolumn{3}{|c|}{$\begin{array}{c}\text { Occupation Score } \mid \text { occupation not } \\
\text { missing }\end{array}$} & \multirow{2}{*}{$\begin{array}{c}\text { Earned } \\
\text { Income | } \\
\text { income }>0\end{array}$} & \multicolumn{2}{|c|}{ Lives in same county } & \multicolumn{2}{|c|}{$\begin{array}{c}\text { Lives in more educated } \\
\text { county }\end{array}$} & \multirow[t]{2}{*}{ Longevity } & \multirow{2}{*}{$\begin{array}{c}\text { Household } \\
\text { income } \\
1940 \\
\end{array}$} \\
\hline & pre 1920 & 1930 & 1940 & pre 1920 & 1930 & 1940 & & 1930 & 1940 & 1930 & 1940 & & \\
\hline & \multicolumn{13}{|c|}{ H. counties with high share males (sex ratio above median) } \\
\hline Accepted & 0.059 & -0.022 & 0.012 & 1.907 & -0.504 & -0.588 & 7.448 & 0.040 & 0.038 & 0.030 & 0.020 & 0.245 & -44.491 \\
\hline Clustered at county level & $(0.036)$ & $(0.025)$ & $(0.022)$ & $(0.788)^{* *}$ & $(0.651)$ & $(0.755)$ & $(45.198)$ & $(0.024)^{*}$ & $(0.023)$ & $(0.031)$ & $(0.040)$ & $(0.753)$ & (49.184) \\
\hline $\mathrm{R}$-squared & 0.091 & 0.068 & 0.065 & 0.223 & 0.139 & 0.152 & 0.192 & 0.196 & 0.142 & 0.421 & 0.394 & 0.034 & 0.083 \\
\hline Mean outcome for rejected & 0.348 & 0.342 & 0.215 & 13.342 & 15.778 & 16.031 & 557.079 & 0.611 & 0.585 & 0.516 & 0.541 & 73.907 & 1055.150 \\
\hline Observations & 1942 & 5460 & 4727 & 576 & 1688 & 1286 & 986 & 5462 & 4730 & 1706 & 1778 & 6462 & 4730 \\
\hline \multicolumn{14}{|c|}{ I. counties with low share males (sex ratio below median) } \\
\hline $\begin{array}{l}\text { Accepted } \\
\text { Clustered at county level }\end{array}$ & 0.078 & 0.052 & 0.046 & 0.512 & -0.686 & -0.064 & 16.414 & 0.060 & 0.096 & 0.060 & 0.035 & 0.423 & -46.787 \\
\hline $\begin{array}{l}\text { Clustered at county level } \\
\text { K-squared }\end{array}$ & $(0.034)^{* *}$ & $(0.013)^{* * *}$ & $(0.022)^{* *}$ & (1.433) & $(0.860)$ & $(1.005)$ & $(40.038)$ & $(0.042)$ & $(0.034)^{* * *}$ & $(0.037)$ & $(0.029)$ & $(0.936)$ & $(39.696)$ \\
\hline $\mathrm{R}$-squared & 0.089 & 0.089 & 0.083 & 0.175 & 0.109 & 0.120 & 0.179 & 0.161 & 0.093 & 0.381 & 0.426 & 0.034 & 0.089 \\
\hline Mean outcome for rejected & 0.365 & 0.312 & 0.202 & 15.841 & 15.937 & 15.512 & 408.886 & 0.686 & 0.594 & 0.473 & 0.469 & 72.888 & 890.679 \\
\hline Observations & 2185 & 5710 & 4624 & 737 & 1784 & 1451 & 1097 & 5716 & 4628 & 1417 & 1399 & 6527 & 4628 \\
\hline $\mathrm{P}$-value of test that $\mathrm{H}=\mathrm{I}$ & 0.841 & 0.006 & 0.092 & 0.222 & 0.803 & 0.656 & 0.928 & 0.696 & 0.178 & 0.516 & 0.628 & 0.844 & 0.872 \\
\hline \multicolumn{14}{|c|}{ J. counties with high female labor force participation (LFP above median) } \\
\hline Accepted & 0.067 & 0.001 & 0.051 & 0.886 & -1.408 & -0.435 & 20.168 & 0.072 & 0.039 & 0.030 & 0.072 & 0.082 & -40.826 \\
\hline Clustered at county level & $(0.034)^{*}$ & $(0.022)$ & $(0.021)^{* *}$ & (1.226) & $(0.730)^{*}$ & $(0.755)$ & $(37.556)$ & $(0.039)^{*}$ & $(0.030)$ & $(0.041)$ & $(0.029)^{* *}$ & $(0.867)$ & $(42.838)$ \\
\hline R-squared & 0.097 & 0.079 & 0.077 & 0.191 & 0.115 & 0.120 & 0.158 & 0.153 & 0.104 & 0.378 & 0.357 & 0.031 & 0.079 \\
\hline Mean outcome for rejected & 0.383 & 0.346 & 0.206 & 15.569 & 17.720 & 16.494 & 509.048 & 0.678 & 0.652 & 0.384 & 0.392 & 73.072 & 1073.101 \\
\hline Observations & 1504 & 5708 & 4796 & 476 & 1892 & 1544 & 1218 & 5713 & 4798 & 1253 & 1366 & 6292 & 4798 \\
\hline \multicolumn{14}{|c|}{ K. counties with low female labor force participation (LFP below median) } \\
\hline Accepted & 0.076 & 0.024 & 0.007 & 0.960 & 0.678 & -0.064 & -56.764 & 0.036 & 0.091 & 0.032 & -0.001 & 0.372 & -72.742 \\
\hline Clustered at county level & $(0.039)^{*}$ & $(0.021)$ & $(0.021)$ & $(1.262)$ & $(0.821)$ & $(1.042)$ & $(48.125)$ & $(0.026)$ & $(0.028)^{* * *}$ & $(0.034)$ & $(0.035)$ & $(0.700)$ & $(43.639) *$ \\
\hline R-squared & 0.093 & 0.074 & 0.064 & 0.182 & 0.124 & 0.162 & 0.205 & 0.181 & 0.120 & 0.422 & 0.453 & 0.040 & 0.081 \\
\hline Mean outcome for rejected & 0.328 & 0.311 & 0.212 & 13.297 & 14.065 & 15.243 & 452.915 & 0.620 & 0.537 & 0.582 & 0.579 & 73.751 & 902.924 \\
\hline Observations & 2623 & 5462 & 4555 & 837 & 1580 & 1193 & 865 & 5465 & 4560 & 1870 & 1811 & 6697 & 4560 \\
\hline$P$-value of test that $\mathrm{J}=\mathrm{K}$ & 0.895 & 0.417 & 0.040 & 0.761 & 0.039 & 0.720 & 0.250 & 0.587 & 0.245 & 0.694 & 0.309 & 0.955 & 0.371 \\
\hline \multicolumn{14}{|l|}{ L. moms above median age } \\
\hline Accepted & 0.056 & 0.008 & 0.022 & 1.260 & 1.085 & 0.406 & -61.413 & 0.014 & 0.033 & -0.001 & -0.017 & 0.113 & -120.033 \\
\hline Clustered at county level & $(0.044)$ & $(0.027)$ & $(0.020)$ & $(1.219)$ & $(0.844)$ & $(1.315)$ & $(66.576)$ & $(0.032)$ & $(0.033)$ & $(0.037)$ & $(0.054)$ & $(0.563)$ & $(78.797)$ \\
\hline $\mathrm{R}$-squared & 0.120 & 0.100 & 0.119 & 0.226 & 0.124 & 0.229 & 0.338 & 0.196 & 0.132 & 0.490 & 0.446 & 0.047 & 0.106 \\
\hline Mean outcome for rejected & 0.356 & 0.306 & 0.160 & 13.797 & 13.517 & 14.298 & 445.395 & 0.716 & 0.649 & 0.520 & 0.589 & 74.100 & 956.395 \\
\hline Observations & 1855 & 5098 & 3970 & 615 & 1562 & 992 & 715 & 5101 & 3972 & 1203 & 1186 & 6259 & 3972 \\
\hline \multicolumn{14}{|l|}{ M. moms below median age } \\
\hline Accepted & 0.065 & 0.021 & 0.035 & 1.144 & -1.418 & -0.514 & 26.870 & 0.074 & 0.078 & 0.044 & 0.034 & 0.355 & 2.880 \\
\hline Clustered at county level & $(0.030)^{* *}$ & $(0.020)$ & $(0.026)$ & $(1.343)$ & $(0.897)$ & $(0.875)$ & $(48.863)$ & $(0.025)^{* * *}$ & $(0.018)^{* * *}$ & $(0.031)$ & $(0.027)$ & $(0.909)$ & $(45.509)$ \\
\hline $\mathrm{R}$-squared & 0.122 & 0.091 & 0.071 & 0.251 & 0.153 & 0.124 & 0.176 & 0.177 & 0.125 & 0.393 & 0.429 & 0.038 & 0.106 \\
\hline Mean outcome for rejected & 0.355 & 0.346 & 0.244 & 15.224 & 17.720 & 16.464 & 492.558 & 0.589 & 0.546 & 0.484 & 0.463 & 72.767 & 996.110 \\
\hline Observations & 2272 & 6072 & 5381 & 698 & 1910 & 1745 & 1368 & 6077 & 5386 & 1920 & 1991 & 6730 & 5386 \\
\hline $\mathrm{P}$-value of test that $\mathrm{L}=\mathrm{M}$ & 0.808 & 0.687 & 0.520 & 0.938 & 0.105 & 0.590 & 0.508 & 0.123 & 0.400 & 0.893 & 0.322 & 0.924 & 0.437 \\
\hline \multicolumn{14}{|c|}{ N. moms above median age of youngest } \\
\hline & 0.087 & 0.014 & 0.014 & -0.278 & 0.680 & -0.202 & 44.491 & 0.012 & 0.018 & 0.034 & -0.015 & 0.195 & -66.807 \\
\hline Clustered at county level & $(0.054)$ & $(0.018)$ & $(0.025)$ & $(0.814)$ & $(0.574)$ & $(1.240)$ & $(42.940)$ & $(0.028)$ & $(0.031)$ & $(0.041)$ & $(0.043)$ & $(0.807)$ & $(73.805)$ \\
\hline R-squared & 0.124 & 0.114 & 0.126 & 0.258 & 0.136 & 0.253 & 0.299 & 0.201 & 0.139 & 0.477 & 0.467 & 0.048 & 0.097 \\
\hline Mean outcome for rejected & 0.363 & 0.333 & 0.209 & 15.158 & 14.854 & 14.728 & 439.678 & 0.691 & 0.637 & 0.482 & 0.504 & 73.545 & 962.932 \\
\hline Observations & 1601 & 4522 & 3487 & 559 & 1471 & 1010 & 782 & 4525 & 3490 & 1177 & 1146 & 5468 & 3490 \\
\hline$O$. moms below median age if yo & igest & & & & & & & & & & & & \\
\hline Accepted & 0.040 & 0.012 & 0.031 & 1.882 & -0.914 & -0.994 & -0.779 & 0.081 & 0.097 & 0.028 & 0.038 & 0.455 & -45.624 \\
\hline Clustered at county level & $(0.024)^{*}$ & $(0.022)$ & $(0.024)$ & $(1.305)$ & $(0.940)$ & $(0.899)$ & $(48.143)$ & $(0.029)^{* * *}$ & $(0.022)^{* * *}$ & $(0.044)$ & $(0.034)$ & $(0.689)$ & $(56.965)$ \\
\hline $\mathrm{K}$-squared & 0.107 & 0.075 & 0.069 & 0.246 & 0.143 & 0.136 & 0.185 & 0.182 & 0.132 & 0.411 & 0.415 & 0.040 & 0.103 \\
\hline Mean outcome for rejected & 0.348 & 0.322 & 0.209 & 13.667 & 16.779 & 16.634 & 510.500 & 0.609 & 0.550 & 0.508 & 0.510 & 73.311 & 992.780 \\
\hline Observations & 2526 & 6648 & 5864 & 754 & 2001 & 1727 & 1301 & 6653 & 5868 & 1946 & 2031 & 7521 & 5868 \\
\hline P-value of test that $\mathrm{N}=\mathrm{O}$ & 0.340 & 0.509 & 0.752 & 0.246 & 0.042 & 0.545 & 0.990 & 0.011 & 0.014 & 0.691 & 0.745 & 0.870 & 0.873 \\
\hline
\end{tabular}

